\title{
Evaluation of Candidate Linear Variable Displacement Transducers for High Temperature Irradiations in the Advanced Test Reactor
}

D. L. Knudson

J. L. Rempe

J. E. Daw

September 2009

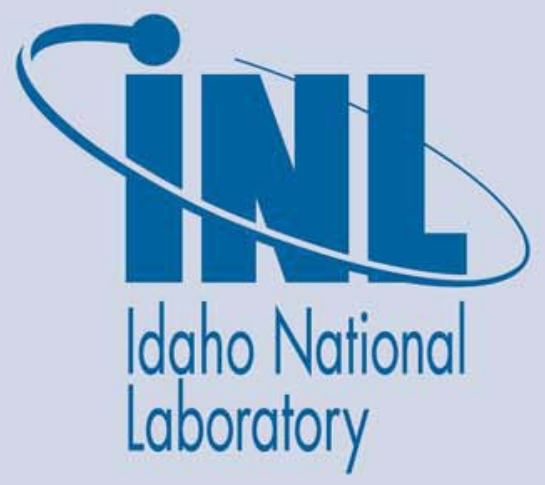

The INL is a U.S. Department of Energy National Laboratory operated by Battelle Energy Alliance 
INL/EXT-09-16972

\title{
Evaluation of Candidate Linear Variable Displacement Transducers for High Temperature Irradiations in the Advanced Test Reactor
}

\author{
D. L. Knudson \\ J. L. Rempe \\ J. E. Daw
}

September 2009

Idaho National Laboratory
Idaho Falls, Idaho 83415

http://www.inl.gov

Prepared for the

U.S. Department of Energy

Office of Nuclear Energy

Under DOE Idaho Operations Office

Contract DE-AC07-05ID14517 


\section{DISCLAIMER}

This information was prepared as an account of work sponsored by an agency of the U.S. Government. Neither the U.S. Government nor any agency thereof, nor any of their employees, makes any warranty, express or implied, or assumes any legal liability or responsibility for the accuracy, completeness, or usefulness of any information, apparatus, product, or process disclosed, or represents that its use would not infringe privately owned rights. References herein to any specific commercial product, process, or service by trade name, trademark, manufacturer, or otherwise, does not necessarily constitute or imply its endorsement, recommendation, or favoring by the U.S. Government or any agency thereof. The views and opinions of authors expressed herein do not necessarily state or reflect those of the U.S. Government or any agency thereof. 



\section{CONTENTS}

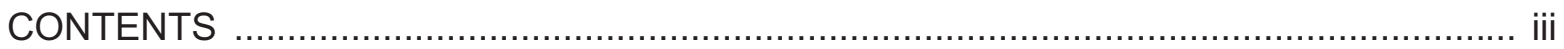

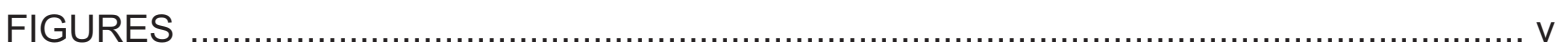

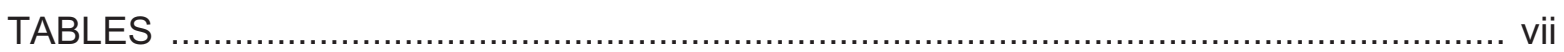

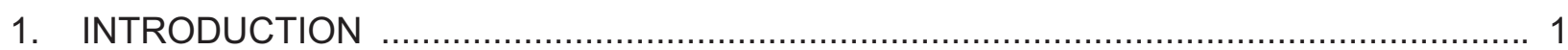

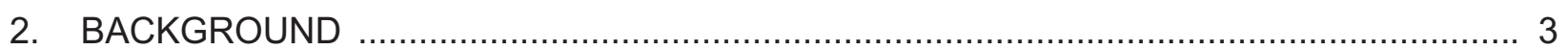

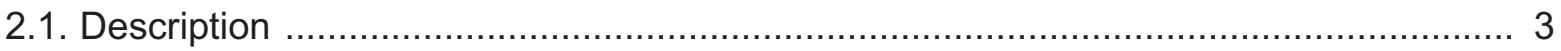

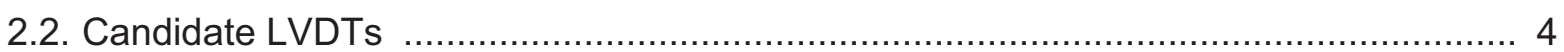

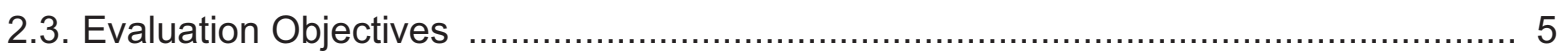

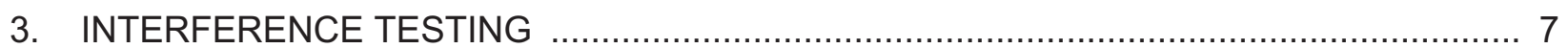

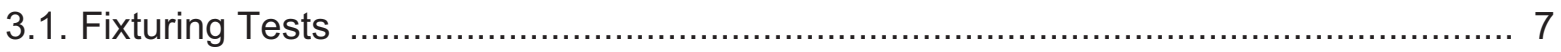

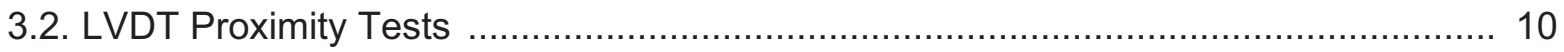

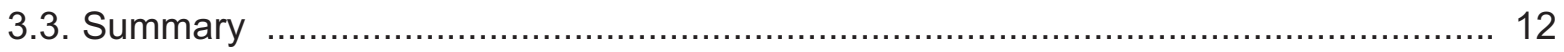

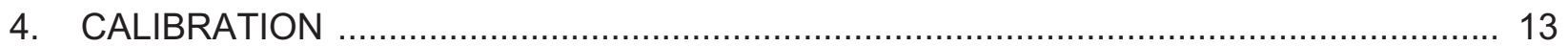

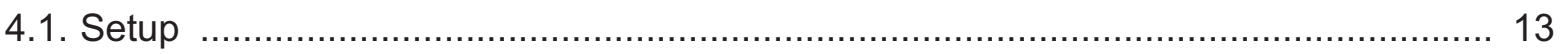

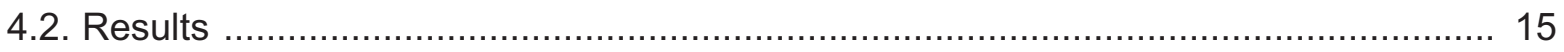

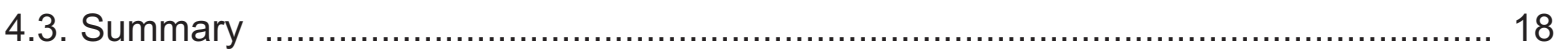

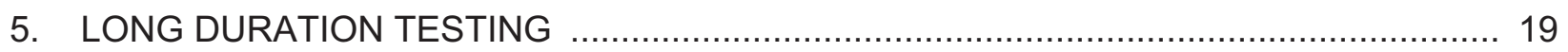

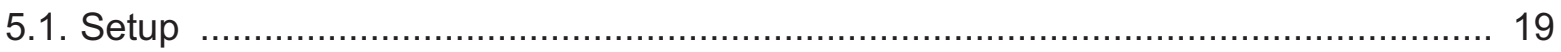

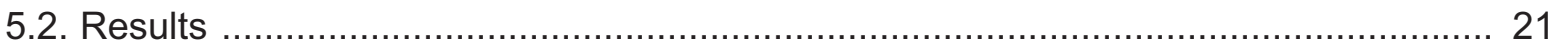

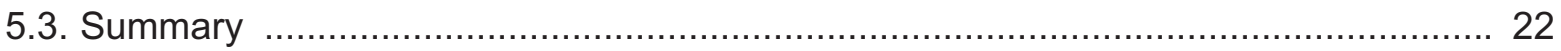

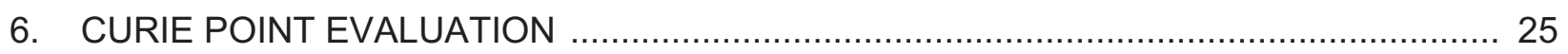

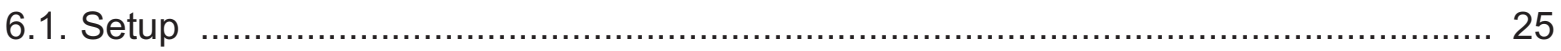

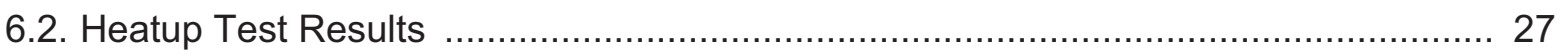

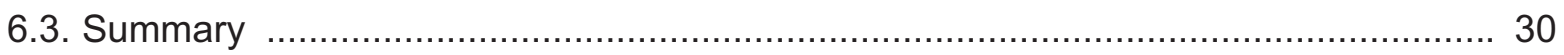

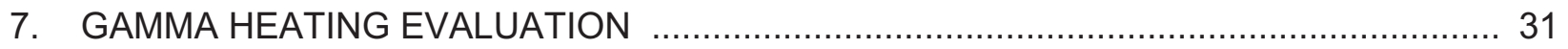

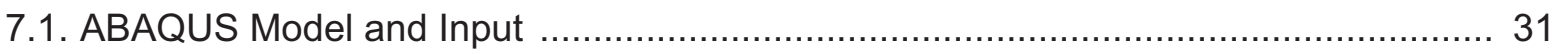

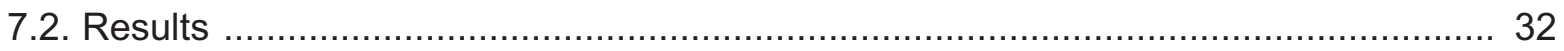

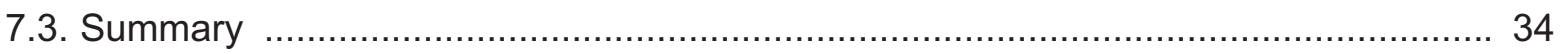

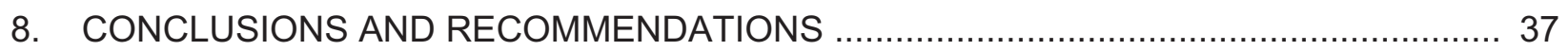

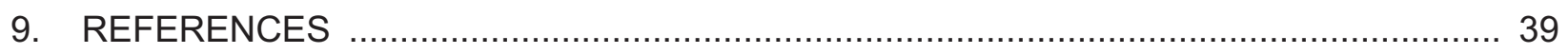

APPENDIX A - FIXTURE INTERFERENCE CALIBRATION DATA ............................ A-1

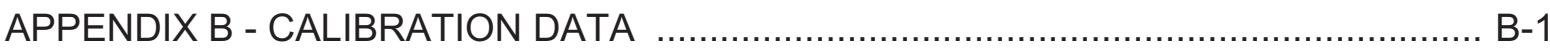


INL/EXT-09-16972 


\section{FIGURES}

2-1. Principle design of a Linear Variable Displacement Transducer. ................................................ 3

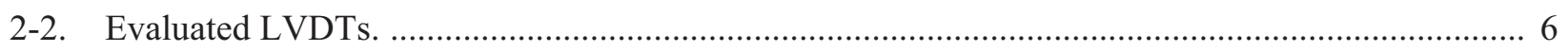

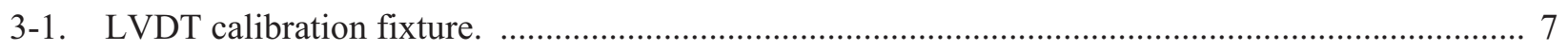

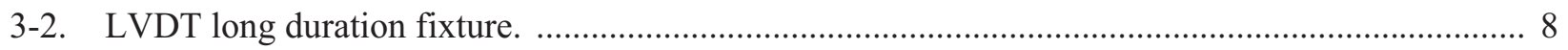

3-3. Vendor A LVDT 1096 room temperature calibration results. .................................................... 8

3-4. Vendor A LVDT 1097 room temperature calibration results. ..................................................... 9

3-5. Vendor B LVDT 1444 room temperature calibration results. ................................................... 9

3-6. Vendor B LVDT 1449 room temperature calibration results. ................................................... 10

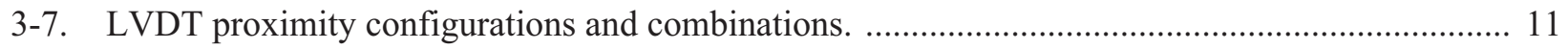

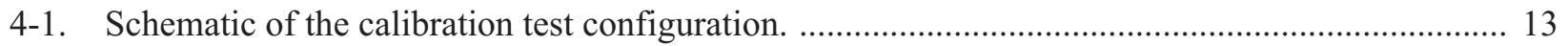

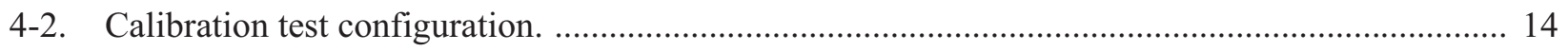

4-3. Calibration data for Vendor A LVDT 1097 (or LVDT A1) at $500{ }^{\circ} \mathrm{C}$. ....................................... 15

4-4. Calibration data for Vendor B LVDT 1449 (or LVDT B1) at $500{ }^{\circ} \mathrm{C}$....................................... 16

4-5. Comparison of LVDT sensitivities as a function of temperature. ................................................ 17

4-6. Comparison of LVDT insulation resistances as a function of temperature. ................................ 18

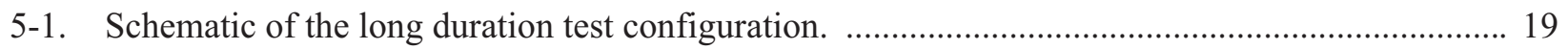

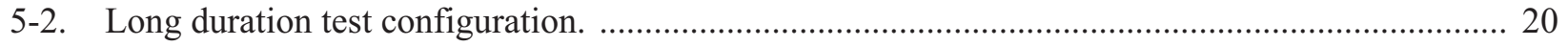

5-3. Comparison of LVDT response during long duration testing. .................................................. 21

5-4. Comparison of the response of LVDTs A1 and B1 during long duration testing. ........................ 23

5-5. Comparison of LVDT cores following the long duration test at $500{ }^{\circ} \mathrm{C}$ (where both Vendor B cores are shown centered between the Vendor A cores). .............................................. 23

6-1. Lindberg horizontal split tube furnace used in Curie point heatup tests. .................................... 26

6-2. Data acquisition system used in Curie point heatup tests. ......................................................... 26

6-3. Insulating blocks as used to prevent fixture/heating element contact in Curie point

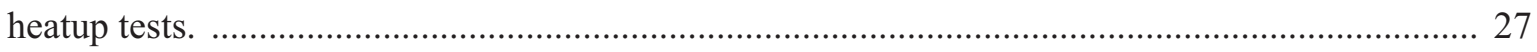

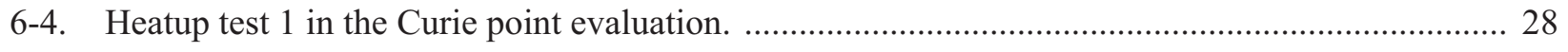

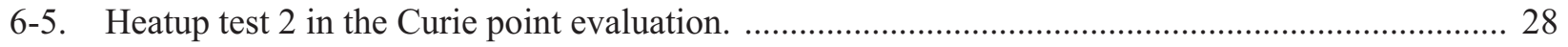

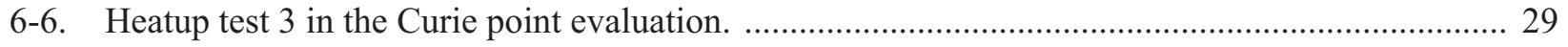

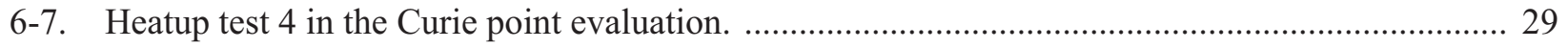

7-1. LVDT body and core with automatically generated finite element mesh. ................................. 32

7-2. Gamma heating rates as a function of axial position for the ATR center flux trap. ..................... 33

7-3. Radial temperature profiles at maximum heat generation. ......................................................... 33

7-4. Maximum temperature of the LVDT body in center flux trap. ................................................ 34 
7-5. Maximum temperature of the LVDT core in center flux trap. 35

7-6. Maximum temperatures observed within LVDT body for different flux traps. 


\section{TABLES}

2-1. Desired LVDT characteristics for use in ATR. ....................................................................... 5

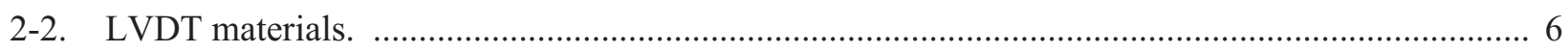

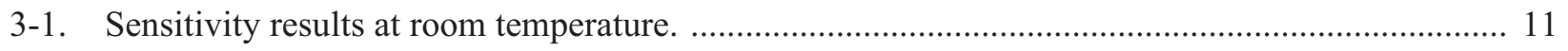

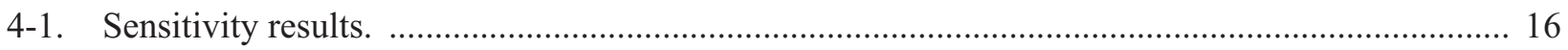

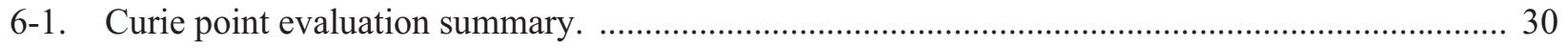

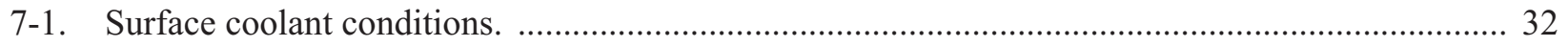

A-1. Set 1 interference calibration outside all fixtures. .................................................................. A-1

A-2. Set 1 interference calibration inside calibration fixture. ......................................................... A-2

A-3. Set 1 interference calibration inside long duration fixture. ...................................................... A-3

A-4. Set 2 interference calibration outside all fixtures. .................................................................. A-4

A-5. Set 2 interference calibration inside calibration fixture. .............................................................. A-5

A-6. Set 2 interference calibration inside long duration fixture. ...................................................... A-6

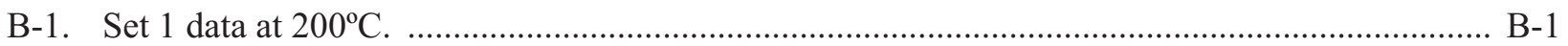

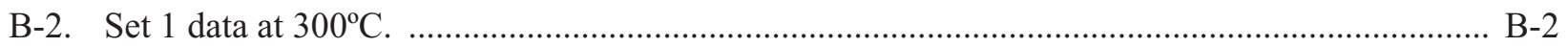

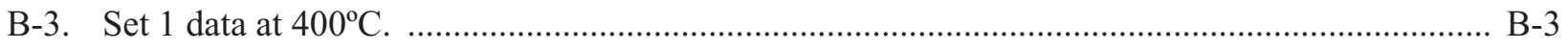

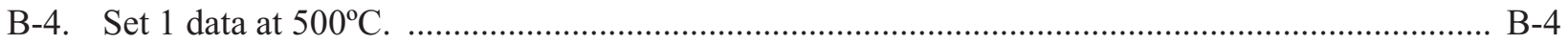

B-5. Room temperature data for Set 1 after high temperature calibration. ........................................ B-5

B-6. Room temperature data for Set 2 before high temperature calibration. ..................................... B-6

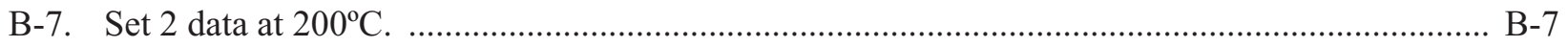

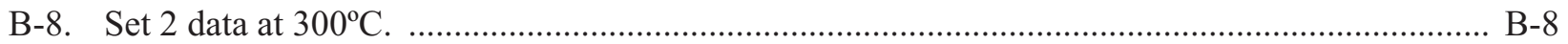

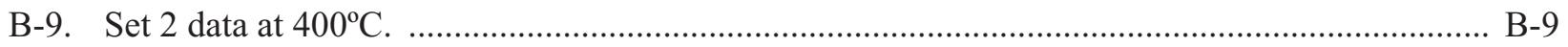

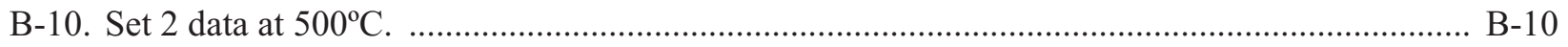

B-11. Room temperature data for Set 2 after high temperature calibration. ....................................... B-11 
INL/EXT-09-16972 


\section{INTRODUCTION}

The United States (U.S.) Department of Energy (DOE) designated the Advanced Test Reactor (ATR) as a National Scientific User Facility (NSUF) in April 2007 to promote nuclear science and technology in the U.S. Given this designation, the ATR is supporting new users from universities, laboratories, and industry as they conduct basic and applied nuclear research and development to advance the nation's energy security needs. A fundamental component of the ATR NSUF program is to develop in-pile instrumentation capable of providing real-time measurements of key parameters during irradiation experiments.

Dimensional change is a key parameter that must be monitored during irradiation of new materials being considered for fuel, cladding, and structures in next generation and existing nuclear reactors. Such materials can experience significant changes during high temperature irradiation. Currently, dimensional changes are determined by repeatedly irradiating a specimen for a defined period of time in the ATR and then removing it from the reactor for evaluation. The time and labor to remove, examine, and return irradiated samples for each measurement makes this approach very expensive. In addition, such techniques provide limited data (i.e., only characterizing the end state when samples are removed from the reactor) and may disturb the phenomena of interest.

To address these issues, the Idaho National Laboratory (INL) recently initiated efforts to evaluate candidate linear variable displacement transducers (LVDTs) for use during high temperature irradiation experiments in typical ATR test locations. Two nuclear grade LVDT vendor designs were identified for consideration - a smaller diameter design qualified for temperatures up to $350{ }^{\circ} \mathrm{C}$ and a larger design with capabilities to $500{ }^{\circ} \mathrm{C}$. Initial evaluation efforts include collecting calibration data as a function of temperature, long duration testing of LVDT response while held at high temperature, and the assessment of changes in performance that may be introduced as a result of high temperature operation in a radiation environment. The performance assessment focuses on the potential for any changes or degradation in sensitivity and/or electrical resistance. After initial testing, additional testing was completed for the more promising design to detect the changes that occur when some of its components are subjected to their Curie temperature. Results from this study are provided as the first step in qualifying these sensors for possible ATR use. (Note that this report will be submitted to the Institute for Energy at the Halden Reactor Project \{IFE-HRP $\}$ for confirmation of appropriate test procedures. Furthermore, this report will be updated during fiscal year 2010 to include results from the evaluation of "developmental" LVDTs to be provided by IFE-HRP.)

This document presents results from laboratory evaluations and results from scoping calculations completed to assess the possible effects of gamma heating during irradiation for the most promising LVDT design. Section 2 of this document provides background information related to LVDT operation and both designs evaluated in this effort. Section 3 contains a description of tests needed to ensure that LVDT outputs will not be adversely affected by fixturing and/or the proximity of other LVDTs during this evaluation. Results from calibration evaluations are provided in Section 4 and results from long duration tests are presented in Section 5. Curie temperature evaluation results are documented in Section 6. Scoping calculations to assess the impact of gamma heating during LVDT irradiation are presented in Section 7. Recommendations from these evaluations are documented in Section 8. References cited in this report are listed in Section 9. 
INL/EXT-09-16972 


\section{BACKGROUND}

The use of LVDTs to measure linear displacement is a relatively mature technology. LVDTs are relied upon because they are accurate, very reliable, simple in terms of design and operation, and relatively inexpensive. However, as discussed below, options for use in the ATR are limited when considering LVDT vendors with sensor operating histories in a nuclear reactor environment. This section provides background information related to LVDT operation and the designs evaluated in this effort.

\subsection{Description}

LVDTs have been used for many decades for the accurate measurement of displacement and within systems for positioning control. In its simplest form, an LVDT consists of one primary (center) coil and two (outer) secondary coils wrapped around a coil former (which is a hollow non-conducting cylinder). A ferromagnetic core attached to the object whose position is to be measured moves inside the coil former based on displacement of the object of interest. (See Figure 2-1a.) An alternating current is driven through the primary, causing a voltage to be induced in each secondary, which is proportional to its mutual inductance in the primary. The frequency is typically between 1 and $10 \mathrm{kHz}$. As the core moves, these mutual inductances change, causing the voltages induced in the secondaries to change. The coils are connected in reverse series, so that the output voltage is the difference between the two secondary voltages. When the core is in its central (or "null") position, equidistant between the two secondaries, equal but opposite voltages are induced in these two coils and the output voltage is zero (see Figure 2-1b). One important advantage of using an LVDT is that the moving core does not make contact with the coil former or any other components of the assembly. The absence of friction between sensor components results in high reliability and long life.

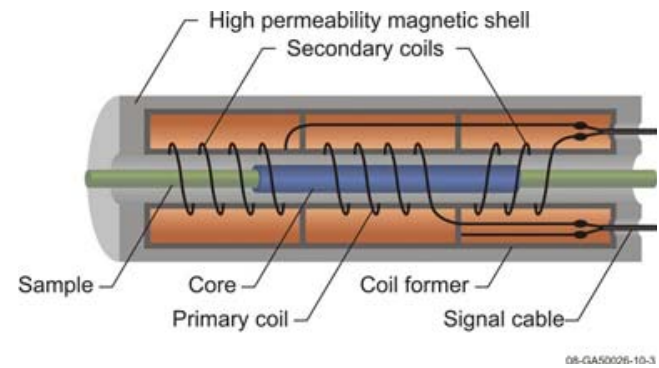

a.

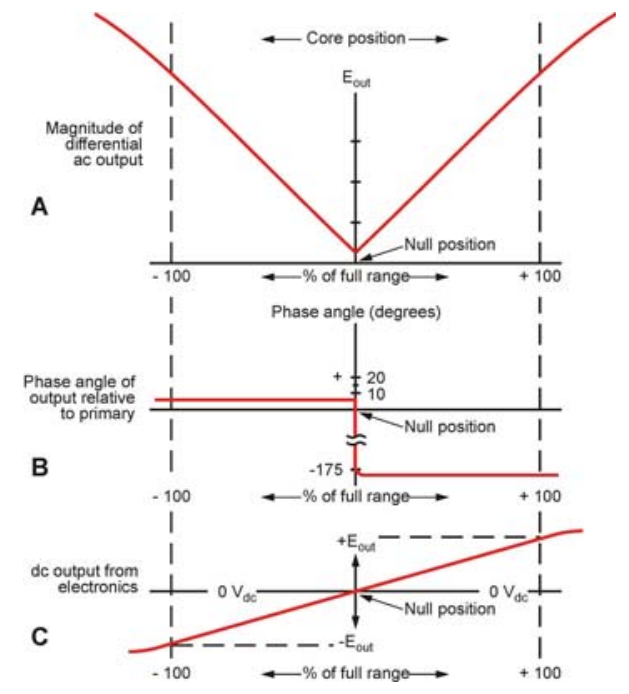

b.

Figure 2-1. Principle design of a Linear Variable Displacement Transducer. 
IFE-HRP is one of the pioneers in LVDT development for in-pile testing. In an IFE-HRP LVDT design, ${ }^{1}$ the primary coil is activated by a $400 \mathrm{~Hz}$ constant current generator and the position of the core can be measured with an accuracy of $\pm 1 \mu \mathrm{m}$. Since the IFE-HRP began making in-core measurements, more than 2200 LVDTs of different types have been installed in different test rigs in their Halden Boiling Water Reactor (HBWR). Failure rates of less than $10 \%$ after 5 years of operation is expected for their LVDTs operating in BWR, PWR or CANDU conditions.

Using LVDTs as a base instrument, the IFE-HRP has developed specialized sensors that allow on-line monitoring of a wide-range of parameters, such as fuel stack or tensile specimen elongation, cladding elongation, fuel centerline temperature, and fuel rod pressure. One example of note is an HRP-developed diameter gauge that enables on-line measurement of cladding diameter changes due to pellet cladding interaction, creep, and/or crud deposition. Recently, IFE-HRP has explored several improvements for LVDTs. For example, the IFE-HRP staff has collaborated with the French Commissariat a l'Energie Atomique (CEA) to improve the accuracy of their LVDTs when they pass through their Curie temperature. Currently, IFE-HRP staff are collaborating with INL to investigate the use of alternate coil wires and design modifications that would improve the performance of LVDTs at higher temperatures.

\subsection{Candidate LVDTs}

An INL survey revealed that, with minor modifications, two candidate nuclear grade LVDT vendor designs could meet the ATR-specific customer requirements listed in Table 2-1. Specifically, one supplier, hereafter identified as Vendor $\mathrm{A},{ }^{1}$ can currently provide LVDTs qualified to a maximum operating temperature of only $350^{\circ} \mathrm{C}$ while another supplier, hereafter identified as Vendor B, can currently provide only LVDTs with diameters exceeding listed ATR design limits. Note that the Vendor A temperature limitation was established primarily because of instabilities associated the sensor response as its coils pass through a material-specific Curie temperature at approximately $360^{\circ} \mathrm{C}$. However, including the Vendor A LVDT was deemed appropriate because alternate materials, that are not susceptible to the Curie temperature effects, could be incorporated into their design. (For example, components used in LVDTs developed for INL's Loss of Fluid Test were found to produce stable signals up to $500{ }^{\circ} \mathrm{C} .{ }^{2}$ ) Likewise, Vendor B indicated that alternate materials could be used in their sensor in order to reduce its size. In both cases, limited date were available to verify either manufacturer's claims regarding their performance at high temperatures. Hence, INL deemed that evaluations were needed prior to incorporating either design into ATR irradiations experiments. The sensors procured by INL for evaluation here are shown in Figure 2-2.

In addition to the obvious physical differences shown in the figure, a number of differences exist in the materials used in these LVDTs as indicated in Table 2-2. In this table, materials used in past designs for INL-specific tests ${ }^{2}$ are compared to materials used by Vendors A and B. Of particular note, Vendor A uses a nickel clad wire for primary and secondary coils that is subject to a Curie temperature effect at $\sim 360{ }^{\circ} \mathrm{C}$. In addition, Vendor B uses a lava core form, which is a primary factor contributing to the relatively-large diameter of their sensor. In both cases, the table indicates other materials are available that could be used to eliminate these design issues.

1. After reviewing results presented in this document, Vendor A indicated that it was acceptable for them to be identified. Vendor A is the Institute for Energy Technology at the Halden Reactor Project. 
Table 2-1. Desired LVDT characteristics for use in ATR.

\begin{tabular}{l|c}
\hline Parameter & ATR Specification \\
\hline Total LVDT displacement (e.g., stroke), mm & $> \pm 2.5$ \\
Resolution, mm & $10^{-2}$ \\
Sensitivity, V/m & $>50$ \\
Maximum operating temperature, $\mathrm{K}$ & 773 \\
Normal operating pressure, MPa & $0.101-15.5$ \\
Thermal flux, neutrons $/ \mathrm{cm}^{2} \mathrm{~s}^{\mathrm{a}}$ & $1.8 \times 10^{14}$ \\
Integrated thermal fluence, neutrons $/ \mathrm{cm}^{2 \mathrm{a}}$ & $8.5 \times 10^{21}$ \\
Fast flux, E $>1 \mathrm{MeV}$, neutrons $/ \mathrm{cm}^{2} \mathrm{~s}^{\mathrm{a}}$ & $1.2 \times 10^{14}$ \\
Integrated fast fluence, $\mathrm{E}>1 \mathrm{MeV}$, neutrons $/ \mathrm{cm}^{2 \mathrm{a}}$ & $5.7 \times 10^{21}$ \\
Gamma flux, $\gamma / \mathrm{cm}^{2} \mathrm{~s}^{\mathrm{a}}$ & $1.1 \times 10^{15}$ \\
Integrated gamma exposure, $\gamma / \mathrm{cm}^{2 \mathrm{a}}$ & $5.2 \times 10^{22}$ \\
Maximum LVDT diameter, $\mathrm{mm}$ & $12-25.4^{\mathrm{b}}$ \\
Maximum LVDT length, mm & $63.8^{\mathrm{b}}$ \\
Test environment & Water to $350^{\circ} \mathrm{C}$ and inert gas (Ne, He) to $500^{\circ} \mathrm{C}$ \\
Distance from test capsule to use of soft extension cable, $\mathrm{m}$ & 12 \\
Length of leads until T $<200{ }^{\circ} \mathrm{C}, \mathrm{m}$ & 7 \\
\hline
\end{tabular}

a. Peak values based on 24.3 MW center lobe power. Fluence is based on 2 years of operation at $75 \%$ utilization. These conditions are expected to bound anticipated test conditions.

b. Smaller diameter and lengths preferred.

\subsection{Evaluation Objectives}

As noted above, two candidate LVDT designs were identified as having the potential to meet ATR customer test conditions. However, limited data were available to verify their performance and there were concerns with each design's ability to meet some ATR test conditions. Hence, INL completed several tasks to compare candidate design performance. First, laboratory calibration tests were completed to compare candidate LVDT response at temperatures up to $500{ }^{\circ} \mathrm{C}$. Second, LVDT stability and reliability were assessed through long duration testing for $1000 \mathrm{~h}$ at $500^{\circ} \mathrm{C}$. After these initial evaluations, a superior design was selected for additional evaluations. First, additional assessments were completed near $360{ }^{\circ} \mathrm{C}$ to assess any instabilities that may occur when the preferred LVDT design was exposed to its Curie temperature. Second, finite element analyses were completed to verify the impact of gamma heating on LVDT performance. Results from these evaluations are presented in Sections 4 through 7 of this document. (It should be noted that a comprehensive series of interference tests were completed before LVDT candidates were evaluated. These tests, which are described in Section 3, were needed to ensure that LVDT outputs were not adversely affected by fixturing and/or the proximity of other LVDTs.) 


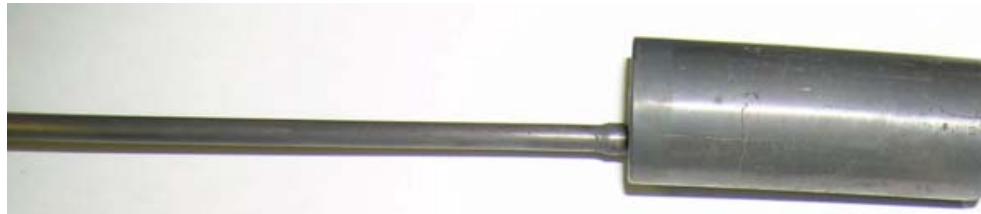

Vendor B LVDT 1449 (or LVDT B1)
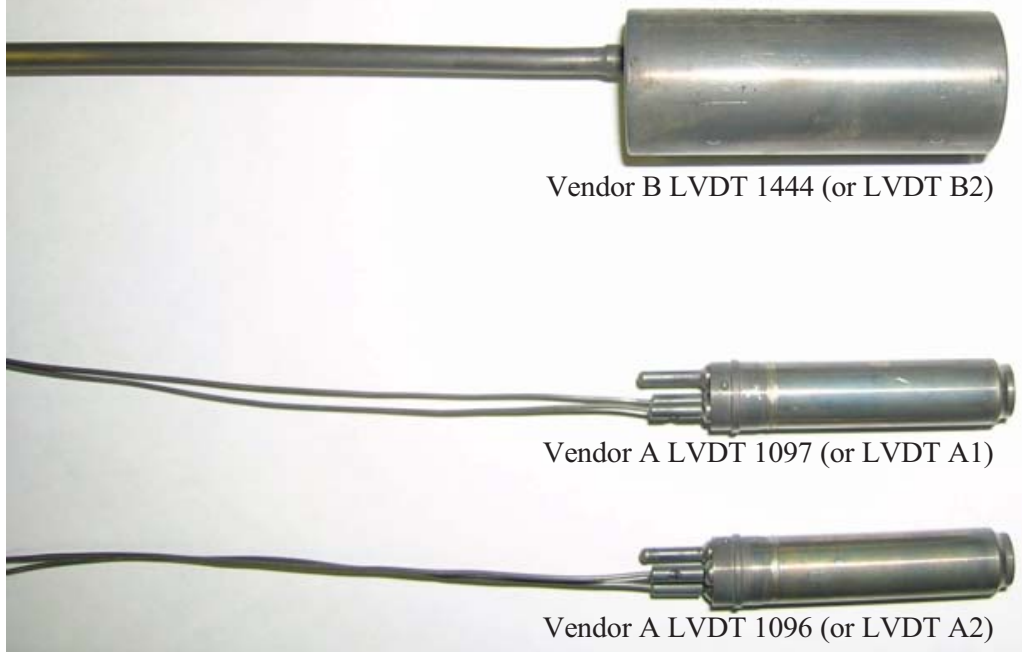

Figure 2-2. Evaluated LVDTs.

Table 2-2. LVDT materials.

\begin{tabular}{|c|c|c|c|}
\hline Component & INL $^{\mathbf{a}}$ & Vendor A & Vendor B \\
\hline Core & 17-4PH SS & Inconel 600 & Vanadium Permendur $^{b}$ \\
\hline Housing & $304 \mathrm{SS}$ & Inconel 600 & $304 \mathrm{SS}$ \\
\hline Coil form & $304 \mathrm{SS}$ & $\begin{array}{l}\text { Inconel } 600 \text {, plasma } \\
\text { sprayed with } \mathrm{Al}_{2} \mathrm{O}_{3}\end{array}$ & Lava (Alumino Silicate) \\
\hline End caps & $304 \mathrm{SS}$ & Inconel 600 & $304 \mathrm{SS}$ \\
\hline Magnetic shield / bore liner & $\begin{array}{c}\text { Silicon steel-AMS } \\
7714 \mathrm{M} 36\end{array}$ & Fe-Si-Foil & $410 \mathrm{SS}$ \\
\hline Coil wire & $\begin{array}{c}\text { Alloy } 406^{\mathrm{c}} \text { with Type } \mathrm{E} \\
\text { high temperature } \\
\text { insulation }\end{array}$ & $\begin{array}{l}\text { Nickel clad Copper }{ }^{\mathrm{d}} \text { with } \\
\text { vitreous enamel film }\end{array}$ & $\begin{array}{l}\text { Alloy } 406^{\mathrm{c}} \text { with high } \\
\text { temperature insulation }\end{array}$ \\
\hline Primary / secondary signal cable & $\begin{array}{l}\text { SS sheath, with nickel- } \\
\text { clad copper }\end{array}$ & $\begin{array}{c}\text { Inconel } 600 \text { sheath with } \\
\mathrm{Al}_{2} \mathrm{O}_{3} \text { insulation and } \\
\text { nickel wires }\end{array}$ & $\begin{array}{c}28 \text { AWG solid nickel with } \\
\text { MgO insulation in SS } \\
\text { sheath }\end{array}$ \\
\hline Cements (for coils, after forming) & $\begin{array}{c}\text { Yellow cerro ceramic } \\
\text { cement }\end{array}$ & $\begin{array}{l}\text { None required (because } \\
\text { core is thermally sprayed) }\end{array}$ & $\begin{array}{l}\text { ADH Ceramic silica base } \\
91825\end{array}$ \\
\hline
\end{tabular}

a. As used in past designs for INL-specific programs. ${ }^{2}$

b. Soft magnetically-permeable alloy containing $2 \%$ vanadium, $49 \%$ cobalt and $49 \%$ iron.

c. Silver wire, currently manufactured by California Fine Wires, contains silver, magnesium, zinc, lead, palladium, indium, manganese, and nickel.

d. Some loss of accuracy occurs temporarily at the Curie temperature of $\sim 360{ }^{\circ} \mathrm{C}$. 


\section{INTERFERENCE TESTING}

Specialized fixturing (to secure LVDT bodies relative to the movement of LVDT cores) was needed to complete this evaluation of candidate LVDTs. In addition, candidate LVDTs may be operated in close proximity to each other in various stages of this evaluation. Therefore, testing was completed to ensure that LVDT outputs were not adversely affected by the fixturing and/or the close proximity of other LVDTs. Otherwise, results and conclusions from this evaluation could not be considered reliable.

This section contains a description of the tests completed to ensure the absence of any LVDT output interference. For convenience, these tests were divided into two categories: (1) configurations that could be directly affected by the use of specialized test fixtures and (2) configurations associated with LVDTs operating in close proximity to each other. Those categories are discussed in the remainder of this section.

\subsection{Fixturing Tests}

Two different fixtures were needed to evaluate candidate LVDTs: one for calibration testing and one for long duration testing. Those fixtures are shown in Figures 3-1 and 3-2 (with more complete descriptions provided in Sections 4 and 5, respectively).

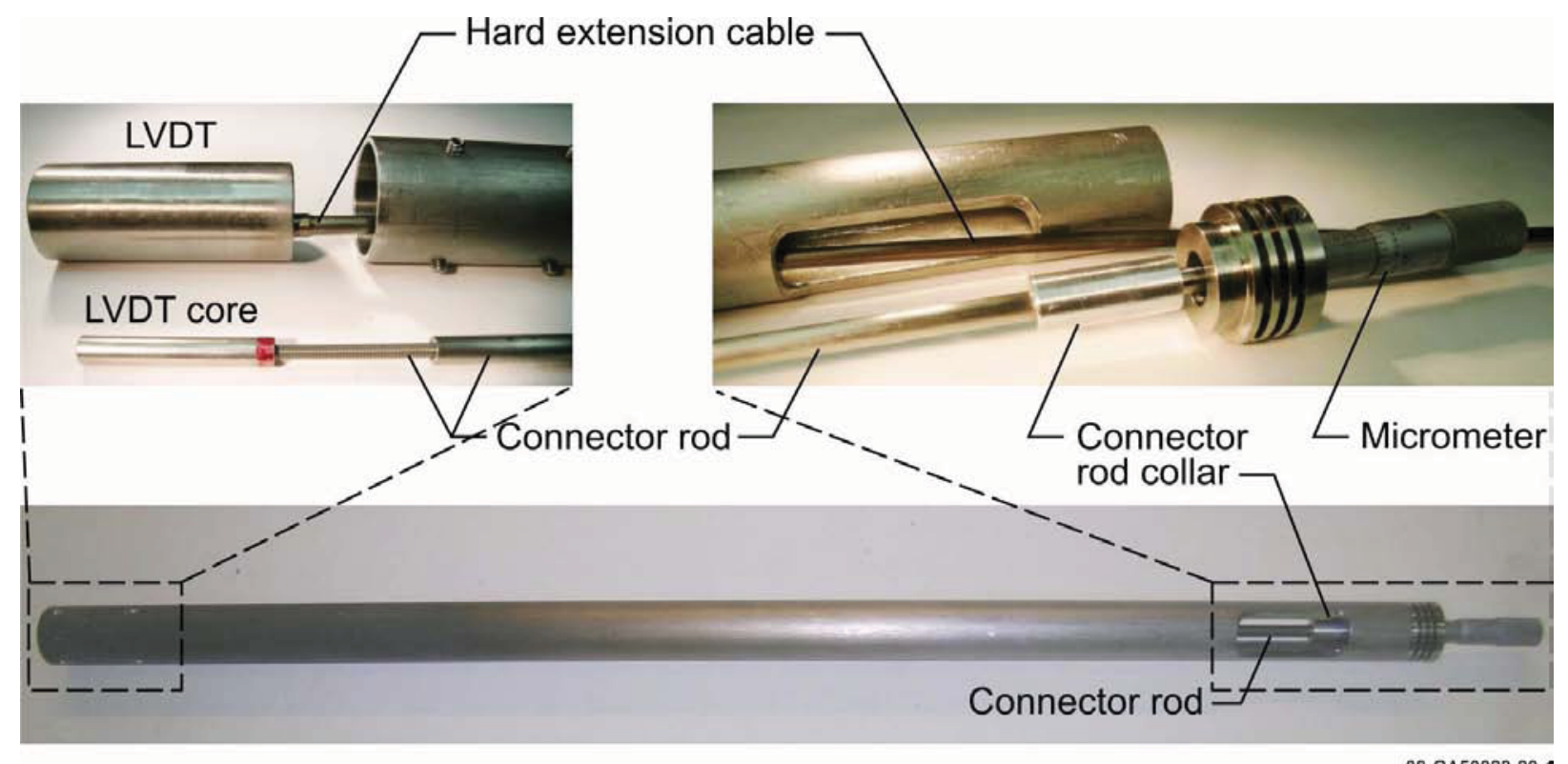

Figure 3-1. LVDT calibration fixture.

Calibration data for the candidate LVDTs were collected (1) outside all fixturing, (2) inside the calibration fixture, and (3) inside the long duration fixture. Data are provided in Appendix A. Corresponding results are shown in Figures 3-3 through 3-6. As indicated in these figures, fixturing has very little impact on LVDT outputs (i.e., outputs from each LVDT are essentially unchanged regardless of whether outputs are collected inside or outside of either fixture). For simplicity, data were collected at room temperature. 

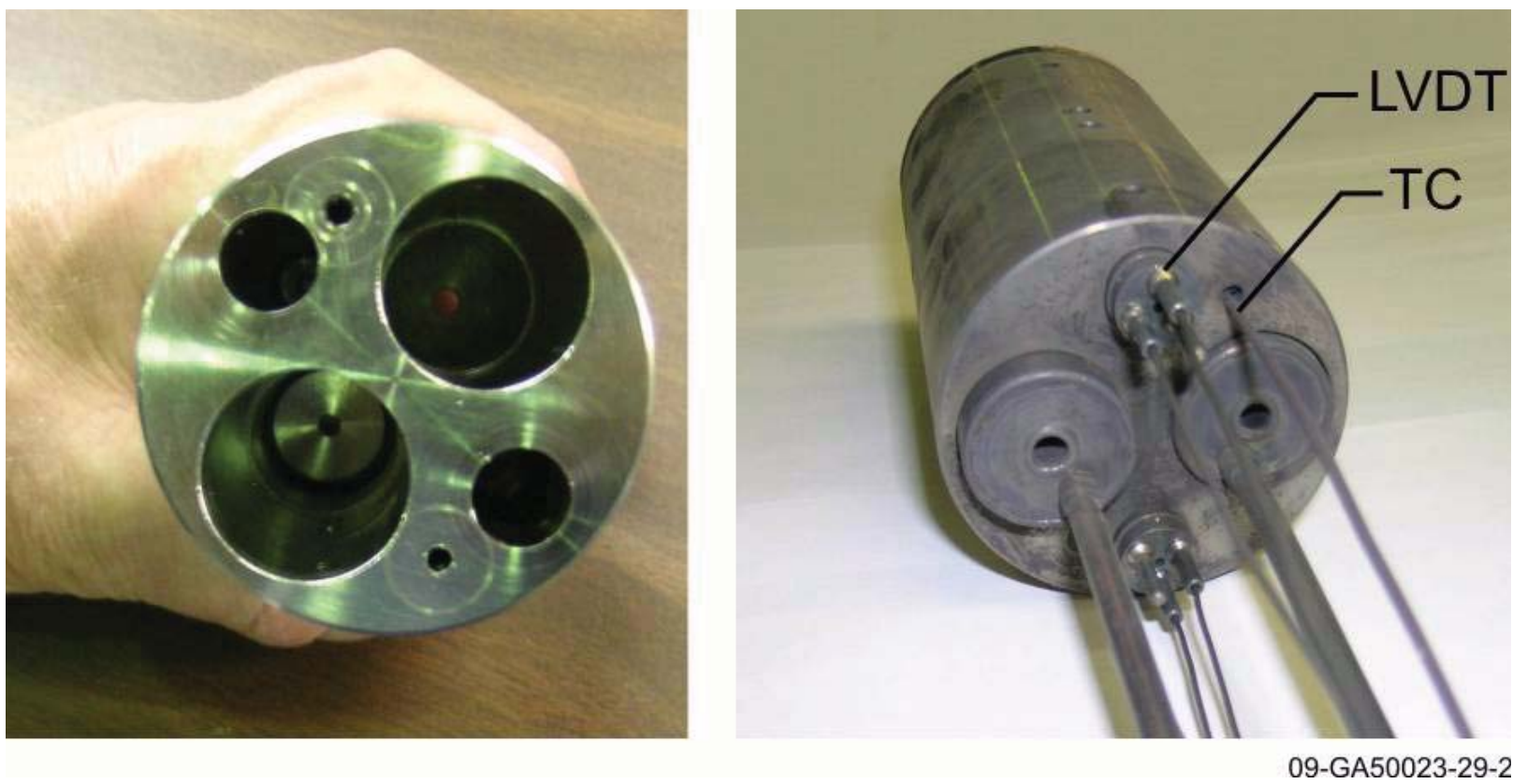

Figure 3-2. LVDT long duration fixture.

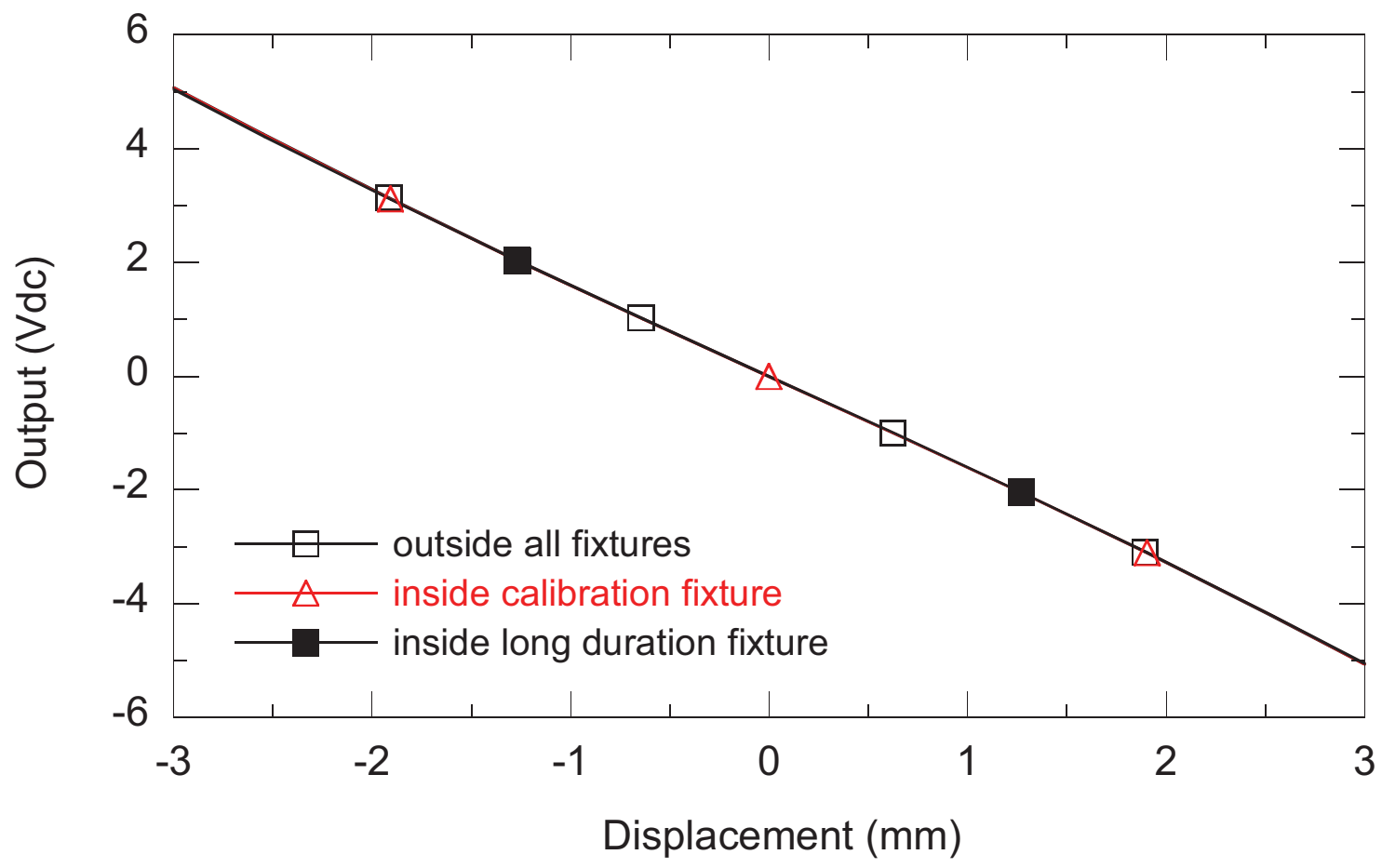

Figure 3-3. Vendor A LVDT 1096 room temperature calibration results. 


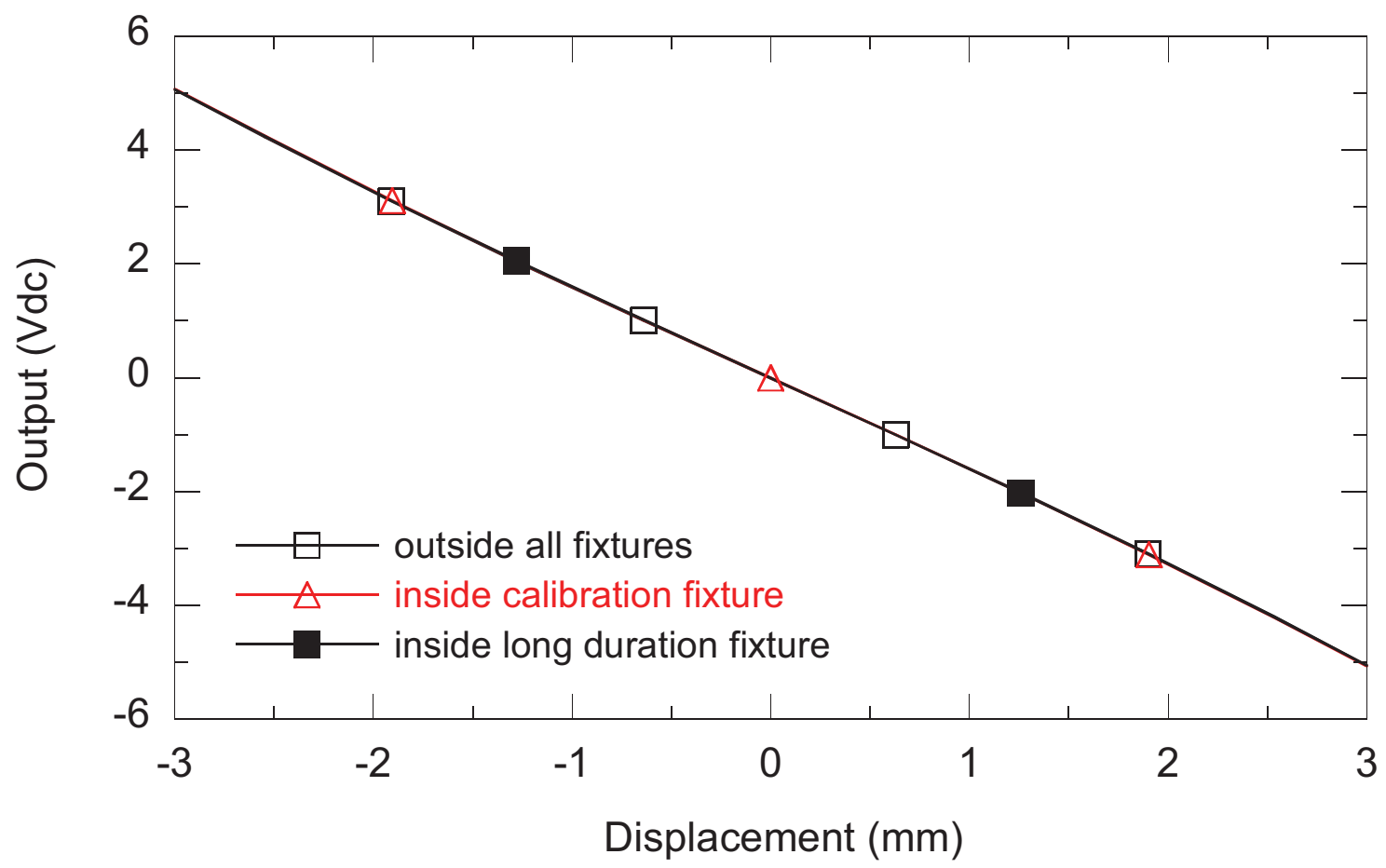

Figure 3-4. Vendor A LVDT 1097 room temperature calibration results.

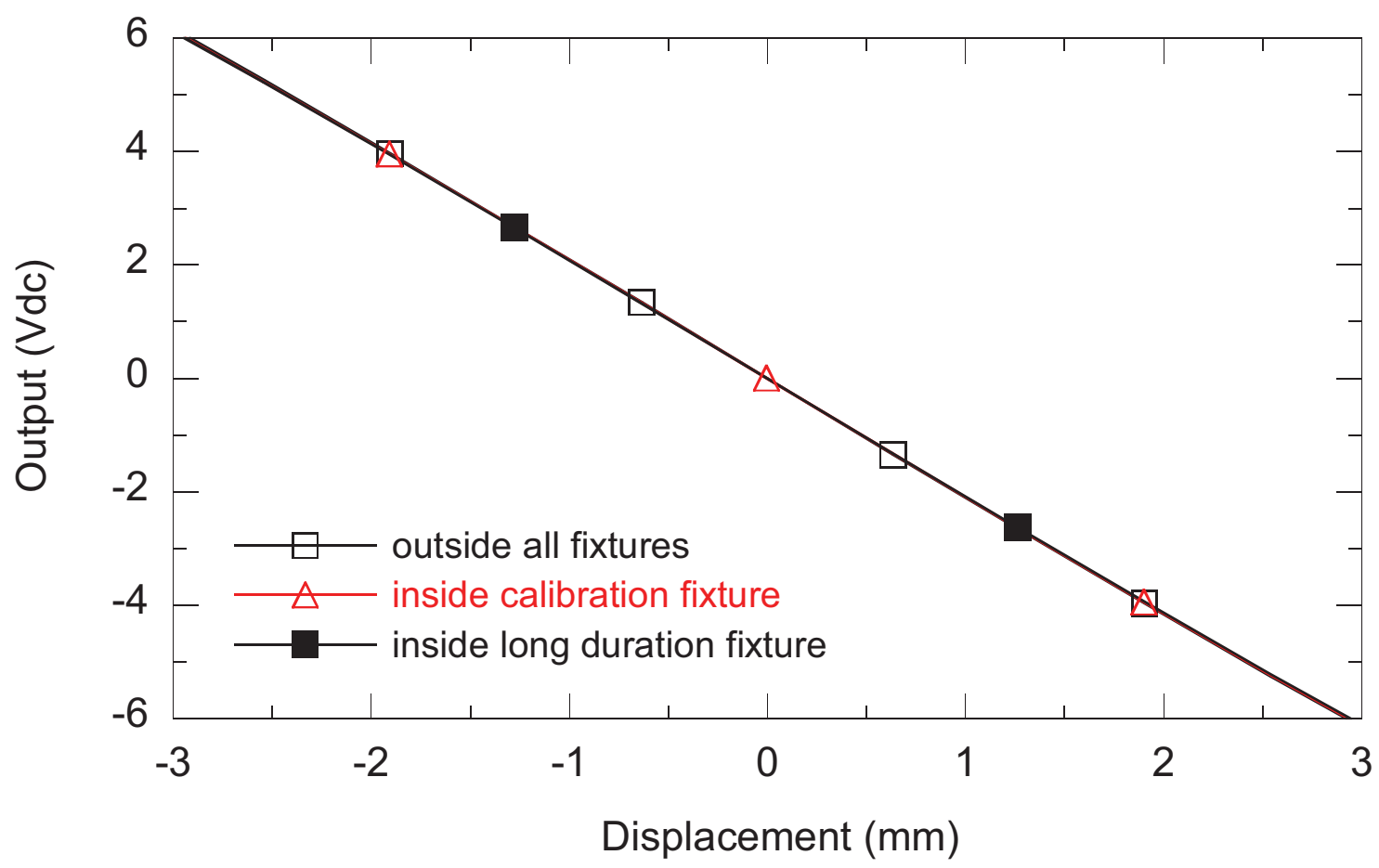

Figure 3-5. Vendor B LVDT 1444 room temperature calibration results. 


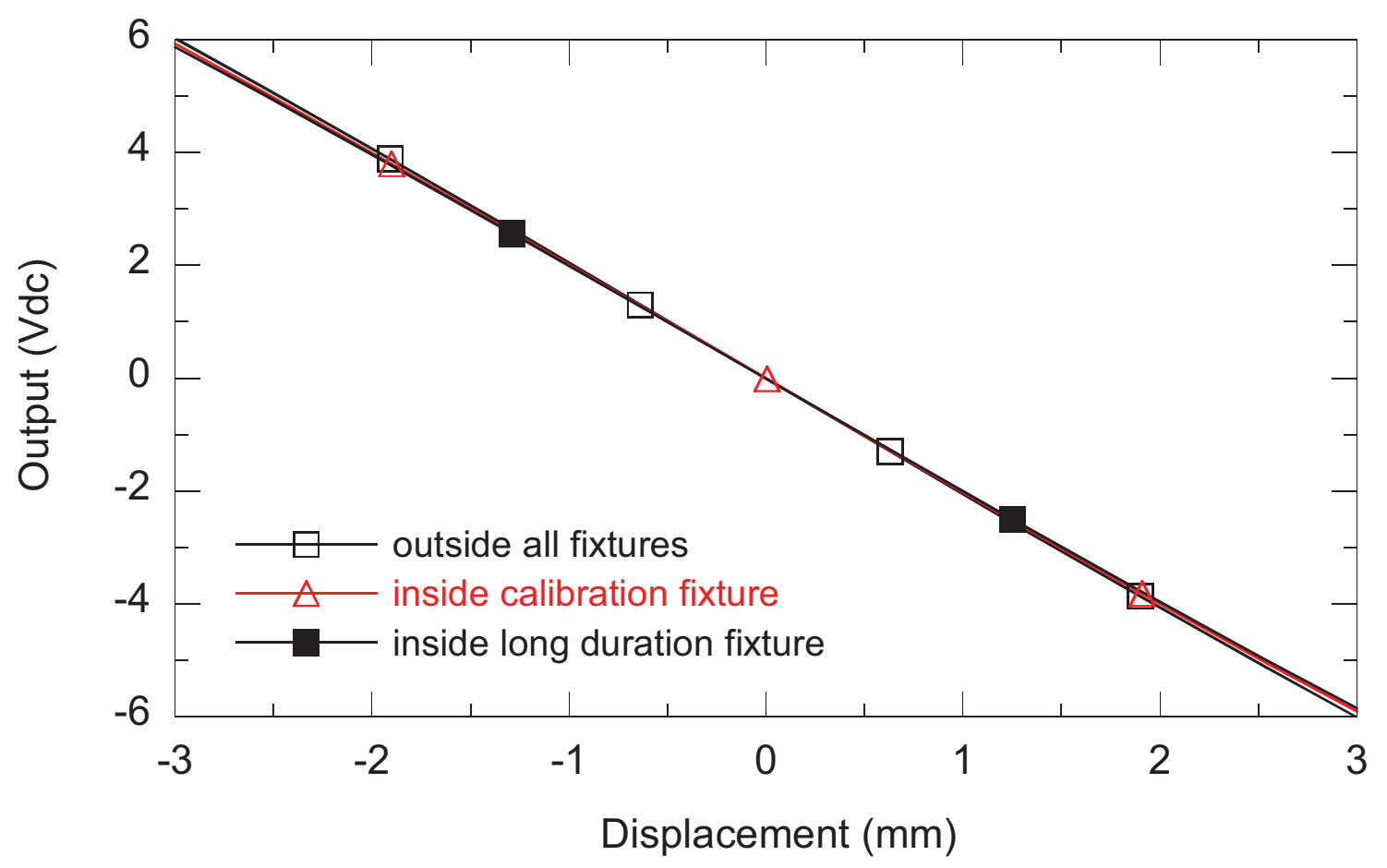

Figure 3-6. Vendor B LVDT 1449 room temperature calibration results.

Results shown in Figures 3-3 through 3-6 are also summarized in Table 3-1 in terms of LVDT sensitivities. (The sensitivity of an LVDT is expressed in terms of electrical output developed for a given displacement. This key metric, generally given in terms of an absolute value, is equivalent to the linear slope of a calibration curve.) As indicated in the table (and in comparisons of Figures 3-3 through 3-6), the largest deviations associated with use of either fixture were reflected in results for Vendor B LVDT 1449. Specifically, the output of this LVDT is $\sim 2.5 \%$ lower inside the long duration fixture than it is outside the fixture. For purposes of this evaluation, this difference (and other differences listed in the table) are considered insignificant. Consequently, these results indicate there is no concern regarding LVDT output interference associated with use of either of the specialized fixtures.

\subsection{LVDT Proximity Tests}

It was necessary to determine if LVDT output could be affected by a second LVDT operating in close proximity. The potential for such interference was evaluated for 3 different configurations including (1) LVDTs lying "head-to-head", (2) LVDTs lying "head-to-tail", and (3) LVDTs lying "across" each other. Furthermore, the potential for interference in these configurations was needed for 3 different LVDT combinations including (1) Vendor A versus Vendor A, (2) Vendor B versus Vendor B, and (3) Vendor A versus Vendor B. A summary of all configurations for all LVDT combinations is shown in Figure 3-7.

In this figure, the top row represents all configurations considered for Vendor A versus Vendor A LVDT combinations. Similarly, the middle row represents all configurations for Vendor B versus Vendor B LVDT combinations. And finally, the bottom row represents all configurations for Vendor A 
Table 3-1. Sensitivity results at room temperature.

\begin{tabular}{|c|c|c|c|c|c|}
\hline & & \multicolumn{4}{|c|}{ LVDT } \\
\hline & & \multicolumn{2}{|c|}{ Vendor A } & \multicolumn{2}{|c|}{ Vendor B } \\
\hline & & 1096 & 1097 & 1444 & 1449 \\
\hline & & \multicolumn{4}{|c|}{ Sensitivities $(\mathrm{mV} / \mathrm{mm})$} \\
\hline & Vendor value & 1640.7 & 1649.0 & na & na \\
\hline \multirow{3}{*}{ Measured } & Outside all fixtures & 1647.8 & 1639.3 & 2077.7 & 2028.7 \\
\hline & Inside calibration fixture & 1644.6 & 1645.0 & 2067.2 & 1995.5 \\
\hline & Inside long duration fixture & 1641.0 & 1642.5 & 2060.6 & 1977.2 \\
\hline & & \multicolumn{4}{|c|}{ Measured deviations (\%) } \\
\hline \multirow{3}{*}{ Relative to vendor value } & Outside all fixtures & 0.433 & -0.588 & na & na \\
\hline & Inside calibration fixture & 0.238 & -0.243 & na & na \\
\hline & Inside long duration fixture & 0.018 & -0.394 & na & na \\
\hline \multirow{2}{*}{ Relative to value outside all fixtures } & Inside calibration fixture & -0.194 & 0.348 & -0.505 & -1.637 \\
\hline & Inside long duration fixture & -0.413 & 0.195 & -0.823 & -2.539 \\
\hline
\end{tabular}

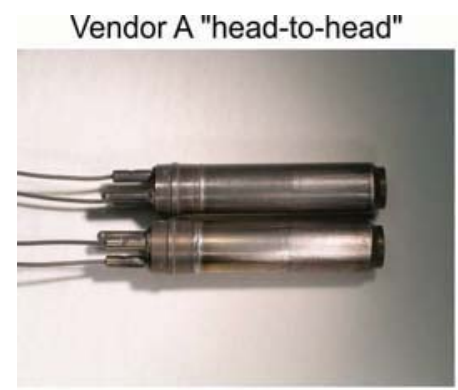

Vendor B "head-to-head"
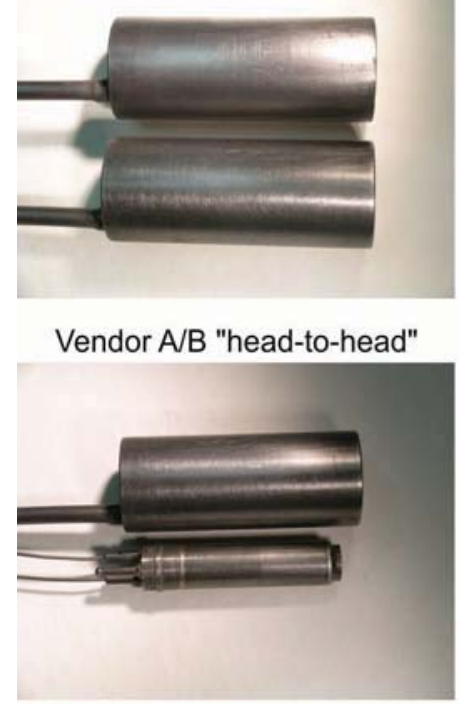

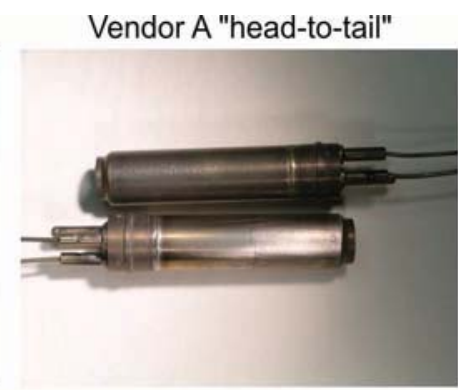

Vendor B "head-to-tail"
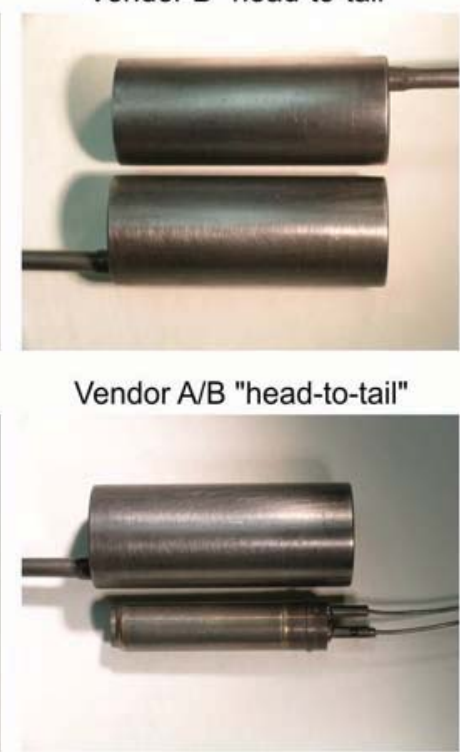

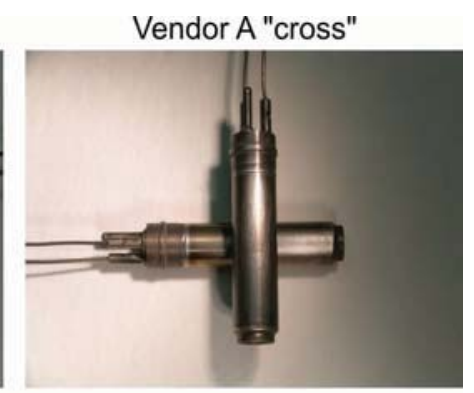

Vendor B "cross"

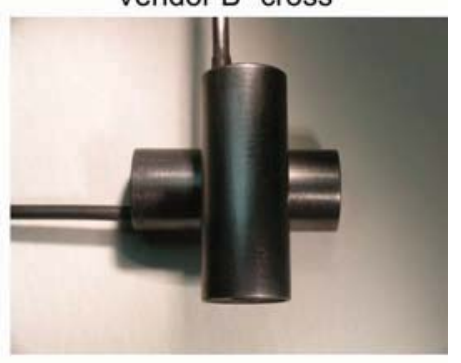

Vendor A/B "cross"

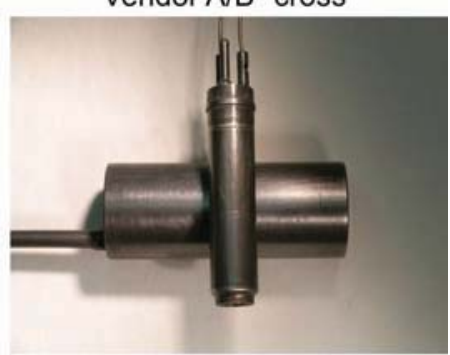

Figure 3-7. LVDT proximity configurations and combinations. 
versus Vendor B combinations. The following steps were completed for each LVDT configuration/combination. (For simplicity, these steps were completed at room temperature.)

1. LVDT cores were inserted into the LVDT bodies to locations near their "null" positions. (Output from each LVDT was checked independently to verify cores were properly positioned.)

2. Output from the first LVDT was obtained while the second LVDT remained de-energized.

3. The second LVDT was then energized to see if there was any impact on the output of the first LVDT. If energizing the second LVDT changed the output of the first LVDT, the induced change was recorded.

4. Output from the second LVDT was noted (while both LVDTs were energized). Then, the first LVDT was de-energized to see if there was any impact on the output of the second LVDT. If deenergizing the first LVDT changed the output of the second LVDT, the induced change was recorded.

5. LVDT cores were then re-positioned to locations in the "positive" direction near the limits of linear travel (or $+2.5 \mathrm{~mm}$ from the "null" positions).

6. Steps 2 through 4 were repeated.

7. LVDT cores were then re-positioned to locations in the "negative" direction near the limits of linear travel (or $-2.5 \mathrm{~mm}$ from the "null" positions).

8. Steps 2 through 4 were repeated.

After completing the steps above for all LVDT configurations/combinations, it was determined that outputs from Vendor A and Vendor B LVDTs were not affected by other LVDTs that may be operating in close proximity (i.e., operation of one LVDT does not induce a change in output of a nearby LVDT). This result, along with the fact that Vendor $\mathrm{A}$ and Vendor B outputs are unaffected by fixturing, means that interference effects are not of concern in these LVDT evaluations.

\subsection{Summary}

A comprehensive series of tests were completed (at room temperature) to ensure that LVDT outputs are not adversely affected by the use of specialized fixturing and/or the close proximity of other operating LVDTs. The results indicate that LVDT outputs are essentially unchanged regardless of whether outputs are collected inside or outside of the specialized fixtures. In addition, it was determined that the operation of one LVDT does not induce a change in output of nearby LVDT. Consequently, interference effects are not a concern in these LVDT evaluations, assuming that room temperature results also apply to higher temperatures. 


\section{CALIBRATION}

LVDTs must be calibrated for the temperatures where they will be deployed. This evaluation consists of collecting calibration data for two Vendor A LVDTs and two Vendor B LVDTs at temperatures up to $500{ }^{\circ} \mathrm{C}$, which is expected to cover the range of temperatures of current interest in potential ATR applications. Identifying any changes or degradation in sensitivity and/or electrical resistance as a function of temperature is the primary focus of this evaluation. LVDTs should produce consistent trends in sensitivity and electrical resistance as a function of temperature in order to be considered for use in ATR in-pile experiments.

\subsection{Setup}

A schematic of the test configuration is provided in Figure 4-1. As indicated, this test required use of a specialized fixture, a tube furnace, LVDT-specific signal conditioners, and a computerized data acquisition system (DAS). The specialized fixture, labeled "SS capsule" in the figure, was fabricated at the INL from stainless steel tubing. The fixture provides a means for securing an LVDT body at one end and a micrometer at the opposite end. The tubing was of a length sufficient to allow positioning of the LVDT at the center of a high temperature tube furnace with the micrometer outside the furnace (and thereby unaffected by the furnace temperature). A stainless steel rod was used to connect the micrometer to the LVDT core, which was initially placed at the null position relative to the LVDT body. The micrometer then provided the mechanism for precise movement of the core (with respect to the body) for calibration purposes. Details for both ends of this fixture and its configuration relative to the tube furnace are shown in Figure 4-2. In this case, a three-zone, horizontal Carbolite furnace with a maximum temperature of $1700^{\circ} \mathrm{C}$ was used.

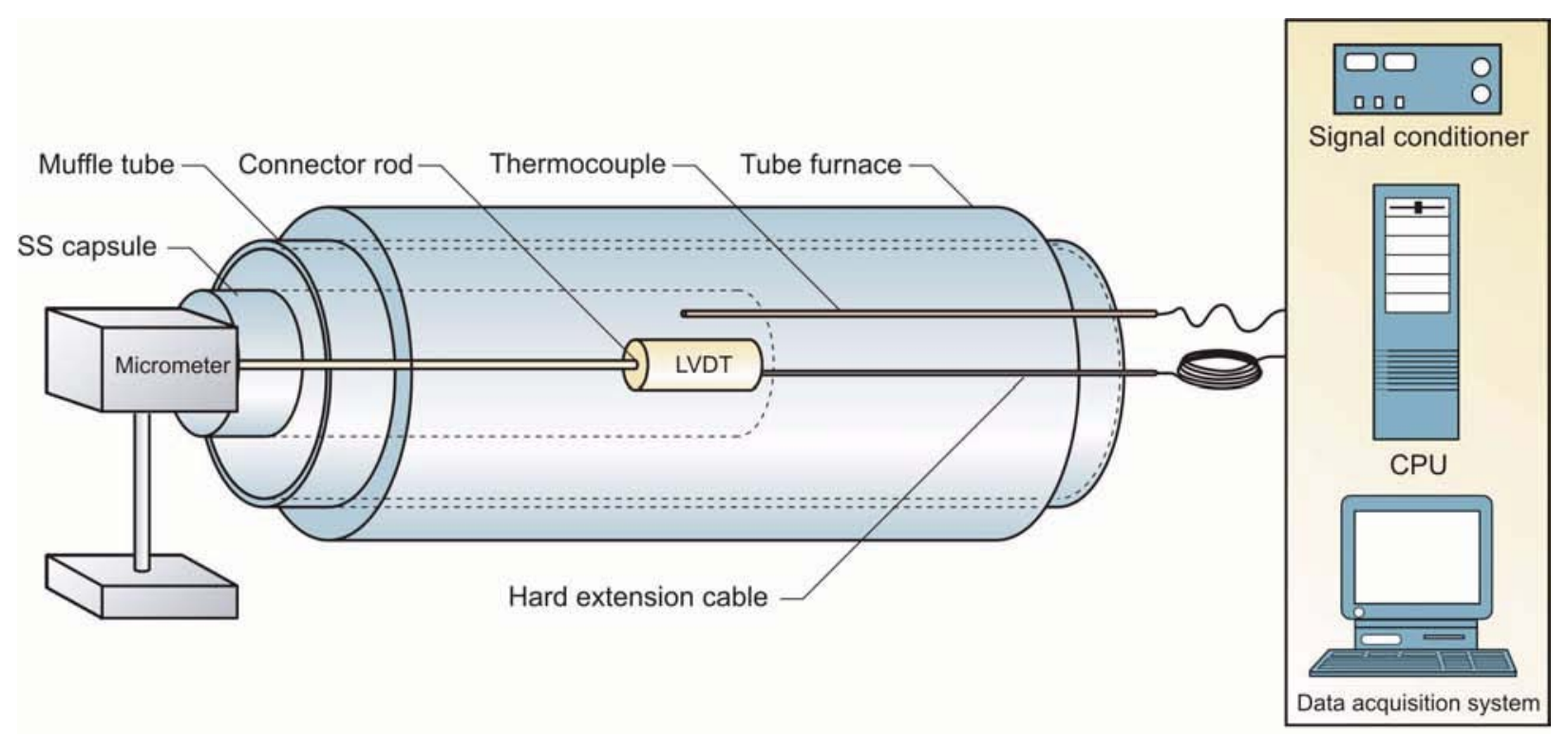

Figure 4-1. Schematic of the calibration test configuration. 


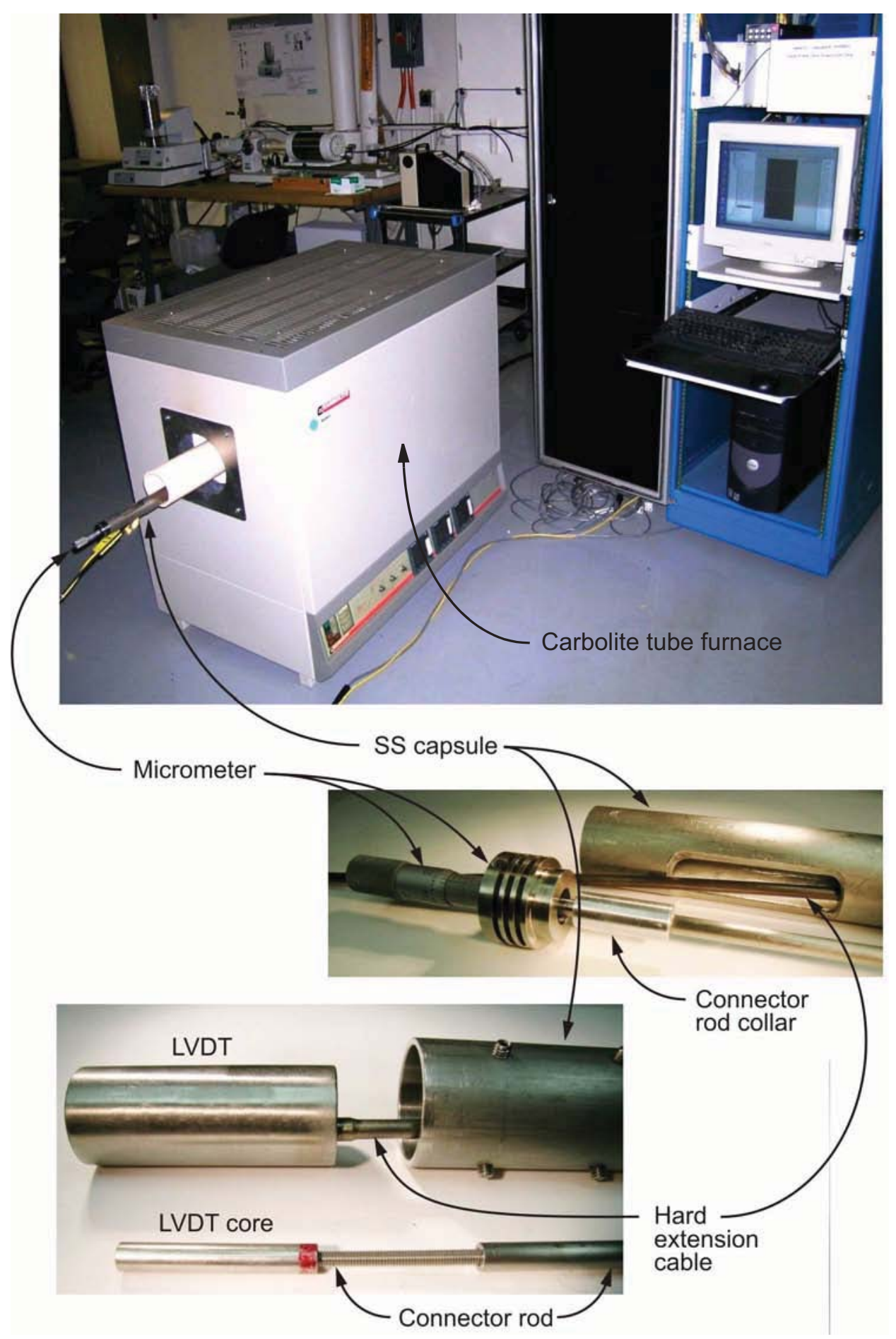

Figure 4-2. Calibration test configuration.

Note that a comprehensive set of tests, as described in detail in Section 3, was conducted prior to this evaluation to ensure that the LVDTs would not be affected by operating in close proximity to each other. Tests were also completed to ensure that LVDT response was not altered through use of the specialized fixture. In addition to supporting the validity of this evaluation, these tests provide important insights that will ultimately be needed in the design of ATR in-pile test configurations. 


\subsection{Results}

Calibration data (i.e., output voltage versus displacement) were collected at 200, 300, 400, and $500{ }^{\circ} \mathrm{C}$ for two Vendor A LVDTs and two Vendor B LVDTs. In addition, data were collected at room temperature both before and after the higher temperature calibration. Appendix B provides all of the corresponding DAS file names (where raw data actually resides) as well as supporting information associated with the calibration. Linear curve fits for the data at each temperature over the design range (of $\pm 2.5 \mathrm{~mm}$ for all candidate LVDTs) were successfully determined. Results for Vendor A LVDT 1097 (also designated as A1) at $500{ }^{\circ} \mathrm{C}$ are shown in Figure 4-3.

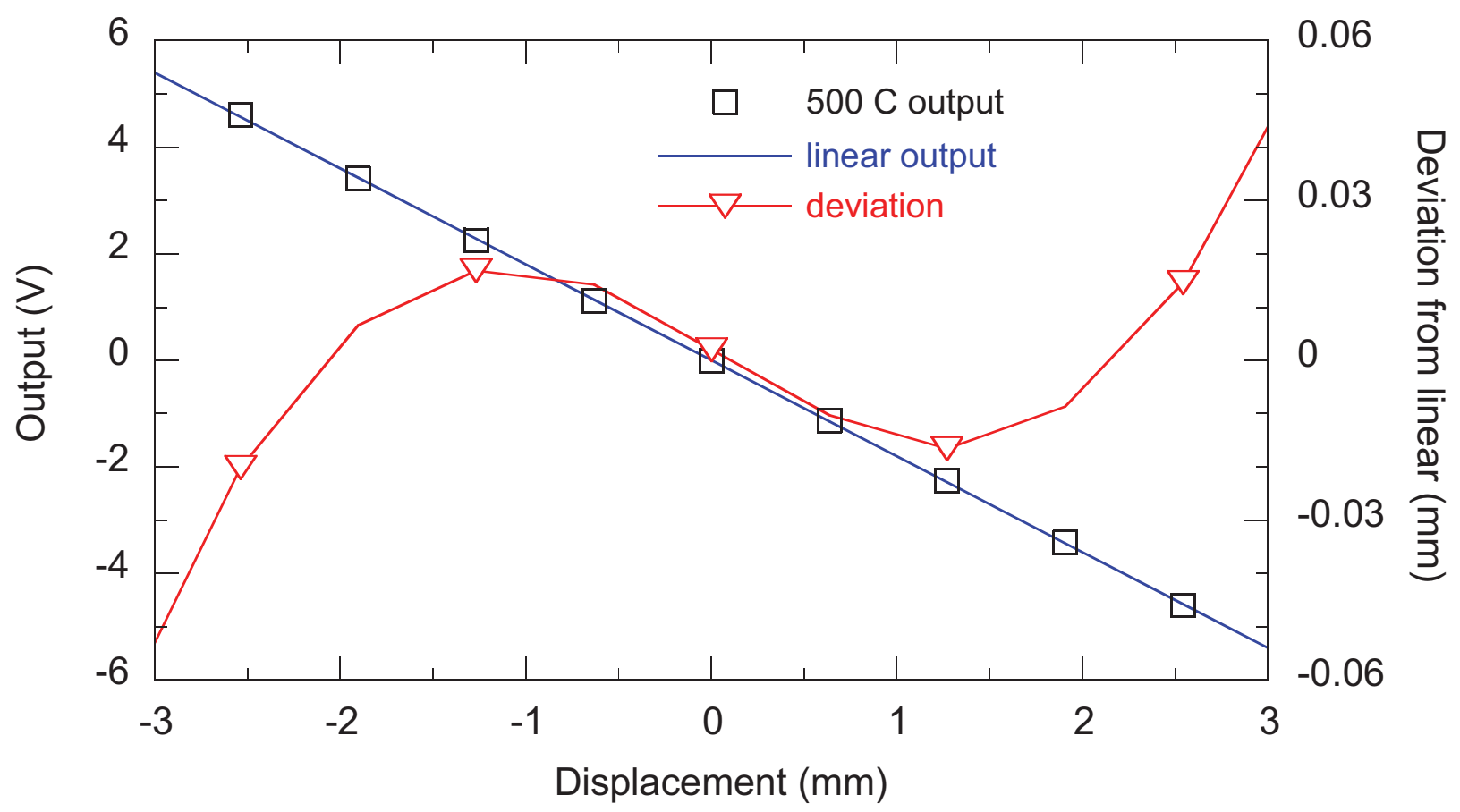

Figure 4-3. Calibration data for Vendor A LVDT 1097 (or LVDT A1) at $500{ }^{\circ} \mathrm{C}$.

LVDT response data, a linear fit through that data, and the deviation of the data relative to the linear fit are all shown in the figure. Note that LVDT A1 has a maximum deviation of less than $\pm 0.02 \mathrm{~mm}$ (or $\pm 0.8 \%$ ) over its design range of $\pm 2.5 \mathrm{~mm}$. Furthermore, its linear deviation is symmetric with respect to its null position. This is evident in that its deviation is $\sim 0$ at a displacement of 0 and the (absolute value of) deviations are approximately equal for equal but opposite displacements from null. These results are typical of those for all other Vendor A LVDTs.

Corresponding results for Vendor B LVDT 1449 (also designated as B1) are shown in Figure 4-4. There are several notable differences apparent through comparison of Figures 4-3 and 4-4. Specifically, the maximum linear deviation of LVDT B1 (at more than $0.044 \mathrm{~mm}$, or more than $1.8 \%$, over its design range of $\pm 2.5 \mathrm{~mm}$ ) is more than twice the LVDT A1 maximum deviation. Furthermore, the linear deviation of LVDT B1 is not symmetric with respect to its null position. In fact, its deviation is $\sim 0$ at a displacement of $\sim 1.2 \mathrm{~mm}$. Deviations at $\pm 2.5 \mathrm{~mm}$ are $\sim 0.017$ and $0.044 \mathrm{~mm}$, respectively. Although there are no 
ATR symmetry specifications, symmetric behavior is desirable. Both LVDTs should be capable of resolution in the $0.010 \mathrm{~mm}$ range, which is an ATR specification. However, LVDT A1 would be expected to have a lower degree of uncertainty (as compared to LVDT B1) because its deviation from linearity is relatively small.

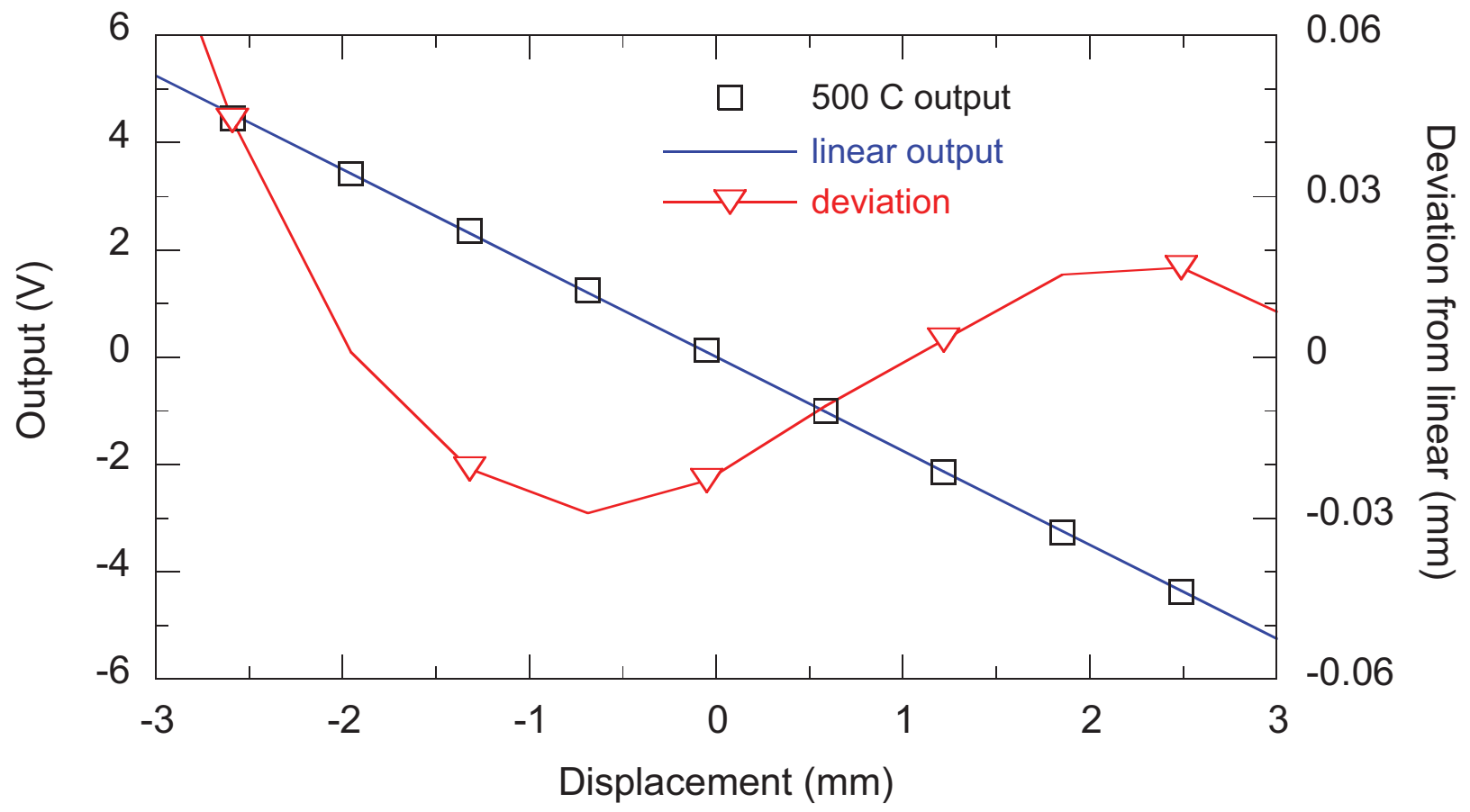

Figure 4-4. Calibration data for Vendor B LVDT 1449 (or LVDT B1) at $500{ }^{\circ} \mathrm{C}$.

The sensitivity of an LVDT is expressed in terms of electrical output developed for a given displacement. This key metric is equivalent to the linear slope of a calibration curve (like the linear curves shown in Figures 4-3 and 4-4). Sensitivities, (generally given in terms of an absolute value), for all LVDTs at all temperatures are summarized in Table 4-1.

Table 4-1. Sensitivity results.

\begin{tabular}{l|c|c|c|c}
\hline \multirow{2}{*}{ Condition } & \multicolumn{3}{|c}{ LVDT Sensitivities (mV/mm) for } \\
\cline { 2 - 5 } & \multicolumn{2}{|c|}{ Vendor A } & \multicolumn{3}{|c}{ Vendor B } \\
\cline { 2 - 5 } Room temperature (before higher temperature calibration) & 1096 & 1097 & 1444 & 1449 \\
\hline $200{ }^{\circ} \mathrm{C}$ & 1638.8 & 1645.0 & 2078.3 & 1995.5 \\
\hline $300{ }^{\circ} \mathrm{C}$ & 1690.4 & 1696.2 & 2176.5 & 2067.1 \\
\hline $400{ }^{\circ} \mathrm{C}$ & 1703.4 & 1706.5 & 2221.8 & 2096.7 \\
\hline $500{ }^{\circ} \mathrm{C}$ & 1782.7 & 1788.7 & 2187.0 & 2094.5 \\
\hline Room temperature (after higher temperature calibration) & 1796.3 & 1800.7 & 1672.5 & 1750.6 \\
\hline
\end{tabular}


LVDTs A1 and B1, with sensitivities at $500{ }^{\circ} \mathrm{C}$ of 1800 and $1750 \mathrm{mV} / \mathrm{mm}$, respectively, easily exceed the ATR specification of $50 \mathrm{mV} / \mathrm{mm}$ (listed in Table 2-1). However, the effects of temperature on sensitivity are of interest given the cyclic nature of ATR operations. This temperature dependence for LVDTs A1 and $\mathrm{B} 1$ is presented in Figure 4-5.

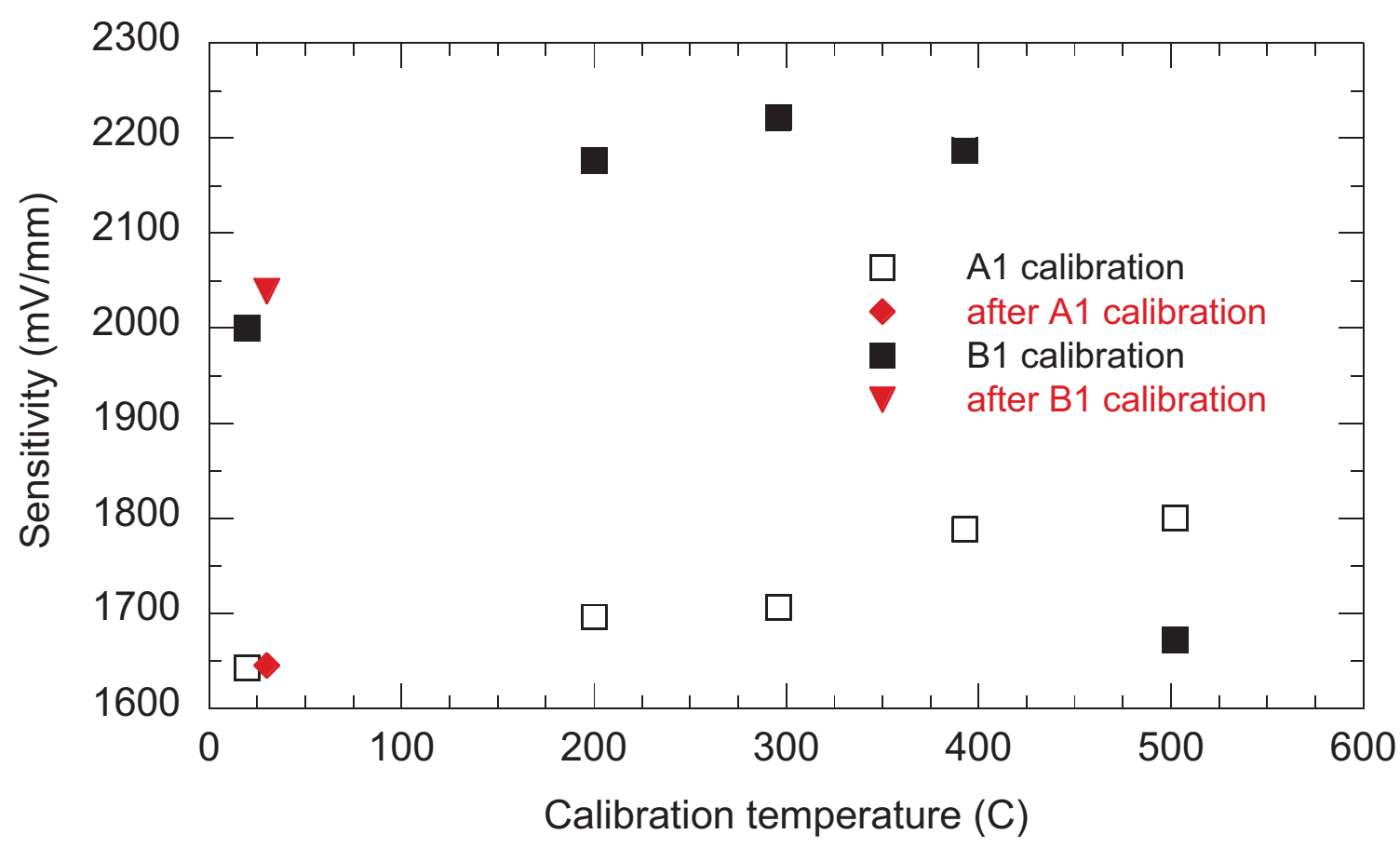

Figure 4-5. Comparison of LVDT sensitivities as a function of temperature.

LVDT A1 sensitivity was found to increase (somewhat linearly) with temperature as shown in the figure. This increasing trend is beneficial in that sensor resolution is favorably affected. Furthermore, the sensitivity of LVDT A1 was found to return to its room temperature value following calibration at temperatures as high as $500{ }^{\circ} \mathrm{C}$. These results provide some evidence that Vendor A LVDTs are robust through temperature cycling up to the design specification. In contrast, LVDT B1 sensitivity increased (almost) linearly with temperature only up to $\sim 300^{\circ} \mathrm{C}$. Thereafter, the sensitivity decreased sharply as shown. Although LVDT B1 sensitivity at $500^{\circ} \mathrm{C}$ exceeds ATR specifications, the sharply decreasing trend is not favorable. Relative to LVDT A1, LVDT B1 pre- and post-calibration room temperature sensitivities differed noticeably. Again, this LVDT B1 result is not favorable (as compared to results for LVDT A1).

Electrical resistance is one factor that could affect LVDT sensitivities. In this study, the resistance of (both primary and secondary) loop windings was found to increase with temperature in LVDTs from both vendors, which was expected. Insulation resistance, however, generally tends to decrease with temperature. Insulation resistance measurements relative to primary and secondary windings for LVDTs A1 and B1 are shown in Figure 4-6 as a function of temperature. (Note that $1 \times 10^{8}$ ohms was a limitation of the meter used in this study.) 


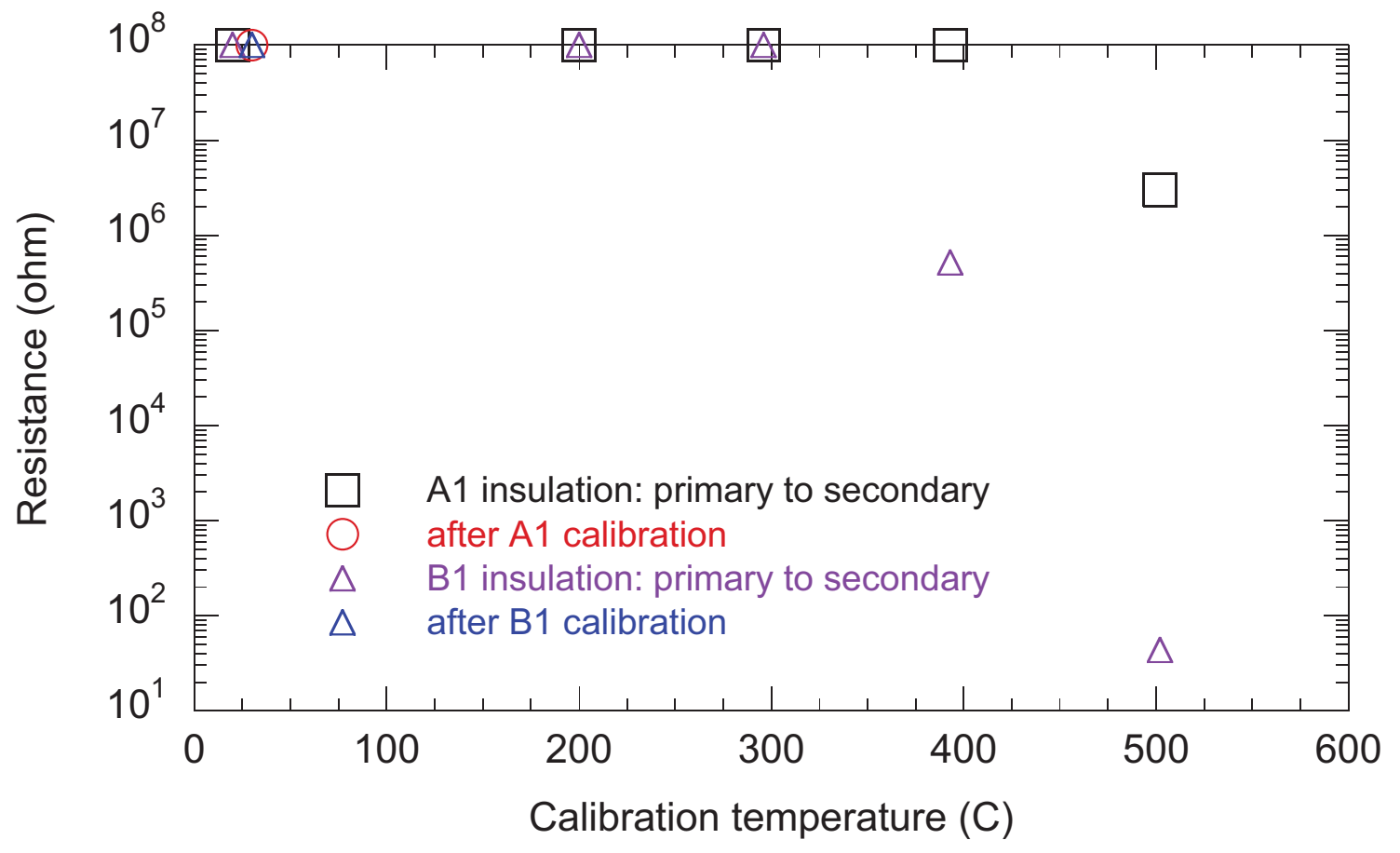

Figure 4-6. Comparison of LVDT insulation resistances as a function of temperature.

As indicated in Figure 4-6, the primary to secondary insulation resistance for LVDT B1 showed a sharp decrease after $300^{\circ} \mathrm{C}$. This trend appears to be consistent with the decreasing trend in sensitivity shown in Figure 4-5. A value of $\sim 40 \mathrm{ohms}$, as measured at $500{ }^{\circ} \mathrm{C}$ for LVDT B1, seems unreasonably low. In contrast, temperatures exceeded $400{ }^{\circ} \mathrm{C}$ before any decreases in the corresponding insulation resistance for LVDT A1 were measured. Furthermore, the decrease for LVDT A1 was relatively small, yielding a value in excess of $1 \times 10^{6} \mathrm{ohms}$ at $500{ }^{\circ} \mathrm{C}$. These results clearly favor the Vendor A LVDT design for use in ATR irradiation experiments.

\subsection{Summary}

LVDTs must be calibrated for the temperatures where they will be deployed. For that reason, calibration was completed for two Vendor A LVDTs and two Vendor B LVDTs at temperatures up to $500{ }^{\circ} \mathrm{C}$, which is expected to cover the range of temperatures of current interest in potential ATR applications. The results clearly favor the Vendor A LVDT design for use in ATR irradiation experiments. Vendor A LVDTs show relatively small deviations from linear behavior (compared to Vendor B LVDTs) and their deviations are symmetric (where Vendor B LVDT deviations are not). Sensitivities of Vendor A LVDTs increase (nearly linearly) with temperature. In contrast, Vendor B LVDT sensitivities increase with temperature to $\sim 300{ }^{\circ} \mathrm{C}$ and sharply drop thereafter. Furthermore, Vendor A LVDT pre- and post-calibration room temperature sensitivities are essentially equivalent while Vendor B pre- and post-calibration sensitivities differ appreciably, indicating a lack of robustness in the Vendor B design. Finally, Vendor B LVDT insulation resistances drop to unreasonably low values at high temperatures while Vendor A resistances do not. For these reasons, Vendor B LVDTs would not be acceptable for use in the ATR. 


\section{LONG DURATION TESTING}

LVDTs must operate reliably for extended periods at elevated temperatures in order to be useful in ATR in-pile experiments. For that reason, LVDT testing for a period of $1000 \mathrm{~h}$ at $500{ }^{\circ} \mathrm{C}$ was needed. The selected temperature of $500{ }^{\circ} \mathrm{C}$ is within the operating range (that extends to $600{ }^{\circ} \mathrm{C}$ ) for Vendor B LVDTs and Vendor A (IFE-HRP) LVDTs have successfully reached that temperature according to user reports. In addition, the selected period of $1000 \mathrm{~h}$ represents a minimum requirement given current ATR operating cycles that typically run from 6 to 8 weeks.

An assessment of changes in performance that may be introduced as a result of high temperature operation was the primary focus of this test. Performance was assessed through the evaluation of any changes or degradation in sensor output stability.

\subsection{Setup}

A schematic of the test configuration is provided in Figure 5-1. As indicated, this test required use of a specialized fixture, a tube furnace, LVDT-specific signal conditioners, and a computerized DAS. The specialized fixture, labeled "SS capsule" in the figure, was fabricated at the INL from a solid block of stainless steel to allow the simultaneous testing of 4 LVDTs (although only 2 LVDTs are shown for clarity). The fixture provides a means for securing each LVDT relative to its associated core and connecting rod as well as positions for $2 \mathrm{TCs}$ to monitor test temperatures independently of the furnace temperature controller. LVDT bodies were secured at one end of the specialized fixture while connecting rods were secured at the opposite end. Connecting rods were of a length sufficient to place LVDT cores as close as possible to null positions relative to the LVDT bodies. Holding the resulting assembly at a constant temperature will reveal any tendency for LVDT signal degradation or oscillation over time.

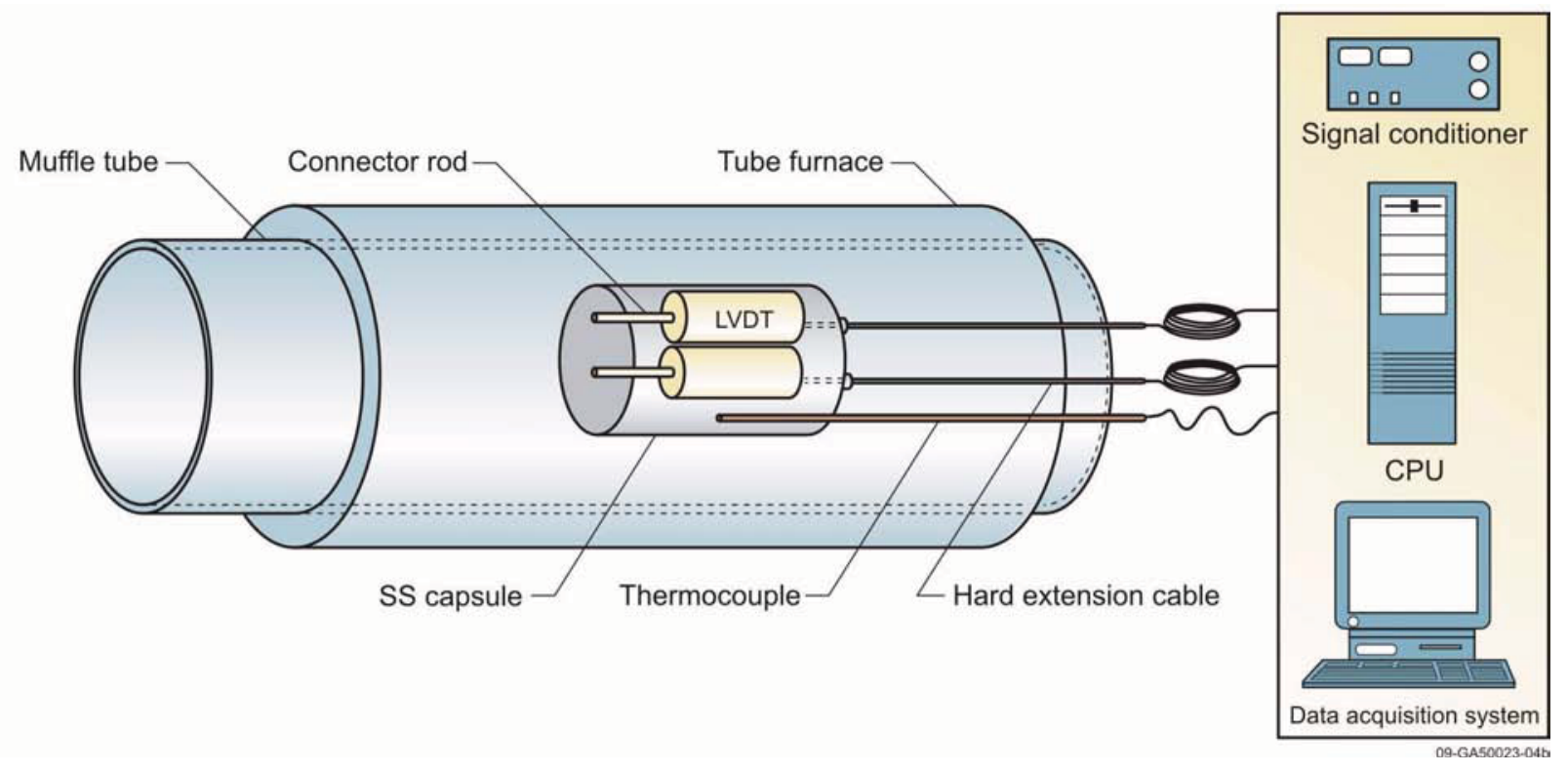

Figure 5-1. Schematic of the long duration test configuration. 
The specialized fixture prior to loading the LVDTs is shown in the lower right inset of Figure 5-2. The smallest holes accommodate TCs, Vendor A LVDTs fit in the medium size holes, and the largest holes are for Vendor B LVDTs. The loaded fixture is also shown prior to insertion into the furnace muffle tube. In this case, a three-zone, horizontal Carbolite furnace with a maximum temperature of $1700{ }^{\circ} \mathrm{C}$ was used.

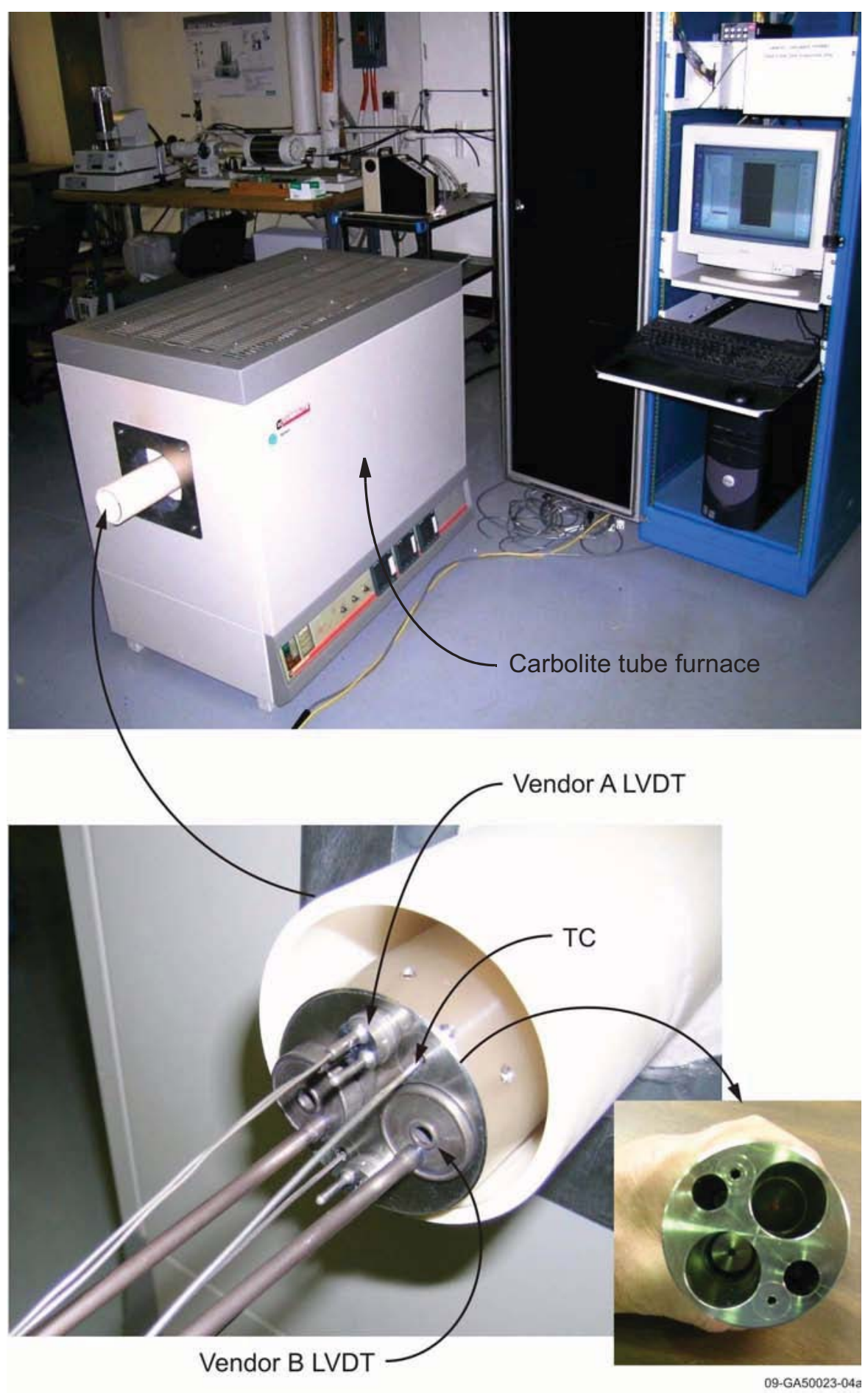

Figure 5-2. Long duration test configuration. 
Note that a comprehensive set of tests, as described in detail in Section 3, was conducted prior to this evaluation to ensure that the LVDTs would not be affected by operating in close proximity to each other. Tests were also completed to ensure that LVDT response was not altered through use of the specialized fixture. In addition to supporting the validity of this evaluation, these tests provide important insights that will ultimately be needed in the design of ATR in-pile test configurations.

\subsection{Results}

Long duration testing of LVDTs from both vendors was necessary to reveal any tendencies for signal degradation or oscillation over time. In this test, two Vendor A LVDTs and two Vendor B LVDTs were held at $500{ }^{\circ} \mathrm{C}$ for $1000 \mathrm{~h}$. Results for all four tested LVDTs are compared in Figure 5-3. (Note that an unplanned power outage interrupted data collection during the time period between $\sim 700$ and $\sim 760 \mathrm{~h}$. The best information available indicates operation of the high temperature furnace was unaffected. Although data were lost during this outage, it is appears that LVDT operation at $500{ }^{\circ} \mathrm{C}$ continued as planned.)

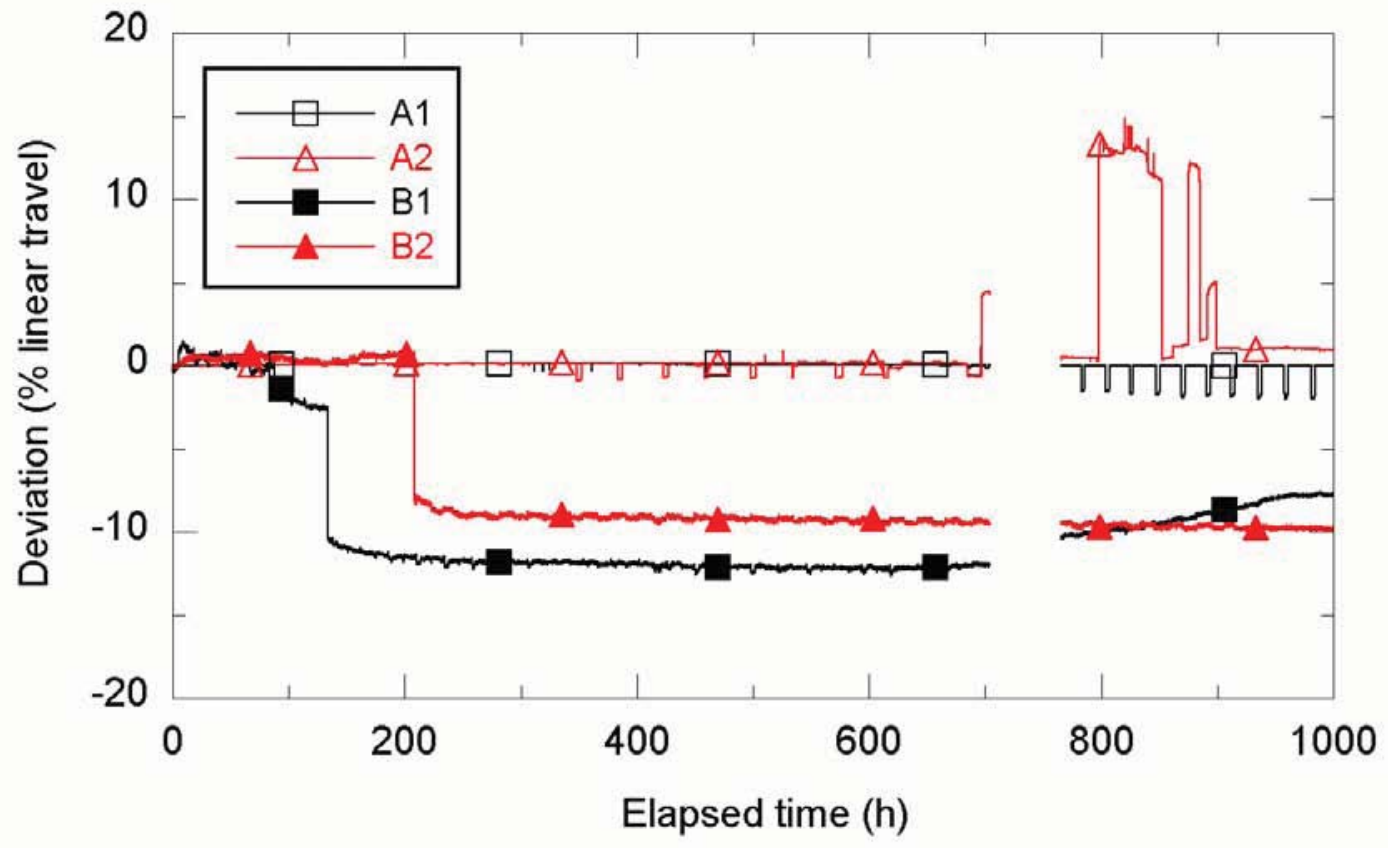

Figure 5-3. Comparison of LVDT response during long duration testing.

In this evaluation, all four LVDTs were configured in the specialized fixture with cores set as close to null positions as possible. Consequently, output for all four LVDTs would be expected to remain near $0 \mathrm{Vdc}$ throughout the test. For comparison purposes, calibration data for each LVDT (at $500{ }^{\circ} \mathrm{C}$ ) was used to convert measured output voltage to an indicated displacement. Figure 5-3 presents the deviation of the indicated displacement, relative to the time 0 output, as a percentage of total linear travel (which is $5 \mathrm{~mm}$ for all sensors). Following this approach, a perfectly stable sensor would then register $0 \%$ deviation through time. 
As indicated Figure 5-3, Vendor A LVDTs were found to be very stable through $\sim 330 \mathrm{~h}$. Their maximum deviation during that period is equivalent to a displacement of $\sim 0.004 \mathrm{~mm}$ relative to their time 0 position. (Note that $\sim 25 \mathrm{~h}$ were set aside for stabilization at $500{ }^{\circ} \mathrm{C}$ before marking time 0 .) However, some periodic fluctuations in the response of Vendor A LVDTs began to appear after $\sim 330 \mathrm{~h}$. Those fluctuations, primarily affecting LVDT A2, remained relatively small for more than $350 \mathrm{~h}$. Just before the unplanned power outage (at $\sim 700 \mathrm{~h}$ ), LVDT A2 fluctuations dramatically increased in both magnitude and duration. Shortly thereafter, LVDT A1 signal fluctuations increased; with relatively frequent oscillations until the end of the $1000 \mathrm{~h}$ test.

Although the reason (or reasons) for the behavior of Vendor A LVDTs during the later part of the long duration test are still under investigation, the vendor has indicated that they have observed similar trends as a result of insulation degradation. Furthermore, Vendor A has indicated that they believe they can correct the long term behavior through alteration of the LVDT heat treatment process.

Results for Vendor B LVDTs differ significantly compared to Vendor A. Specifically, Vendor B LVDTs show substantial oscillation (starting at time 0) in addition to (as yet unexplained) dramatic step changes in indicated deviations (near $130 \mathrm{~h}$ for LVDT B1 and near $210 \mathrm{~h}$ for LVDT B2). In fact, the LVDT B1 step change is equivalent to a displacement of $\sim 0.6 \mathrm{~mm}$, indicating a reduction in stability by a factor of $\sim 150$ compared to Vendor A LVDTs during the first $330 \mathrm{~h}$ of the test.

Further differences between the initial LVDT responses from the two vendors are illustrated in finer detail in Figure 5-4. As indicated, the LVDT A1 response remains very flat with only minor perturbations. In contrast, LVDT B1 shows considerable oscillation during the entire displayed period. The more or less periodic oscillations produced by LVDT B1 are approximately equivalent to a displacement of 0.007 to $0.010 \mathrm{~mm}$; representing values that were not exceeded by Vendor A LVDTs during the first $330 \mathrm{~h}$ of the long duration test. In addition, perturbations in LVDT B1 outputs near 83 and $84.8 \mathrm{~h}$ represent unexpected output deviations that are three times larger (approaching $0.03 \mathrm{~mm}$ ).

To date, Vendor B has not provided their evaluation or interpretation of their long duration results. However, considerable oxidation of the Vendor B LVDT cores occurred during the long duration test as indicated in Figure 5-5. This discovery was unexpected given that all LVDTs were calibrated at $500{ }^{\circ} \mathrm{C}$ without showing any evidence of oxidation. Furthermore, Vendor B cores were reported to be stainless steel, which should not have oxidized at the test temperature. Note the nearly pristine condition of all other pictured components subjected to the same conditions.

Although it is unclear whether oxidation had an adverse impact on Vendor B LVDT response during the long duration test, oxidation is not a desirable outcome. This oxidation and the perturbations observed during the test clearly favor the Vendor A LVDT design for use in ATR irradiation experiments. However, some additional evaluation of the Vendor A LVDT behavior may be needed to resolve instabilities for long duration use at high temperatures.

\subsection{Summary}

LVDTs must operate reliably for extended periods at elevated temperatures in order to be useful in ATR in-pile experiments. For that reason, LVDT testing for a period of $1000 \mathrm{~h}$ at $500{ }^{\circ} \mathrm{C}$ was completed. Results from this testing clearly favor the Vendor A (IFE-HRP) LVDT design. Specifically, Vendor A LVDTs were found to be very stable at $500{ }^{\circ} \mathrm{C}$ for $\sim 300 \mathrm{~h}$. In contrast, Vendor B LVDTs show consider- 


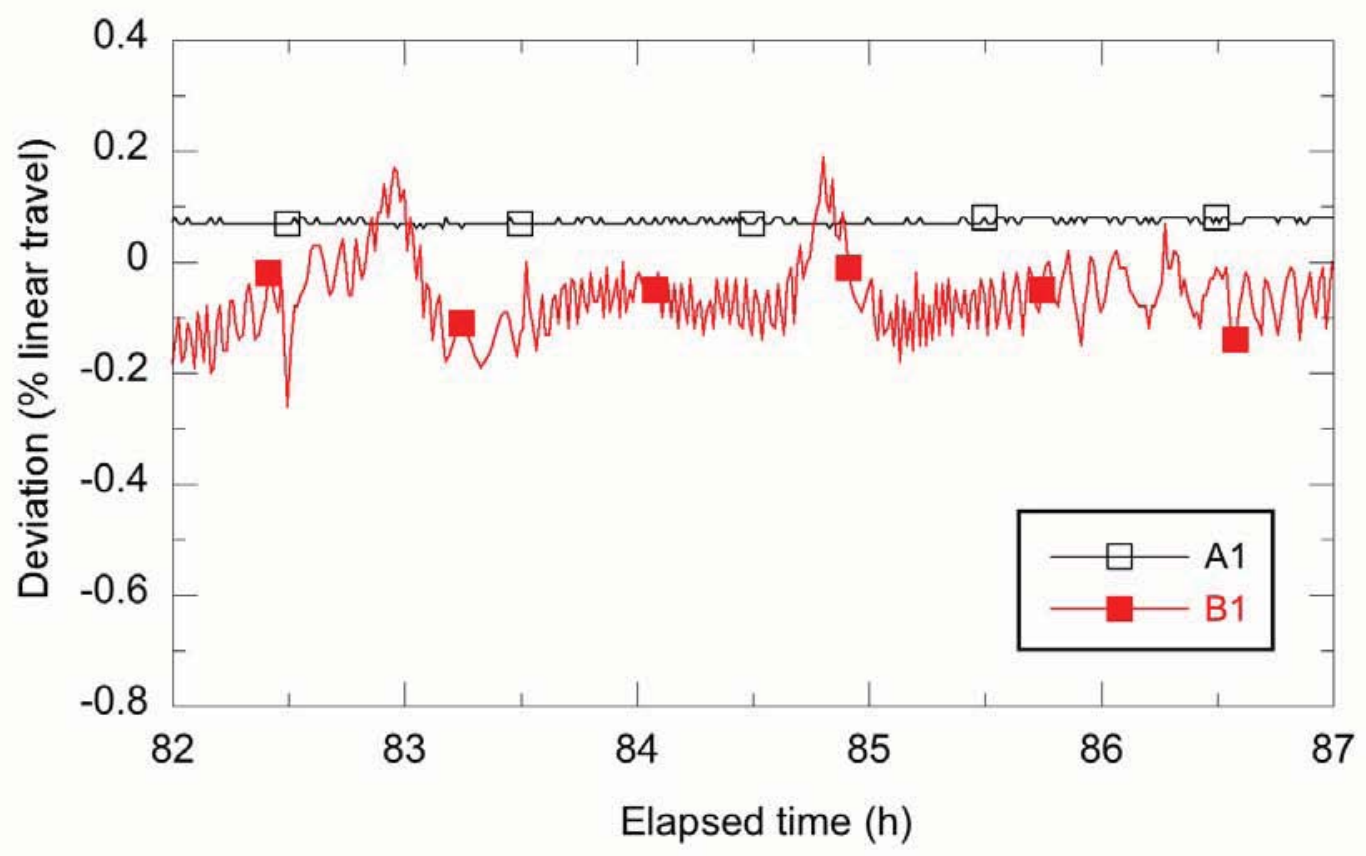

Figure 5-4. Comparison of the response of LVDTs A1 and B1 during long duration testing.

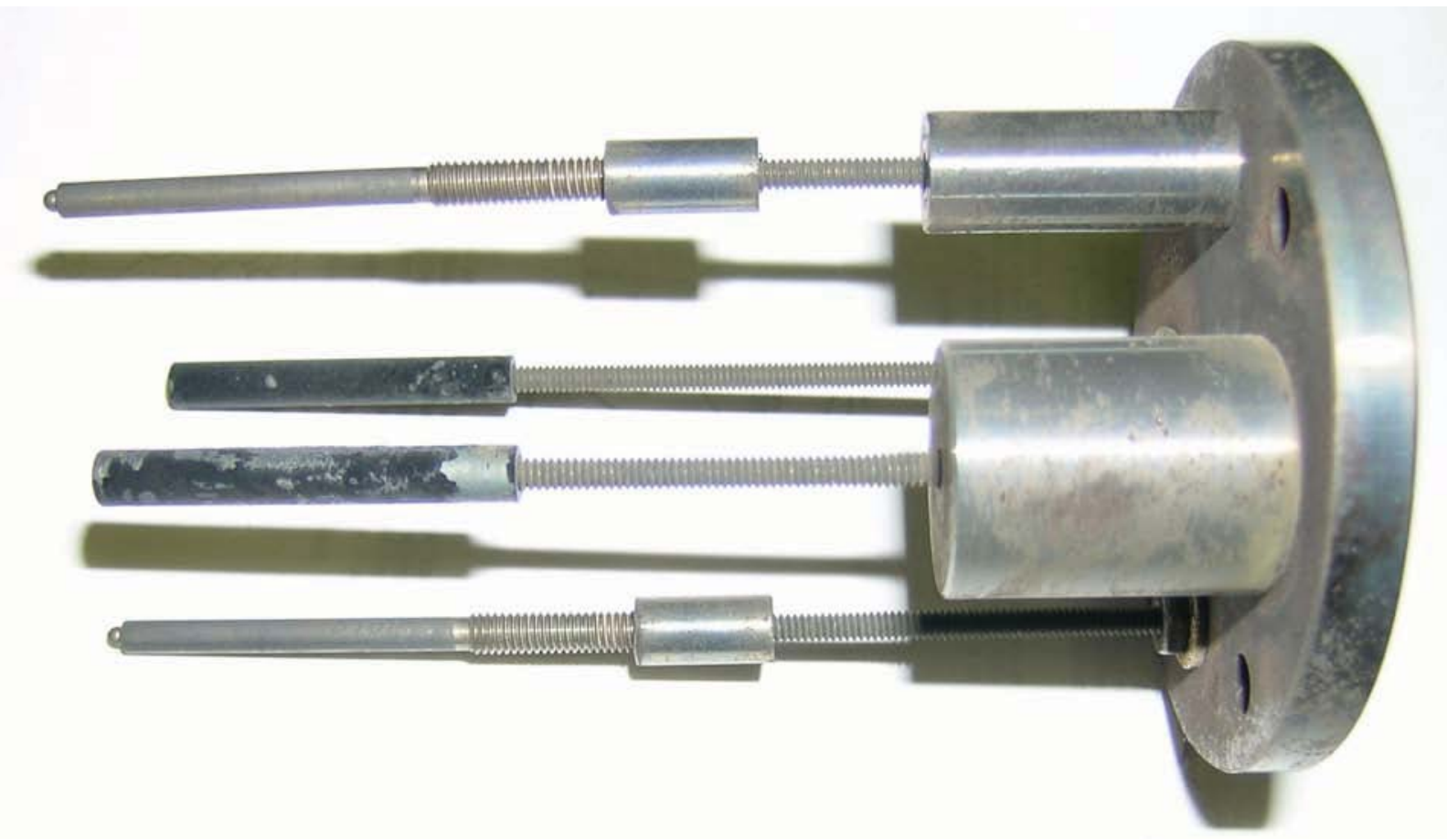

Figure 5-5. Comparison of LVDT cores following the long duration test at $500{ }^{\circ} \mathrm{C}$ (where both Vendor $\mathrm{B}$ cores are shown centered between the Vendor A cores). 
able noise, oscillation, and (as yet unexplainable) step changes in output during long duration testing. Based on these long duration results, Vendor B LVDTs would not be acceptable for use in the ATR.

Some additional testing of Vendor A LVDTs is needed to resolve stability issues that were observed in the later portion of the long duration test. Based on a review by Vendor A, these issues may be related to degradation of the LVDT insulation, which may be resolved through modification of heat treatment applied during fabrication. Furthermore, testing is needed to evaluate the effects of a material-specific Curie temperature transition, which is described in the next section of this report. 


\section{CURIE POINT EVALUATION}

Based on calibration and long duration results (provided in Sections 4 and 5, respectively), LVDTs manufactured by IFE-HRP (or Vendor A) were found to be the preferred design for use in the ATR. Although these LVDTs have been successfully deployed at the Halden Boiling Water Reactor (HBWR) for decades, there are questions that must be addressed prior to their use in the ATR. In particular, there are concerns because current generation LVDTs manufactured by IFE-HRP are known to experience an abrupt change in their output signal near $360^{\circ} \mathrm{C}$. In this case, the output signal change corresponds with passing through the Curie point of the nickel coating on the wire used in the primary and secondary coils.

Calibration and long duration evaluations have demonstrated that IFE-HRP LVDTs function as expected both above and below the Curie point. In addition, there appears to be no impact relative to output repeatability as a result of passing through the Curie point. (See Sections 4 and 5, respectively.) Consequently, it would seem that the existence of this output signal change would be of concern only if a IFEHRP LVDT was operated at (or very near) its Curie temperature.

An evaluation of this effect was needed, however, because LVDTs may be used in ATR test loops operating at pressurized water reactor conditions (or $\sim 15 \mathrm{MPa}$ and $\sim 300^{\circ} \mathrm{C}$ ). As reported in Section 7 , gamma heating under these conditions could increase LVDT temperatures to levels of concern (depending on the in-core position). The Curie point temperature, the affected temperature range, and the magnitude of the output signal change were of primary interest in this evaluation, which is described in the remainder of this section.

It should be noted that IFE-HRP is sending INL several "developmental" LVDTs for further evaluation that will have a silver alloy wire in the primary and secondary coils. This silver alloy wire should be free of the Curie point issues of their current generation of LVDTs. Results from this evaluation (of the current generation of LVDTs), and the related evaluation of LVDTs with silver alloy wire (when those instruments become available), will be useful in determining the importance of implementing a formal LVDT modification using an alternative wire that is free from Curie point effects.

\subsection{Setup}

A series of heatup tests were conducted to determine the Curie point temperature, the affected temperature range, and the magnitude of the output signal change. All heatup tests were conducted using IFEHRP LVDT 1095 in a Lindberg horizontal split tube furnace as shown in Figure 6-1. (Note that the Lindberg furnace was used because its temperature controller is relatively stable.)

As indicated in this figure, the calibration fixture was inserted from the right to position the LVDT at the furnace centerline. (The LVDT body, core, and extension rod were assembled and connected to the micrometer in the calibration fixture as described in Section 4). This arrangement left the micrometer outside the furnace (and therefore unaffected by furnace heatup). A Type $\mathrm{K}$ thermocouple was inserted in the fixture to monitor LVDT temperature independently of the furnace controller. Leads for the thermocouple can be seen leaving the furnace on the right while LVDT leads can be seen leaving the furnace on the left. All leads were routed to a computerized DAS as shown in Figure 6-2. Insulating blocks were used throughout testing to support the calibration fixture (and the LVDT) thereby preventing direct contact with furnace heating elements as shown in Figure 6-3. 


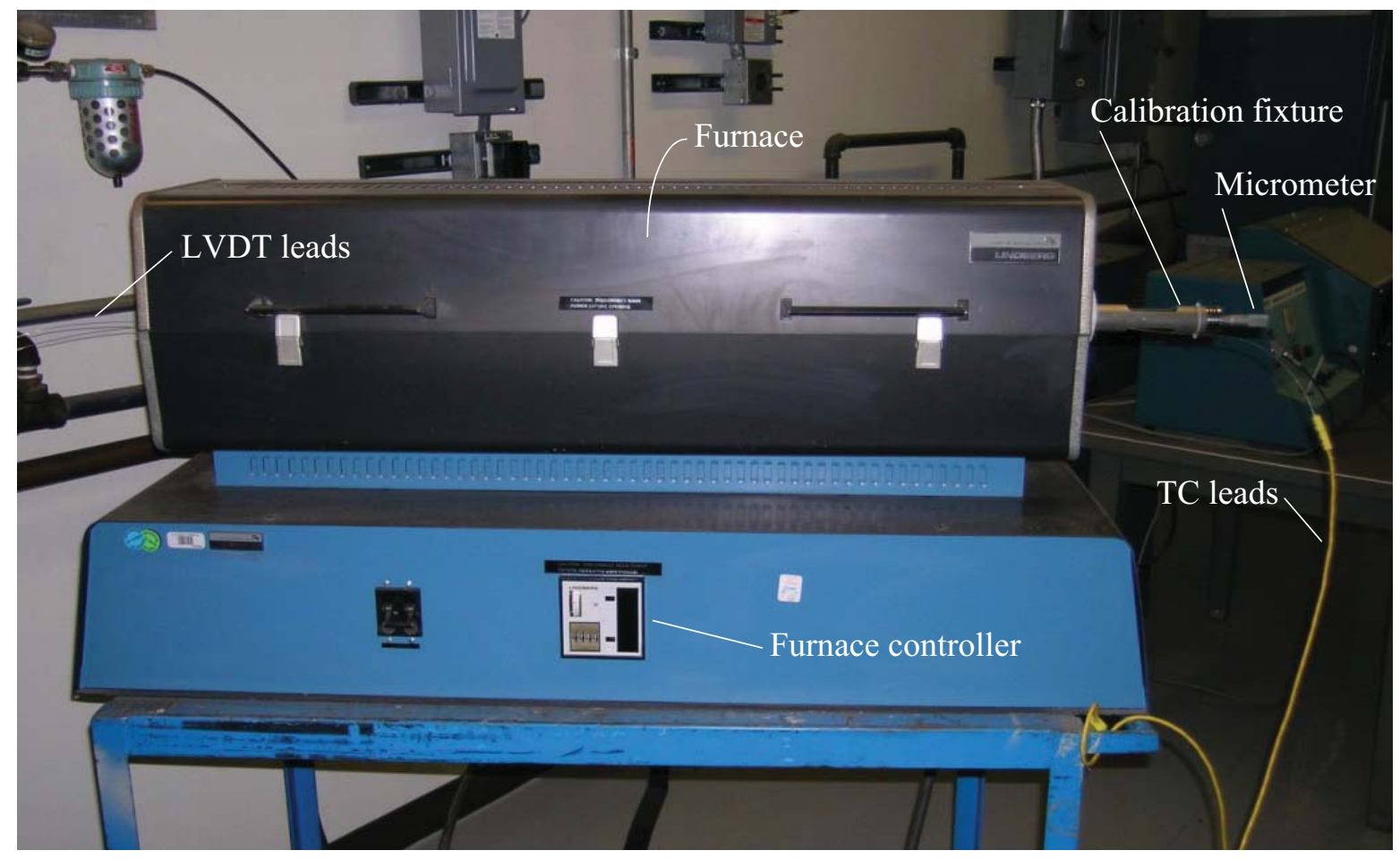

Figure 6-1. Lindberg horizontal split tube furnace used in Curie point heatup tests.



Figure 6-2. Data acquisition system used in Curie point heatup tests. 


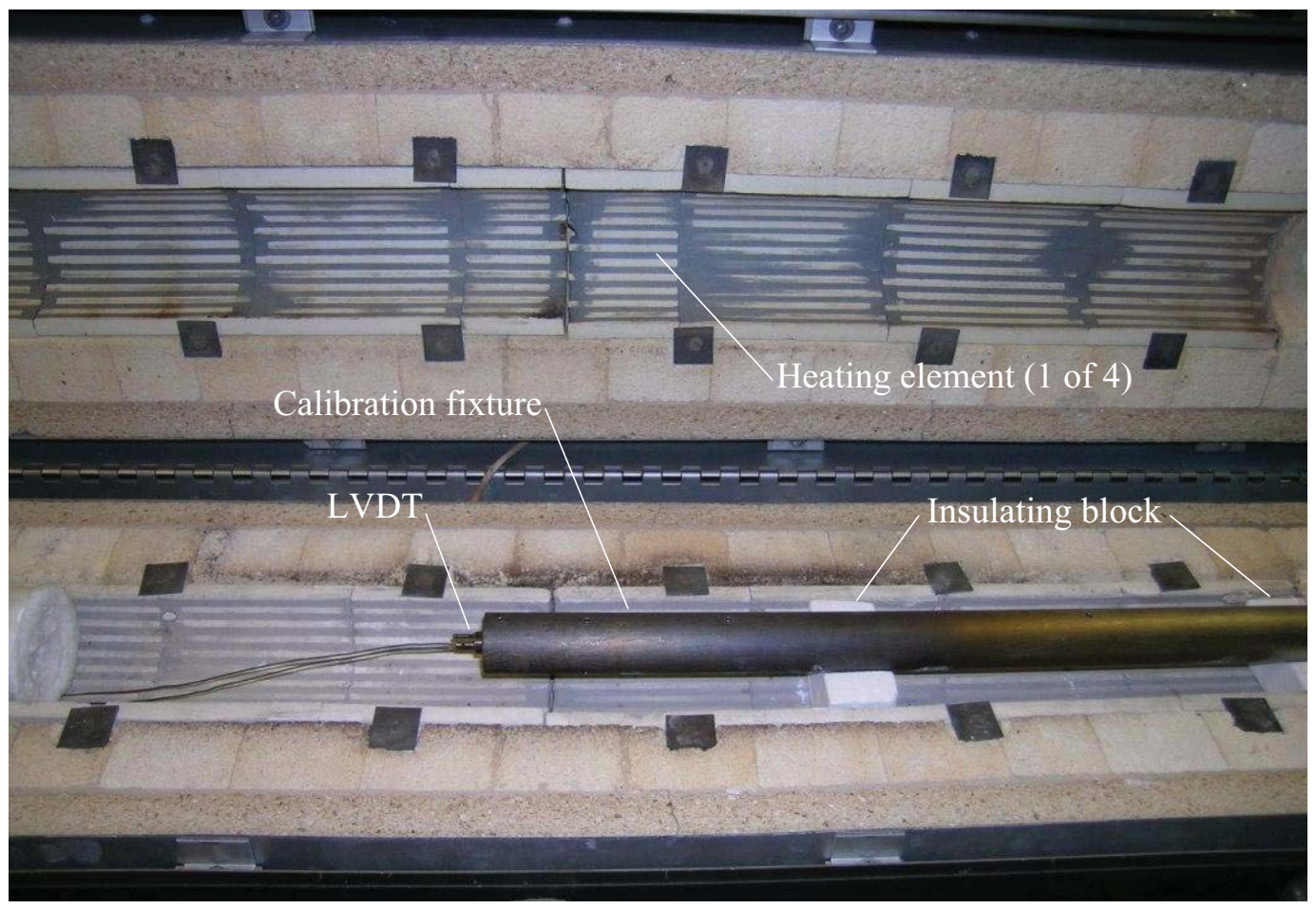

Figure 6-3. Insulating blocks as used to prevent fixture/heating element contact in Curie point heatup tests.

\subsection{Heatup Test Results}

Four heatup tests were completed. Each test began after a stabilization period at a temperature between 300 and $330^{\circ} \mathrm{C}$. Stabilization was considered adequate (or complete) when changes in the Type K thermocouple remained within $\pm 1{ }^{\circ} \mathrm{C}$ for a period of $\sim 5$ minutes. At that time, heatup was initiated by setting the furnace controller to $450{ }^{\circ} \mathrm{C}$. Data, in the form of temperature from the Type $\mathrm{K}$ thermocouple and output voltage from the LVDT, were collected during the heatup at a frequency of $0.1 \mathrm{~Hz}$. Corresponding results are plotted in Figures 6-4 through 6-7.

Results have been summarized in Table 6-1 relative to the Curie point temperature, the affected temperature range, and the magnitude of the output signal change. In this table, the Curie point temperature was taken to be the temperature corresponding with the largest LVDT output signal change observed during heatup. (From Figure $6-4$, the largest output signal change clearly occurs at a temperature of $\sim 402{ }^{\circ} \mathrm{C}$.) The affected temperature range starts and ends where the LVDT output voltage change starts and ends. (From Figure 6-4, the affected temperature range is between $\sim 398$ and $\sim 406{ }^{\circ} \mathrm{C}$.) And finally, the magnitude of the output signal change is calculated relative to the output signal just before Curie point effects begin. (From Figure 6-4, there is a output signal change of $\sim 32 \%$, which is estimated as $100 \times[-1.240-\{-$ $1.632\} /-1.240]$.)

Results from Table 6-1 indicate that the Curie temperature lies between $\sim 380$ and $\sim 400{ }^{\circ} \mathrm{C}$. This differs from the estimate of $\sim 360^{\circ} \mathrm{C}$ provided by IFE-HRP. ${ }^{3}$ The fact that the Type $\mathrm{K}$ thermocouple will respond faster than the LVDT is the most likely reason for this discrepancy. As heatup progresses, the rel- 


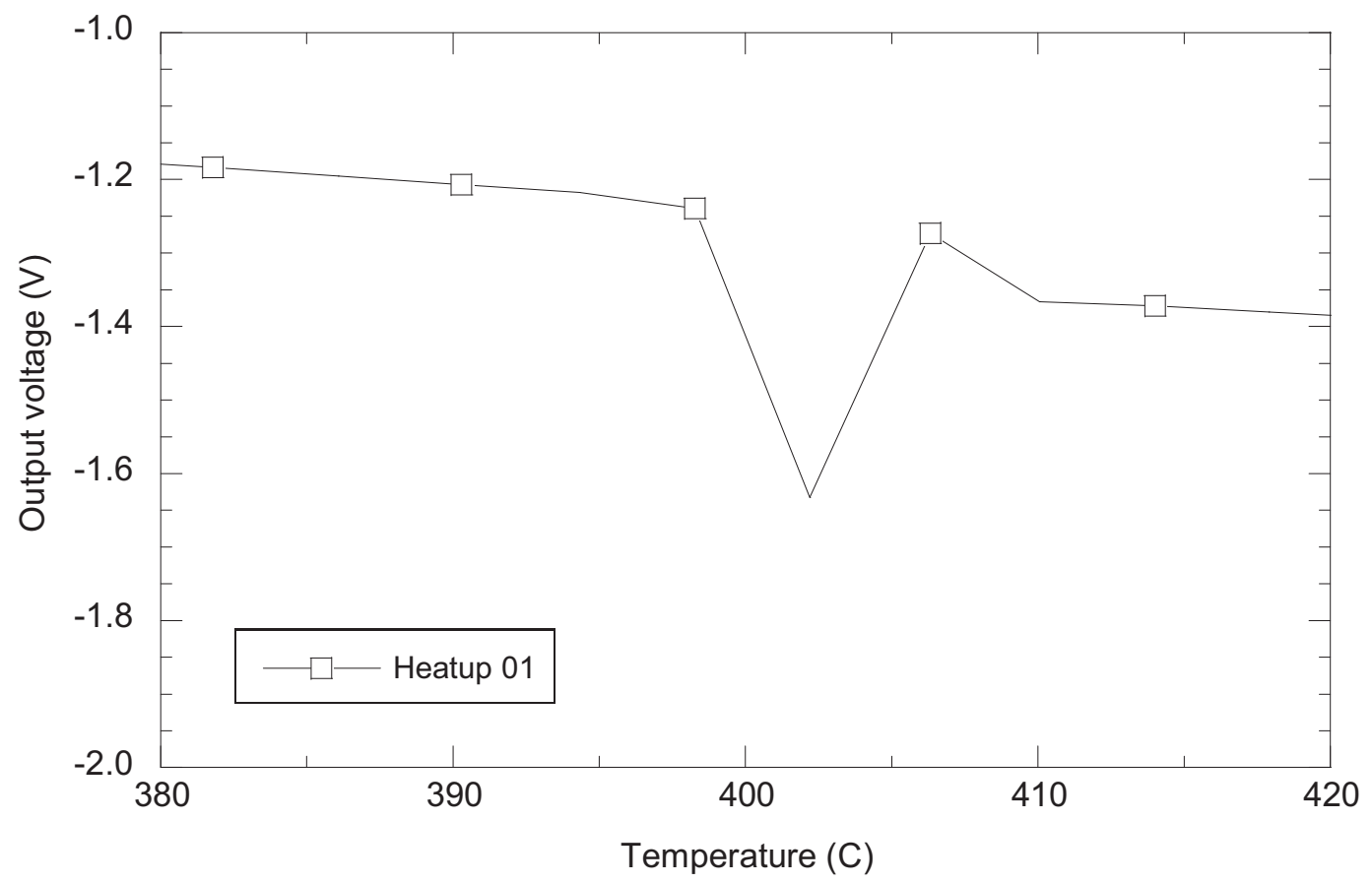

Figure 6-4. Heatup test 1 in the Curie point evaluation.

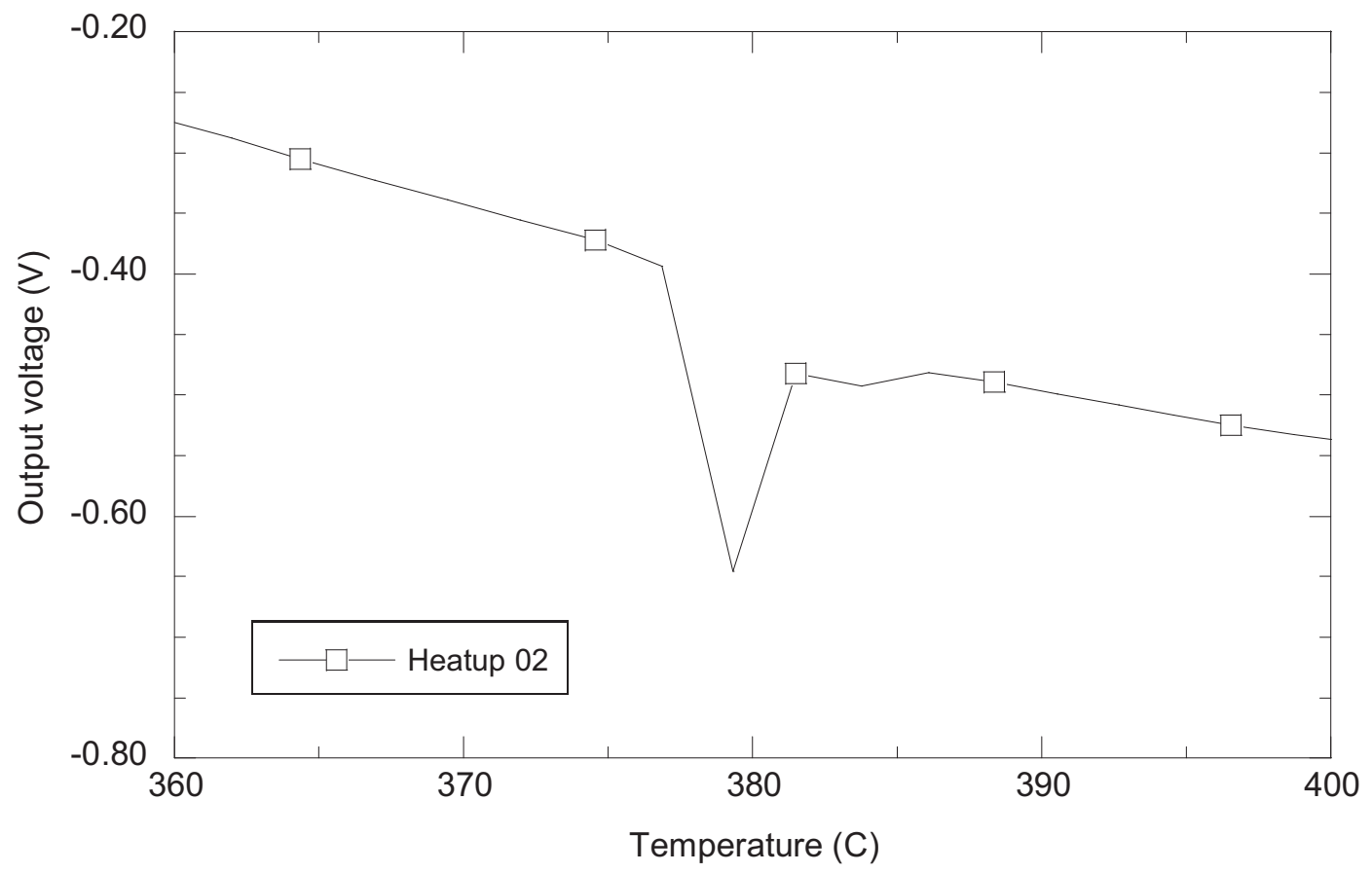

Figure 6-5. Heatup test 2 in the Curie point evaluation. 


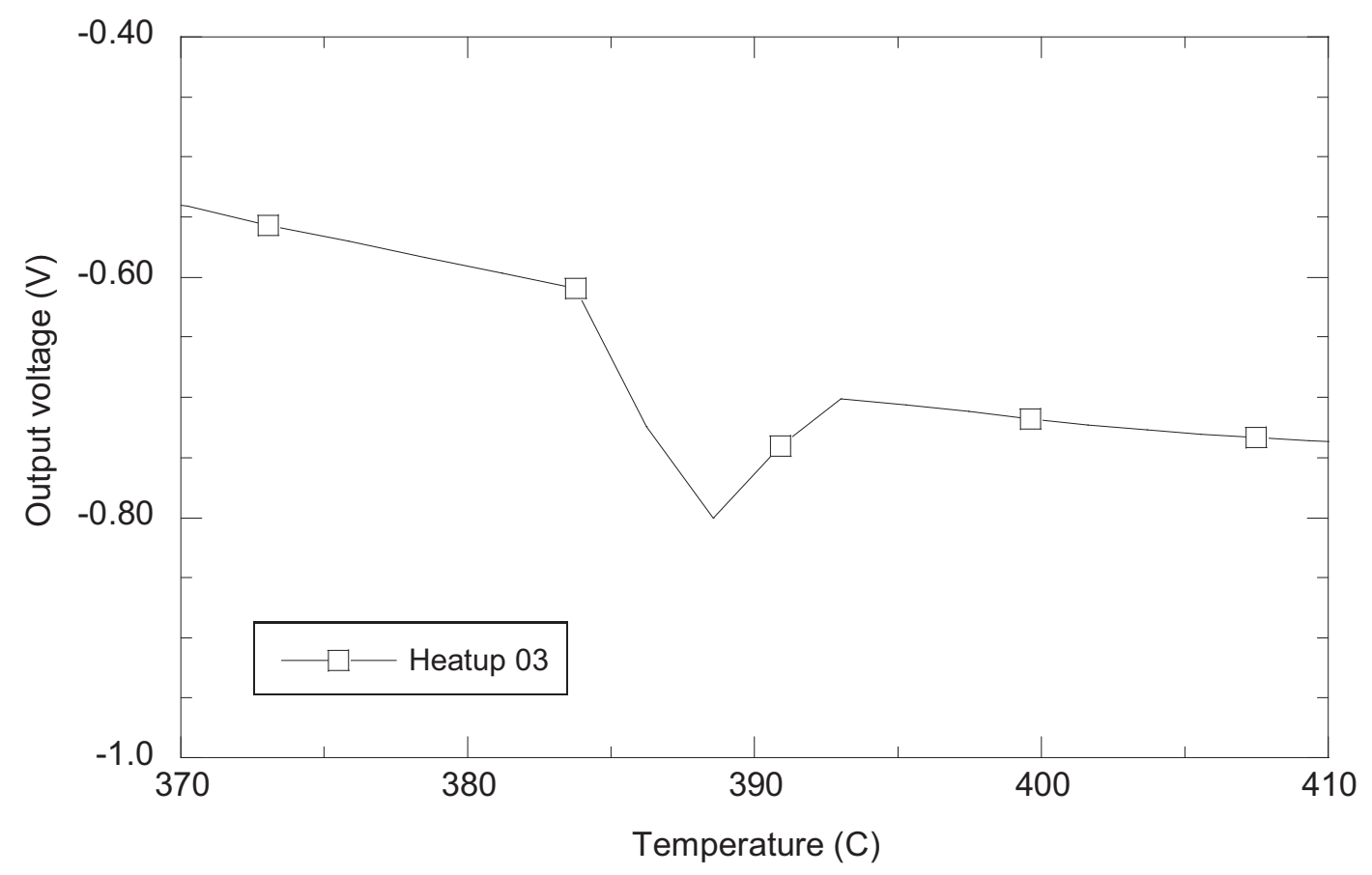

Figure 6-6. Heatup test 3 in the Curie point evaluation.

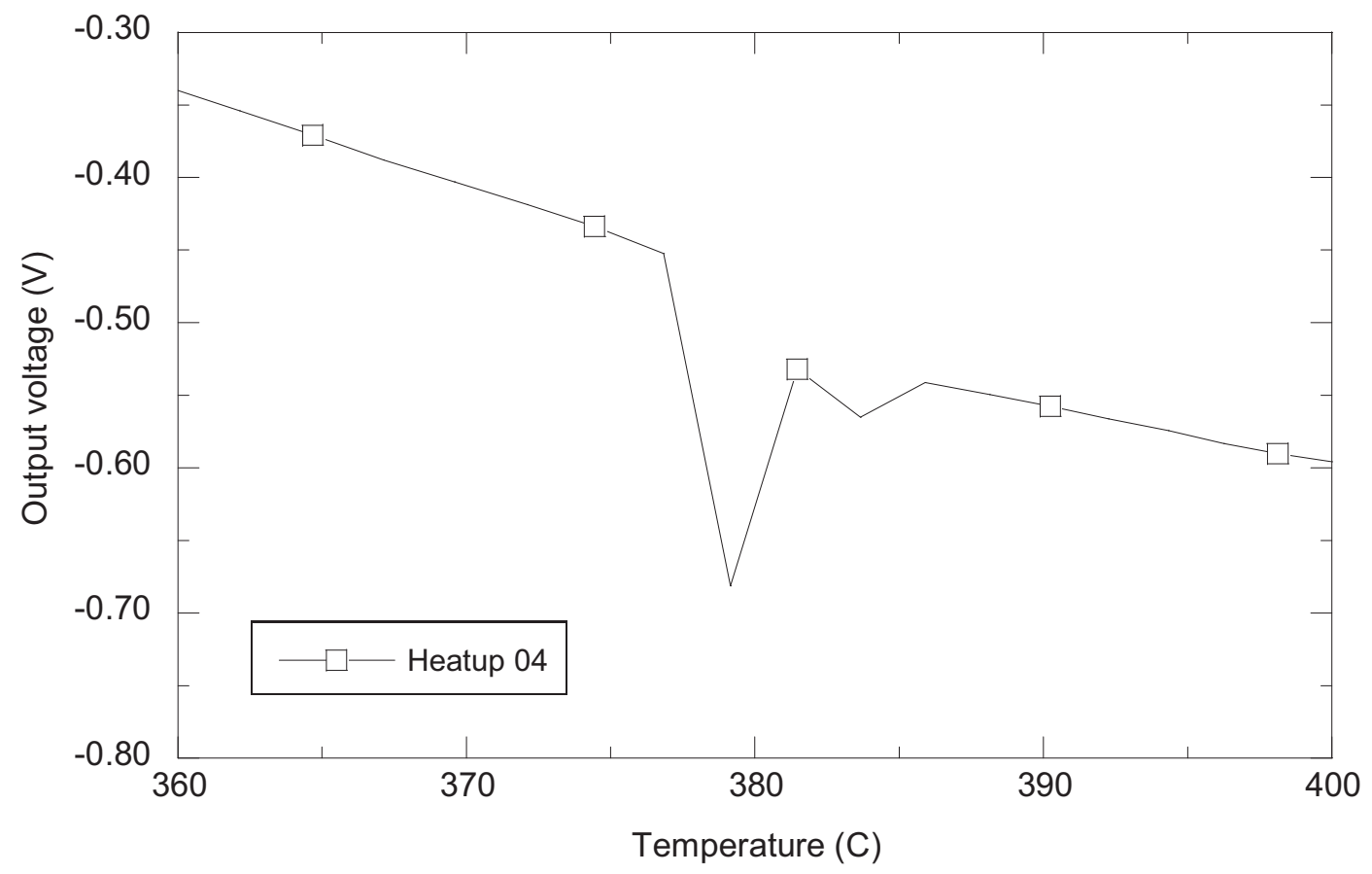

Figure 6-7. Heatup test 4 in the Curie point evaluation. 
Table 6-1. Curie point evaluation summary.

\begin{tabular}{c|c|c|c}
\hline Test & $\begin{array}{c}\text { Temperature at maximum } \\
\text { signal change }\left({ }^{\circ} \mathrm{C}\right)\end{array}$ & $\begin{array}{c}\text { Temperature range of } \\
\text { signal change }\left({ }^{\circ} \mathrm{C}\right)\end{array}$ & $\begin{array}{c}\text { Signal change }(\% \text { relative to } \\
\text { lowest unaffected temperature })\end{array}$ \\
\hline 1 & 402 & $8(406-398)$ & -32 \\
2 & 379 & $4(381-377)$ & -64 \\
3 & 389 & $4(390-386)$ & -10 \\
4 & 379 & $4(381-377)$ & -51 \\
\hline
\end{tabular}

atively massive LVDT will take longer to heat than the (1.6 mm OD) thermocouple. Therefore, the indicated temperature at the maximum signal change (as based on the Type $\mathrm{K}$ thermocouple reading) will probably be higher than the actual temperature of the LVDT. The effect of this problem could be minimized (or eliminated) if the heatup rate was reduced to a point where all heated components remain in quasi-thermal equilibrium throughout the tests. However, there are no provisions to control the heatup rate of the Lindberg furnace that was used in this evaluation.

Although Table 6-1 temperatures at the maximum signal change will be higher than the actual Curie point, the temperature range associated with the Curie effect and the magnitude of the output signal change are probably better estimates. There should be less error associated with the temperature range simply because it is the result of a difference (in temperature) as opposed to being tied to an absolute value. Therefore, it may be reasonable to assume that the Curie effect could impact LVDT response over a temperature range of $\sim 4{ }^{\circ} \mathrm{C}$ as indicated in Table 6-1. Like the temperature range, the signal change associated with the Curie point is also the result of a difference (in output signals). As such, it may be reasonable to assume that the Curie effect could alter the LVDT output by as much as $\sim 60 \%$. Although the impact of such an output variation may be considered unacceptable, it should be noted that this effect would only be realized if the LVDT was used within $\pm 2{ }^{\circ} \mathrm{C}$ of the actual Curie point. In addition, a higher data sampling frequency may lead to some reduction in the affected temperature range. These results tend to support the assumption that the existence of the Curie point would be of concern only if a IFE-HRP LVDT was operated at (or very near) its affected temperature.

\subsection{Summary}

An evaluation of IFE-HRP LVDTs was needed before use in the ATR because the current generation of these instruments are known to experience an abrupt change in their output signal due the effects of passing through the Curie point. The evaluation, which consisted of a series of four heatup tests, was designed to determine the Curie point temperature, the affected temperature range, and the magnitude of the output signal change. Each test consisted of the collection of LVDT output voltage and temperature while heating from $\sim 300$ to $\sim 450{ }^{\circ} \mathrm{C}$. The results indicate the Curie point occurs at a temperature between $\sim 380$ and $\sim 400{ }^{\circ} \mathrm{C}$, which is somewhat higher than the IFE-HRP estimate of $\sim 360{ }^{\circ} \mathrm{C}$. This discrepancy could be minimized (or eliminated) if the heatup rate was reduced to a point where all heated components remain in quasi-thermal equilibrium throughout the tests. In addition, results indicate the Curie effect could alter the LVDT output by as much as $\sim 60 \%$, although the impact of such an output variation would only be realized if the LVDT was used within $\pm 2{ }^{\circ} \mathrm{C}$ of the actual Curie point. These results tend to support the assumption that the existence of the Curie point would be of concern only if a IFE-HRP LVDT was operated at (or very near) its affected temperature. 


\section{GAMMA HEATING EVALUATION}

Based on calibration and long duration results (provided in Sections 4 and 5, respectively), LVDTs manufactured by IFE-HRP (or Vendor A) were found to be the preferred design for use in the ATR. Although these LVDTs have been successfully deployed at the Halden Boiling Water Reactor (HBWR) for decades, there are questions that must be addressed prior to their use in the ATR. In particular, there are concerns about the impact of the higher testing temperatures and power levels in the ATR with the corresponding impact of higher gamma heating.

This section contains a thermal analysis completed to evaluate the potential impact on LVDT temperatures due to gamma heating. To bound the potential impact, the analysis was completed assuming that the LVDTs will be placed in ATR flux traps. The analysis was based on the use of ABAQUS, Version 6.8-2. ${ }^{4}$ (Note that a core physics evaluation could be performed which would allow scaling of these results to represent the thermal effects that could be expected if the LVDTs were placed in any of the lower flux irradiation locations available in the ATR.)

\subsection{ABAQUS Model and Input}

The LVDT core (with an OD of $3.2 \mathrm{~mm}$ ) was modeled as a cylinder concentric with the LVDT body (with an ID of $4 \mathrm{~mm}$ and an OD of $14 \mathrm{~mm}$ ). Standard metric units $\left(\mathrm{kg}, \mathrm{W},{ }^{\circ} \mathrm{C}\right.$, s) were used, except that millimeters were used for length. This is because when meters were used, the mesh becomes problematic (elements do not meet geometric requirements for validity). The corresponding finite-element mesh, as shown in Figure 7-1, was automatically generated by ABAQUS based on a global seed size of $0.2 \mathrm{~mm}$.

In this analysis, the LVDT (core and body) was modeled as stainless steel. Temperature dependent thermal properties for the steel were inputs in the simulation. Those properties were taken from Reference 5 over the range of 200 to $1000^{\circ} \mathrm{C}$.

A gap exists between the core and body of the LVDT. Conduction and radiation heat transfer were modeled in this gap. Gap conductivity was estimated as that of helium at $450{ }^{\circ} \mathrm{C}$ (which was assumed to be

near the expected gas temperature). ${ }^{6}$ Emissivities of the surfaces were varied from 0.2 (polished steel) to 0.8 (heavily oxidized) to represent different levels of oxidation that may be present. ${ }^{6}$

Cooling by fluid flow along the outer LVDT body was modeled using a convection film condition. This film condition was based on calculations using the in-pile tube and coolant conditions (in-pile tube diameter, coolant temperature, flow velocity, etc.) listed in Table 7-1. Coolant thermal properties (at $350{ }^{\circ} \mathrm{C}$ ) were taken from Reference 6 . (Note that $350^{\circ} \mathrm{C}$, which is near the saturation temperature for an ATR flux trap, was selected as a way to bound LVDT gamma heating. However, some degree of subcooling would actually be required in practice.)

Gamma heat generation varies according to position in the core. Gamma heating rates for stainless steel (in W/g) as a function of axial position in the center flux trap for a peak power 27.6 MW are shown in Figure 7-2. ${ }^{7}$ Under the same conditions, the northeast and northwest traps provide a peak power of $18 \mathrm{MW}$ while the southeast and southwest traps provide a peak power of $25 \mathrm{MW}$. Sensitivity calculations were performed to evaluate maximum LVDT temperatures for a range of power. (In all cases, heating rates were converted to $\mathrm{W} / \mathrm{mm}^{3}$ using the stainless steel density, as ABAQUS requires a volumetric heat load.) 


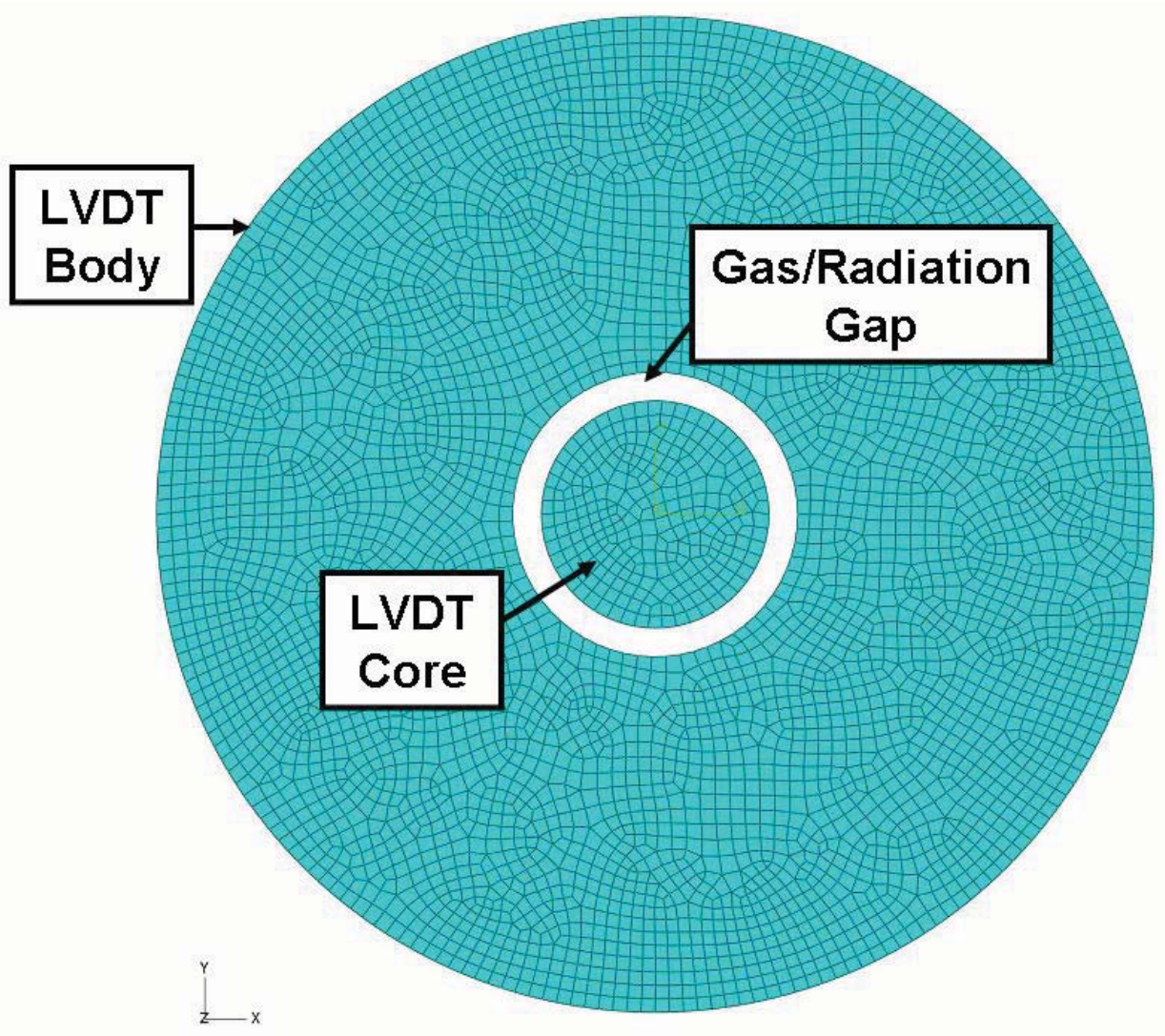

Figure 7-1. LVDT body and core with automatically generated finite element mesh.

Table 7-1. Surface coolant conditions.

\begin{tabular}{c|c}
\hline Condition & Magnitudes Considered \\
\hline Temperature & $350{ }^{\circ} \mathrm{C}$ \\
Flow velocity & 3 to $6 \mathrm{~m} / \mathrm{s}$ \\
Pressure & $15.9 \mathrm{MPa}$ \\
In-pile tube diameter & $44 \mathrm{~cm} \mathrm{and} 102 \mathrm{~cm}$ \\
In-pile tube and LVDT surface roughness & $0.002 \mathrm{~mm}^{6}$ \\
\hline
\end{tabular}

\subsection{Results}

Radial temperature profiles of the LVDT core and body calculated by ABAQUS are shown in Figure 7-3 for a position in the center flux trap (with a peak power of 27.6 MW) at the mid-plane of the core. These temperatures were validated using hand calculations and equations from Reference 6 .

Figure 7-3 results indicate that the assumed emissivities had little impact on predicted body and core temperatures. It was also observed that surface cooling coefficient had negligible effect on temperatures 


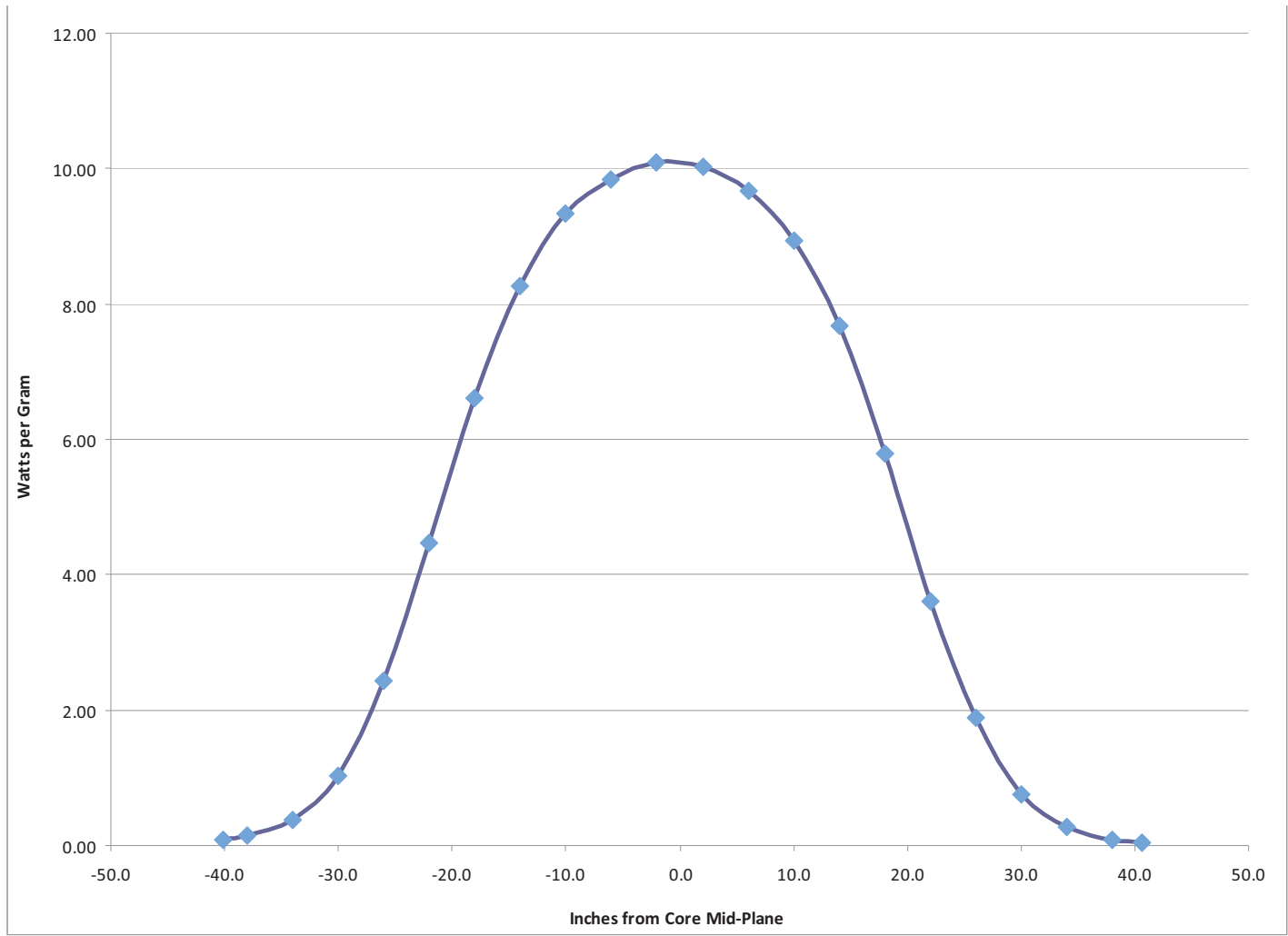

Figure 7-2. Gamma heating rates as a function of axial position for the ATR center flux trap.

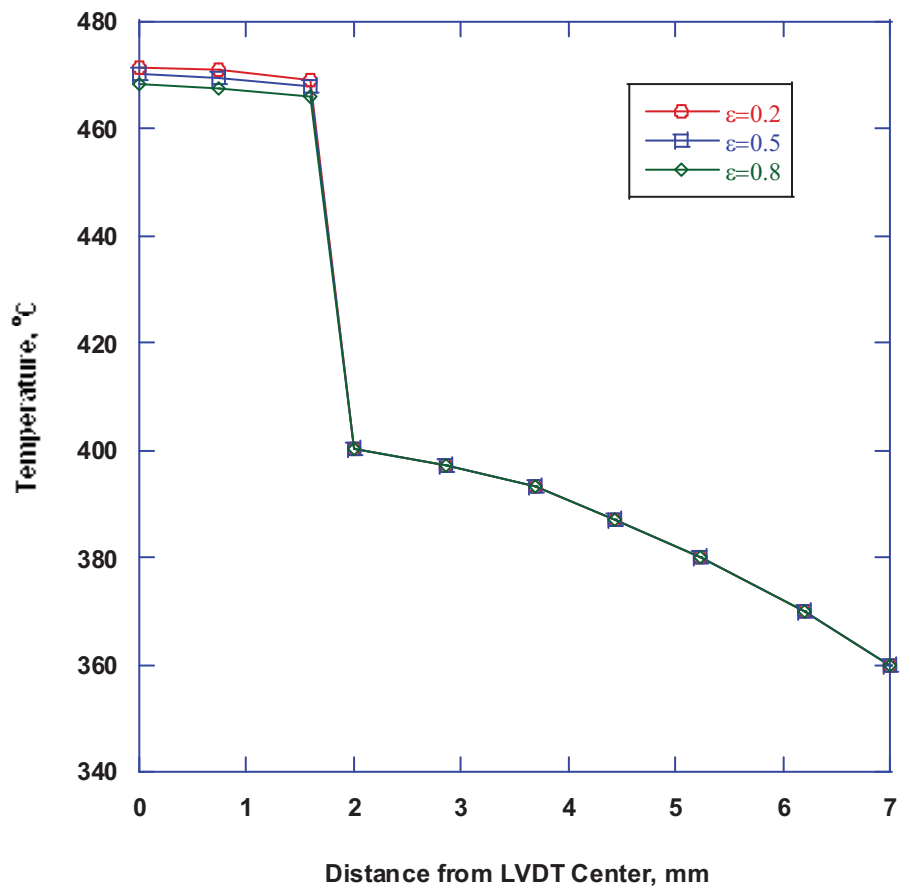

Figure 7-3. Radial temperature profiles at maximum heat generation. 
(either within the LVDT body or at the center of the LVDT core), thus the simulation was carried out using the minimum cooling coefficient value. Convection within the gas gap was calculated and observed to be negligible when compared to radiant and conductive heat transfer.

Maximum LVDT body temperatures, in the center flux trap, as a function of reactor core elevation are shown in Figure 7-4. As expected (due to the cylindrical geometry, internal heat generation, and insulating gas gap), the maximum temperature observed within the body was along the inner wall, opposite the core. The maximum temperature observed within the LVDT body was $400{ }^{\circ} \mathrm{C}$. This value was constant for all emissivity values. Maximum temperatures observed within the LVDT core are shown in Figure 7-5.

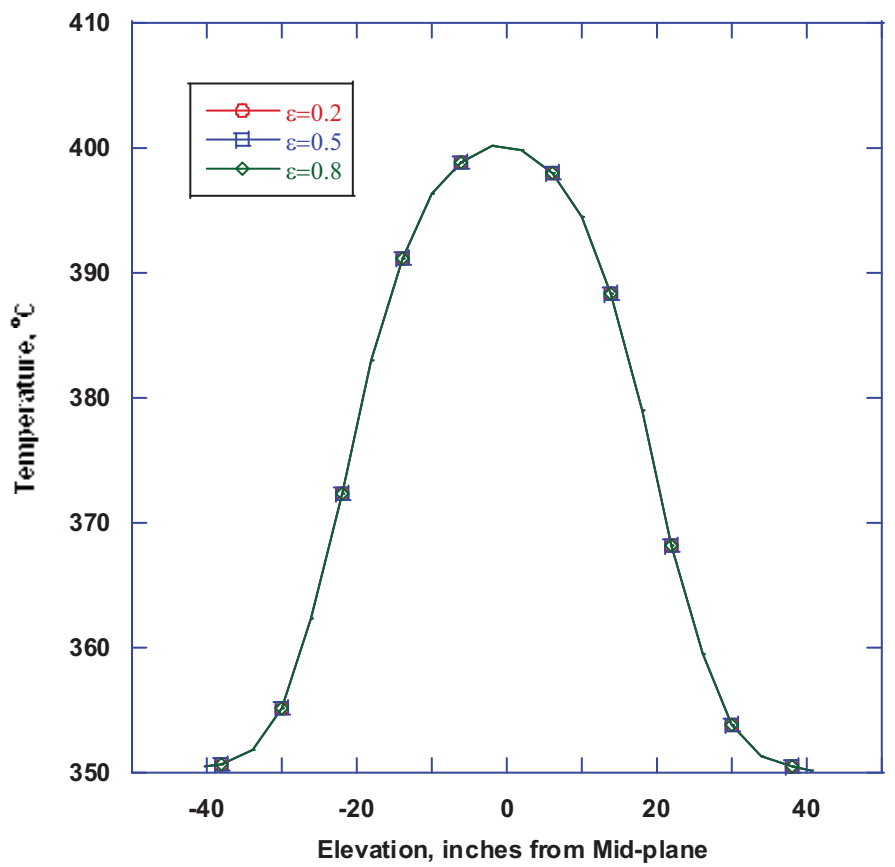

Figure 7-4. Maximum temperature of the LVDT body in center flux trap.

The temperature data shown in the preceding figures were produced using power levels seen in the ATR center flux trap. Other flux traps may be used for irradiation testing with lower peak power levels. The northeast and northwest traps typically run with peak powers of $18 \mathrm{MW}$, while the southeast and southwest traps typically run with peak power levels of $25 \mathrm{MW}$. Maximum temperatures observed in the LVDT body (emissivity $=0.2$ for all cases) are compared in Figure 7-6. As shown in this figure, peak temperatures can be decreased by over $20^{\circ} \mathrm{C}$.

\subsection{Summary}

To assess the impact on gamma heating on LVDT temperatures, calculations were performed assuming that these sensors were placed at several irradiation locations in the ATR. Results presented in Section 7.2 indicate that peak LVDT temperatures will remain very close to $400{ }^{\circ} \mathrm{C}$. As noted in 


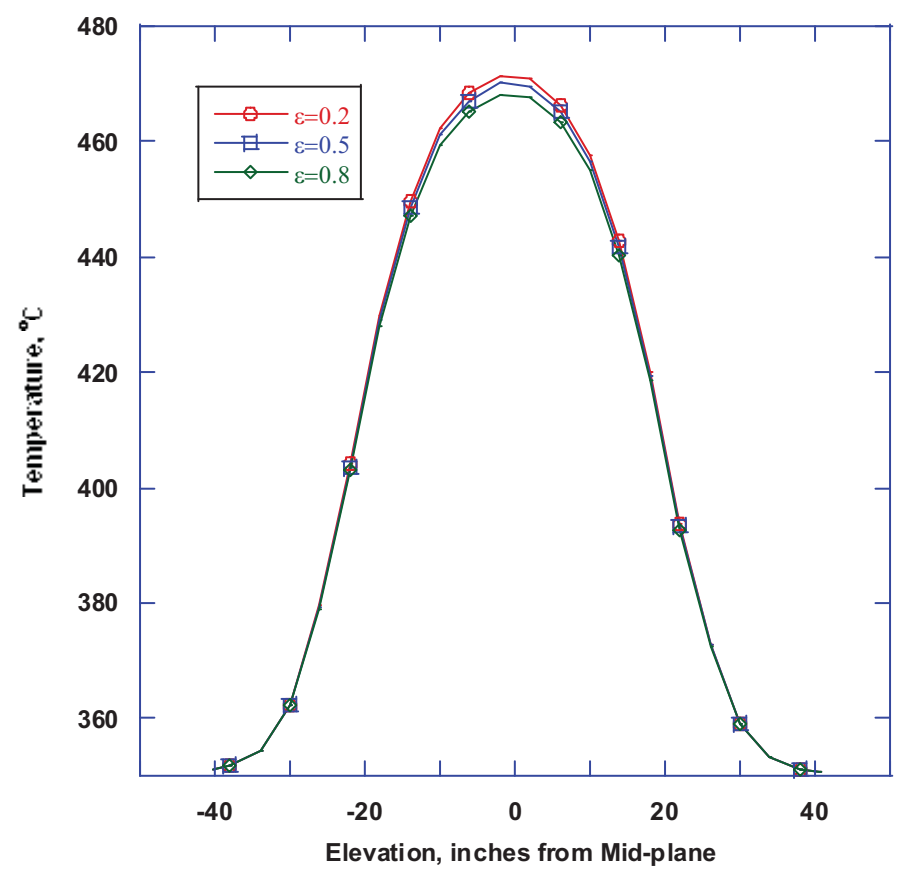

Figure 7-5. Maximum temperature of the LVDT core in center flux trap.

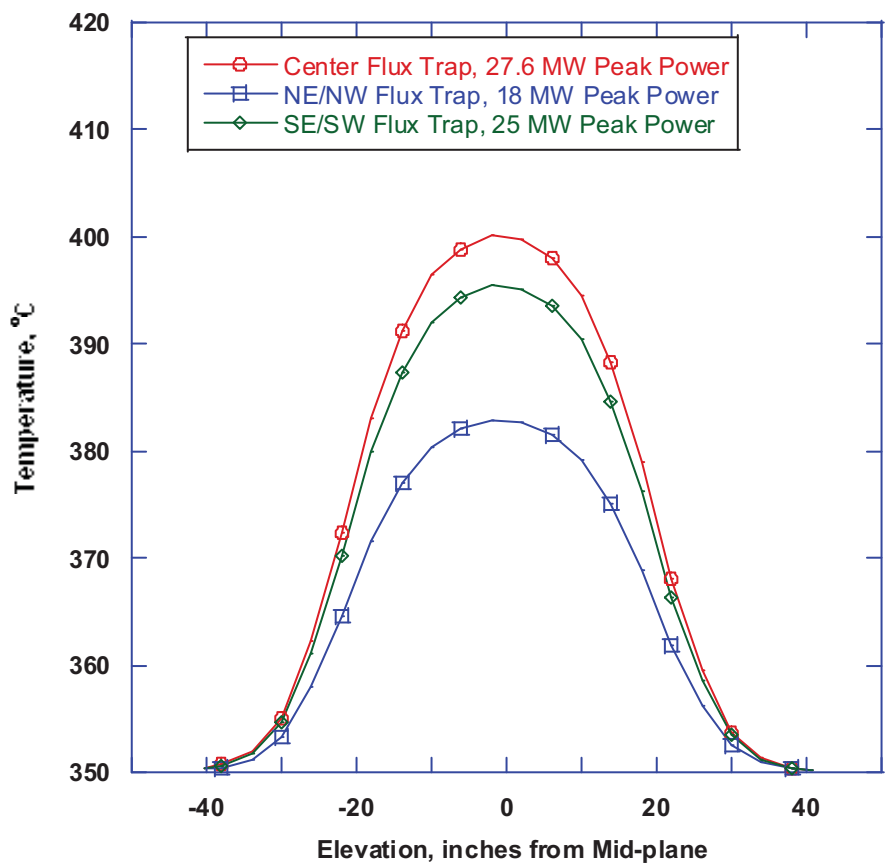

Figure 7-6. Maximum temperatures observed within LVDT body for different flux traps. 
Section 7.1, IFE-HRP LVDTs have run for long durations in the HBWR at $350{ }^{\circ} \mathrm{C}$ without experiencing degradation. Therefore, the predicted temperatures of $400{ }^{\circ} \mathrm{C}$ (due to gamma heating) may not be of concern. Furthermore, these results are well below the temperature of $500{ }^{\circ} \mathrm{C}$ where HTTL tests have shown that LVDT signals can degrade if the sensors are exposed for prolonged periods. ${ }^{8}$ Note that efforts are underway to improve IFE-HRP LVDT long duration performance at temperatures up to $500{ }^{\circ} \mathrm{C}$ (and possibly higher).

These results were based on an assumed coolant temperature of $350{ }^{\circ} \mathrm{C}$, which was selected to bound possible LVDT temperatures. However, a coolant temperature of $\sim 300{ }^{\circ} \mathrm{C}$ would be more likely given the need for subcooling in the ATR flux traps. In that case, peak LVDT temperatures would be expected to decrease by $\sim 50{ }^{\circ} \mathrm{C}$, which would mean that parts of the LVDT body could be very near the Curie temperature of $\sim 360^{\circ} \mathrm{C}$. Clearly, the possibility of operating near the Curie temperature would require further evaluation before actual ATR testing occurs to ensure that LVDT response is not adversely affected. Such evaluation would need very specific data relative to power levels, sensor position, and coolant conditions. 


\section{CONCLUSIONS AND RECOMMENDATIONS}

Initial evaluations of candidate LVDTs have been completed at INL as a first step in establishing suitability for use during ATR high temperature irradiation experiments. Two nuclear grade LVDTs were considered - a smaller diameter design (from Vendor A or the IFE-HRP) qualified for temperatures up to $350{ }^{\circ} \mathrm{C}$ and a larger design (from Vendor B) with capabilities to $500{ }^{\circ} \mathrm{C}$. Initial evaluation efforts included collecting calibration data as a function of temperatures up to $500{ }^{\circ} \mathrm{C}$ and long duration $(1000 \mathrm{~h})$ testing of the output response while LVDTs were held at high temperature $\left(500{ }^{\circ} \mathrm{C}\right)$. A comprehensive series of tests were conducted before these evaluations to ensure that LVDT outputs were unaffected by use of specialized fixtures and unaffected by the operation of other nearby LVDTs. The evaluation then focused on the potential for any changes or degradation in sensitivity and/or electrical resistance that may develop as a result of high temperature operation. After calibration and long duration evaluations, additional testing was completed for the more promising design to detect the changes that occur when some of its components are subjected to their Curie temperature. Furthermore, analyses were completed to determine the potential impact of gamma heating on temperatures of the most promising LVDT design.

Calibration results clearly favor the Vendor A (IFE-HRP) LVDT design for use in ATR irradiation experiments. Vendor A LVDTs show relatively small deviations from linear behavior (compared to Vendor B LVDTs) and their deviations are symmetric (where Vendor B LVDT deviations are not). Sensitivities of Vendor A LVDTs increase (nearly linearly) with temperature. In contrast, Vendor B LVDT sensitivities increase with temperature to $\sim 300{ }^{\circ} \mathrm{C}$ and sharply drop thereafter. Furthermore, Vendor A LVDT pre- and post-calibration room temperature sensitivities are essentially equivalent while Vendor B pre- and post-calibration sensitivities differ appreciably, indicating a lack of robustness in the Vendor B design. Finally, Vendor B LVDT insulation resistances drop to unreasonably low values at high temperatures while Vendor A resistances do not. For these reasons, Vendor B LVDTs would not be acceptable for use in the ATR.

Long duration results clearly favor the Vendor A (IFE-HRP) LVDT design. Specifically, Vendor A LVDTs were found to be very stable at $500{ }^{\circ} \mathrm{C}$ for $\sim 300 \mathrm{~h}$. In contrast, Vendor B LVDTs show considerable noise, oscillation, and unexplainable step changes in output during long duration testing. Some additional testing of Vendor A LVDTs is needed to resolve stability issues that were observed in the later portion of the long duration test. Based on a review by IFE-HRP, these issues may be related to degradation of the LVDT insulation, which may be resolved through modification of heat treatment applied during fabrication. Based on these long duration results, Vendor B LVDTs would not be acceptable for use in the ATR.

A Curie point evaluation for Vendor A (IFE-HRP) LVDTs was completed because they are the most promising design for use in the ATR and because these LVDTs are known to undergo a step change in signal output when passing through the Curie temperature. The results indicate the Curie point occurs at a temperature between $\sim 380$ and $\sim 400{ }^{\circ} \mathrm{C}$, which is somewhat higher than the IFE-HRP estimate of $\sim 360{ }^{\circ} \mathrm{C}$. This discrepancy could be minimized (or eliminated) if the heatup rate was reduced to a point where all heated components remain in quasi-thermal equilibrium throughout the tests. In addition, results indicate the Curie effect could alter the LVDT output by as much as $\sim 60 \%$, although the impact of such an output variation would only be realized if the LVDT was used within $\pm 2{ }^{\circ} \mathrm{C}$ of the actual Curie point. These results tend to support the assumption that the existence of the Curie point would be of concern only if a IFE-HRP LVDT was operated at (or very near) its affected temperature. 
Calculations were also performed to assess the potential impact of gamma heating on Vendor A (IFEHRP) LVDT temperatures. Results indicate that peak LVDT body temperatures should not exceed $400{ }^{\circ} \mathrm{C}$ assuming LVDT placement at the highest flux trap location at a power level of $\sim 28 \mathrm{MWt}$ with an assumed coolant temperature of $350^{\circ} \mathrm{C}$. Although long duration tests have shown that LVDT signals degrade if the sensors are exposed to $500{ }^{\circ} \mathrm{C}$ temperatures for over 700 hours, efforts are underway to improve their performance to allow long duration use at temperatures up to $500{ }^{\circ} \mathrm{C}$ (and possibly higher). Lower temperatures would be expected with reduced power levels, LVDT placement at lower flux level positions, and/or lower coolant temperatures. The assumed coolant temperature of $350^{\circ} \mathrm{C}$, which is near the saturation temperature for an ATR flux trap, would most likely be closer to $\sim 300^{\circ} \mathrm{C}$ to address the need for subcooling. In that case, the peak LVDT body temperature could drop from $400{ }^{\circ} \mathrm{C}$ to $\sim 350{ }^{\circ} \mathrm{C}$, which would mean that parts of the LVDT body could be very near the Curie temperature of $\sim 360^{\circ} \mathrm{C}$. Clearly, the possibility of operating near the Curie temperature would require further evaluation before actual ATR testing occurs to ensure that LVDT response is not adversely affected. Such evaluation would need very specific data relative to power levels, sensor position, and coolant conditions.

Efforts to improve long duration high temperature performance include modified heat treatments during LVDT fabrication to stabilize insulation materials. Furthermore, IFE-HRP will ship "developmental" LVDTs to INL for additional evaluation that use a silver alloy wire in primary and secondary coils. This modification should yield an LVDT design that is not subject to the Curie temperature effect. Assessment of these refinements will be completed and reported in a 2010 revision of this document. Associated results will be provided as the first step in qualifying these sensors for possible ATR use. 


\section{REFERENCES}

1. Solstad, S., and R. V. Nieuwenhove, "Instrument Capabilities and Developments at the Halden Reactor Project," Proceedings of the ANS NPIC HMIT 2009 Topical Meeting on Nuclear Plant Instrumentation, Controls, and Human Machine Interface Technology, Knoxville, TN, April 2009.

2. Wolf, J. R., "The Linear Variable Differential Transformer and its Uses for In-Core Fuel Rod Behavior Measurements," International Colloquium on Irradiation Tests for Reactor Safety Programmes, Petten, The Netherlands, June 25-28, 1979.

3. IFE-HRP email to J. Rempe, INL, 2008.

4. ABAQUS/CEA, Version 6.8-2, Providence, Rhode Island, USA: Dassault Systèmes, 2008.

5. Touloukian, Y. S., et al., Thermophysical Properties of Matter, IFI/Plenum Publishing, New York, New York, 1973.

6. Cengel, Y. A., Heat Transfer, A Practical Approach, Second Edition, McGraw Hill, 2003.

7. Parry, J., INL, email to D. Knudson, INL, April 28, 2009.

8. Knudson, D. L., and J. L. Rempe, "LVDT Evaluations for ATR Irradiations," Proceedings of the ANS NPIC HMIT 2009 Topical Meeting on Nuclear Plant Instrumentation, Controls, and Human Machine Interface Technology, Knoxville, TN, April 2009. 
INL/EXT-09-16972 


\section{APPENDIX A - FIXTURE INTERFERENCE CALIBRATION DATA}

Table A-1. Set 1 interference calibration outside all fixtures.

\begin{tabular}{|c|c|c|c|c|c|}
\hline Date & \multicolumn{2}{|c|}{$9-16-2008 \&$ 9-29-2008 } & \multicolumn{3}{|c|}{ D Knudsor } \\
\hline Calibration at & \multicolumn{2}{|l|}{ room temperature } & Furnace setpoint & na & \\
\hline \multicolumn{6}{|l|}{ LVDT } \\
\hline \multicolumn{3}{|c|}{ Vendor A 1097 (core 1060) } & \multicolumn{3}{|c|}{ Vendor B 1449} \\
\hline \multicolumn{6}{|c|}{ Secondary Coil Resistances ${ }^{\mathrm{a}}$} \\
\hline Loops & Wire colors & Resistance $(\Omega)$ & Loops & Wire colors & Resistance $(\Omega)$ \\
\hline $\mathrm{A}+\mathrm{B}$ & $\mathrm{red} /$ white & 392.7 & \multirow[t]{3}{*}{$\mathrm{A}+\mathrm{B}$} & \multirow[t]{3}{*}{ green/red } & \multirow[t]{3}{*}{122.3} \\
\hline $\mathrm{A}$ & black/red & 646.3 & & & \\
\hline $\mathrm{B}$ & black/white & 646.7 & & & \\
\hline Insulation & & Resistance $(\Omega)$ & Insulation & & Resistance $(\Omega)$ \\
\hline shield-wire & & $>100 \mathrm{e} 6$ & shield-wire & & $>100 \mathrm{e} 6$ \\
\hline primary-secondary & & $>100 \mathrm{e} 6$ & primary-secondary & & $>100 \mathrm{e} 6$ \\
\hline \multicolumn{6}{|c|}{ Primary Coil Resistances $^{\mathrm{a}}$} \\
\hline \multirow[t]{2}{*}{ Loop } & Wire colors & Resistance $(\Omega)$ & Loop & Wire colors & Resistance $(\Omega)$ \\
\hline & $\mathrm{red} /$ white & 91.7 & & black/white & 41.57 \\
\hline Insulation & & Resistance $(\Omega)$ & Insulation & & Resistance $(\Omega)$ \\
\hline shield-wire & & $>100 \mathrm{e} 6$ & shield-wire & & $>100 \mathrm{e} 6$ \\
\hline \multicolumn{6}{|l|}{ Displacement Data } \\
\hline Micrometer (in) ${ }^{\mathrm{b}}$ & $\begin{array}{c}\text { Output } \\
\text { (decreasing Vdc) }\end{array}$ & $\begin{array}{c}\text { Output } \\
\text { (increasing } \mathrm{Vdc} \text { ) }\end{array}$ & Micrometer (in) ${ }^{\mathrm{b}}$ & $\begin{array}{c}\text { Output } \\
\text { (increasing } \mathrm{Vdc} \text { ) }\end{array}$ & $\begin{array}{c}\text { Output } \\
\text { (decreasing Vdc) }\end{array}$ \\
\hline .142 & 9.118 & 9.120 & .100 & -9.734 & -9.734 \\
\hline .167 & 7.850 & 7.850 & .125 & -8.654 & -8.658 \\
\hline .192 & 6.602 & 6.604 & .150 & -7.525 & -7.524 \\
\hline .217 & 5.397 & 5.398 & .175 & -6.345 & -6.347 \\
\hline .242 & 4.230 & 4.230 & .200 & -5.126 & -5.115 \\
\hline .267 & 3.106 & 3.107 & .225 & -3.874 & -3.864 \\
\hline .292 & 2.035 & 2.037 & .250 & -2.598 & -2.601 \\
\hline .317 & 1.007 & 1.010 & .275 & -1.305 & -1.295 \\
\hline .342 & -.001 & .005 & .300 & -.001 & -.001 \\
\hline .367 & -1.003 & -.998 & .325 & 1.305 & 1.301 \\
\hline .392 & -2.026 & -2.021 & .350 & 2.599 & 2.608 \\
\hline .417 & -3.095 & -3.088 & .375 & 3.882 & 3.879 \\
\hline .442 & -4.207 & -4.200 & .400 & 5.139 & 5.139 \\
\hline .467 & -5.371 & -5.365 & .425 & 6.368 & 6.366 \\
\hline .492 & -6.580 & -6.575 & .450 & 7.561 & 7.561 \\
\hline .517 & -7.825 & -7.824 & .475 & 8.711 & 8.712 \\
\hline .542 & -9.093 & -9.093 & .500 & 9.813 & 9.813 \\
\hline
\end{tabular}

a. LVDT resistance measurements using Fluke 8808A, serial number 9556082.

b. Uncorrected relative to the "null" position at " 0 ". 
Table A-2. Set 1 interference calibration inside calibration fixture.

\begin{tabular}{|c|c|c|c|c|c|}
\hline Date & \multicolumn{2}{|c|}{$9-17-2008$ \& 9-29-2008 } & \multicolumn{3}{|c|}{ D Knudjor } \\
\hline Calibration at & \multicolumn{2}{|l|}{ room temperature } & Furnace setpoint & na & \\
\hline \multicolumn{6}{|l|}{ LVDT } \\
\hline \multicolumn{3}{|c|}{ Vendor A 1097 (core 1060) } & \multicolumn{3}{|c|}{ Vendor B 1449} \\
\hline \multicolumn{6}{|c|}{ Secondary Coil Resistances ${ }^{\mathrm{a}}$} \\
\hline Loops & Wire colors & Resistance $(\Omega)$ & Loops & Wire colors & Resistance $(\Omega)$ \\
\hline $\mathrm{A}+\mathrm{B}$ & red/white & 392.7 & \multirow[t]{3}{*}{$\mathrm{A}+\mathrm{B}$} & \multirow{3}{*}{ green/red } & \multirow[t]{3}{*}{122.3} \\
\hline A & black/red & 646.3 & & & \\
\hline $\mathrm{B}$ & black/white & 646.7 & & & \\
\hline Insulation & & Resistance $(\Omega)$ & Insulation & & Resistance $(\Omega)$ \\
\hline shield-wire & & $>100 \mathrm{e} 6$ & shield-wire & & $>100 \mathrm{e} 6$ \\
\hline primary-secondary & & $>100 \mathrm{e} 6$ & primary-secondary & & $>100 \mathrm{e} 6$ \\
\hline \multicolumn{6}{|c|}{ Primary Coil Resistances ${ }^{\mathrm{a}}$} \\
\hline \multirow[t]{2}{*}{ Loop } & Wire colors & Resistance $(\Omega)$ & Loop & Wire colors & Resistance $(\Omega)$ \\
\hline & red/white & 91.7 & & black/white & 44.57 \\
\hline Insulation & & Resistance $(\Omega)$ & Insulation & & Resistance $(\Omega)$ \\
\hline shield-wire & & $>100 \mathrm{e} 6$ & shield-wire & & $>100 \mathrm{e} 6$ \\
\hline \multicolumn{6}{|l|}{ Displacement Data } \\
\hline Micrometer (in) ${ }^{\mathrm{b}}$ & $\begin{array}{c}\text { Output } \\
\text { (decreasing } \mathrm{Vdc} \text { ) }\end{array}$ & $\begin{array}{c}\text { Output } \\
\text { (increasing } \mathrm{Vdc} \text { ) }\end{array}$ & Micrometer (in) ${ }^{\mathrm{b}}$ & $\begin{array}{c}\text { Output } \\
\text { (increasing } \mathrm{Vdc} \text { ) }\end{array}$ & $\begin{array}{c}\text { Output } \\
\text { (decreasing } \mathrm{Vdc})\end{array}$ \\
\hline .097 & 9.125 & 9.112 & .100 & -9.581 & -9.587 \\
\hline .122 & 7.853 & 7.843 & .125 & -8.522 & -8.529 \\
\hline .147 & 6.608 & 6.599 & .150 & -7.405 & -7.409 \\
\hline .172 & 5.401 & 5.392 & .175 & -6.254 & -6.249 \\
\hline .197 & 4.238 & 4.230 & .200 & -5.056 & -5.051 \\
\hline .222 & 3.116 & 3.106 & .225 & -3.824 & -3.820 \\
\hline .247 & 2.044 & 2.032 & .250 & -2.570 & -2.564 \\
\hline .272 & 1.009 & 1.004 & .275 & -1.297 & -1.303 \\
\hline .297 & -.004 & -.006 & .300 & -.006 & -.011 \\
\hline .322 & -1.012 & -1.015 & .325 & 1.266 & 1.272 \\
\hline .347 & -2.043 & -2.043 & .350 & 2.540 & 2.548 \\
\hline .372 & -3.109 & -3.110 & .375 & 3.800 & 3.798 \\
\hline .397 & -4.224 & -4.223 & .400 & 5.041 & 5.039 \\
\hline .422 & -5.388 & -5.386 & .425 & 6.255 & 6.245 \\
\hline .447 & -6.597 & -6.592 & .450 & 7.430 & 7.419 \\
\hline .472 & -7.841 & -7.837 & .475 & 8.561 & 8.552 \\
\hline .497 & -9.111 & -9.111 & .500 & 9.643 & 9.643 \\
\hline
\end{tabular}

a. LVDT resistance measurements using Fluke 8808A, serial number 9556082.

b. Uncorrected relative to the "null" position at " 0 ". 
Table A-3. Set 1 interference calibration inside long duration fixture.

\begin{tabular}{|c|c|c|c|c|c|}
\hline Date & \multicolumn{2}{|l|}{$9-30-2008$} & Tester signature & \multicolumn{2}{|c|}{ D Krudjor } \\
\hline Calibration at & \multicolumn{2}{|l|}{ room temperature } & Furnace setpoint & \multicolumn{2}{|l|}{ na } \\
\hline \multicolumn{6}{|l|}{ LVDT } \\
\hline \multicolumn{3}{|c|}{ Vendor A 1097 (core 1060) } & \multicolumn{3}{|c|}{ Vendor B 1449} \\
\hline \multicolumn{6}{|c|}{ Secondary Coil Resistances $^{\mathrm{a}}$} \\
\hline Loops & Wire colors & Resistance $(\Omega)$ & Loops & Wire colors & Resistance $(\Omega)$ \\
\hline $\mathrm{A}+\mathrm{B}$ & red/white & 392.7 & \multirow[t]{3}{*}{$\mathrm{A}+\mathrm{B}$} & \multirow[t]{3}{*}{ green/red } & \multirow[t]{3}{*}{122.3} \\
\hline $\mathrm{A}$ & black/red & 646.3 & & & \\
\hline B & black/white & 646.7 & & & \\
\hline Insulation & & Resistance $(\Omega)$ & Insulation & & Resistance $(\Omega)$ \\
\hline shield-wire & & $>100 \mathrm{e} 6$ & shield-wire & & $>100 \mathrm{e} 6$ \\
\hline primary-secondary & & $>100 \mathrm{e} 6$ & primary-secondary & & $>100 \mathrm{e} 6$ \\
\hline \multicolumn{6}{|c|}{ Primary Coil Resistances $^{\mathrm{a}}$} \\
\hline \multirow[t]{2}{*}{ Loop } & Wire colors & Resistance $(\Omega)$ & Loop & Wire colors & Resistance $(\Omega)$ \\
\hline & red/white & 91.7 & & black/white & 44.57 \\
\hline Insulation & & Resistance $(\Omega)$ & Insulation & & Resistance $(\Omega)$ \\
\hline shield-wire & & $>100 \mathrm{e} 6$ & shield-wire & & $>100 \mathrm{e} 6$ \\
\hline \multicolumn{6}{|l|}{ Displacement Data } \\
\hline Micrometer (in) ${ }^{\mathrm{b}}$ & $\begin{array}{c}\text { Output } \\
\text { (decreasing Vdc) }\end{array}$ & $\begin{array}{c}\text { Output } \\
\text { (increasing Vdc) }\end{array}$ & Micrometer (in) ${ }^{b}$ & $\begin{array}{c}\text { Output } \\
\text { (increasing Vdc) }\end{array}$ & $\begin{array}{c}\text { Output } \\
\text { (decreasing Vdc) }\end{array}$ \\
\hline .100 & 9.124 & 9.124 & .100 & -9.456 & -9.451 \\
\hline .125 & 7.854 & 7.856 & .125 & -8.404 & -8.396 \\
\hline .150 & 6.611 & 6.610 & .150 & -7.298 & -7.291 \\
\hline .175 & 5.405 & 5.404 & .175 & -6.151 & -6.145 \\
\hline .200 & 4.244 & 4.244 & .200 & -4.962 & -4.958 \\
\hline .225 & 3.126 & 3.121 & .225 & -3.744 & -3.738 \\
\hline .250 & 2.057 & 2.050 & .250 & -2.500 & -2.497 \\
\hline .275 & 1.024 & 1.022 & .275 & -1.240 & -1.234 \\
\hline .300 & .015 & -.011 & .300 & .029 & .028 \\
\hline .325 & -.994 & -.998 & .325 & 1.301 & 1.309 \\
\hline .350 & -2.019 & -2.032 & .350 & 2.562 & 2.569 \\
\hline .375 & -3.087 & -3.090 & .375 & 3.811 & 3.811 \\
\hline .400 & -4.198 & -4.197 & .400 & 5.037 & 5.045 \\
\hline .425 & -5.359 & -5.359 & .425 & 6.235 & 6.231 \\
\hline .450 & -6.551 & -6.563 & .450 & 7.395 & 7.401 \\
\hline .475 & -7.793 & -7.790 & .475 & 8.514 & 8.513 \\
\hline .500 & -9.064 & -9.064 & .500 & 9.586 & 9.586 \\
\hline
\end{tabular}

a. LVDT resistance measurements using Fluke 8808A, serial number 9556082.

b. Uncorrected relative to the "null" position at " 0 ". 
Table A-4. Set 2 interference calibration outside all fixtures.

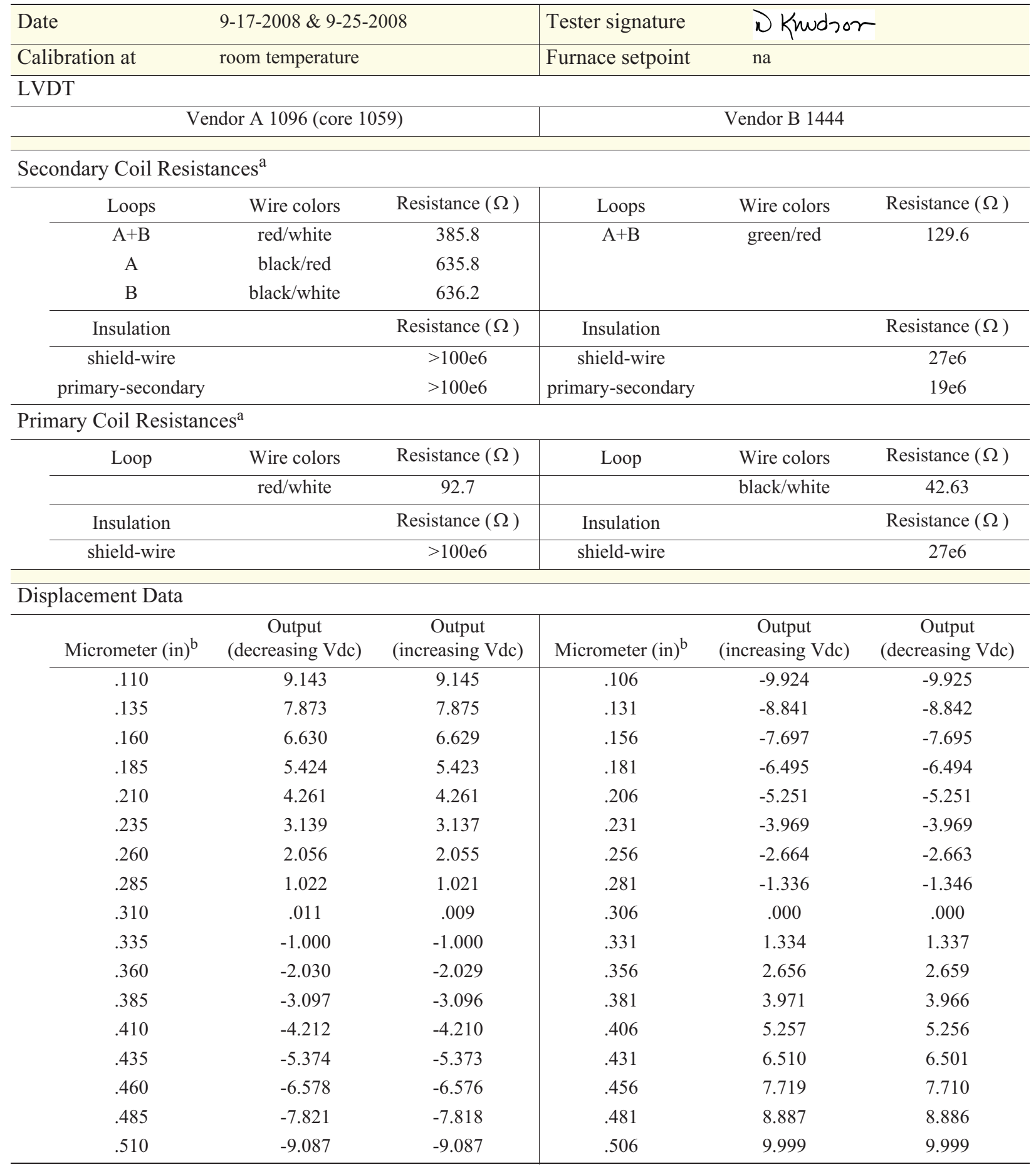

a. LVDT resistance measurements using Fluke 8808A, serial number 9556082.

b. Uncorrected relative to the "null" position at " 0 ". 
Table A-5. Set 2 interference calibration inside calibration fixture.

\begin{tabular}{|c|c|c|c|c|c|}
\hline Date & \multicolumn{2}{|c|}{$9-17-2008$ \& 9-29-2008 } & \multicolumn{3}{|c|}{ D Kundjor } \\
\hline Calibration at & \multicolumn{2}{|l|}{ room temperature } & Furnace setpoint & na & \\
\hline \multicolumn{6}{|l|}{ LVDT } \\
\hline \multicolumn{3}{|c|}{ Vendor A 1096 (core 1059) } & \multicolumn{3}{|c|}{ Vendor B 1444} \\
\hline \multicolumn{6}{|c|}{ Secondary Coil Resistances ${ }^{\mathrm{a}}$} \\
\hline Loops & Wire colors & Resistance $(\Omega)$ & Loops & Wire colors & Resistance $(\Omega)$ \\
\hline $\mathrm{A}+\mathrm{B}$ & red/white & 385.8 & \multirow[t]{3}{*}{$\mathrm{A}+\mathrm{B}$} & \multirow[t]{3}{*}{ green/red } & \multirow[t]{3}{*}{129.6} \\
\hline A & black/red & 635.8 & & & \\
\hline $\mathrm{B}$ & black/white & 636.2 & & & \\
\hline Insulation & & Resistance $(\Omega)$ & Insulation & & Resistance $(\Omega)$ \\
\hline shield-wire & & $>100 \mathrm{e} 6$ & shield-wire & & $27 \mathrm{e} 6$ \\
\hline primary-secondary & & $>100 \mathrm{e} 6$ & primary-secondary & & $19 \mathrm{e} 6$ \\
\hline \multicolumn{6}{|c|}{ Primary Coil Resistances ${ }^{\mathrm{a}}$} \\
\hline \multirow[t]{2}{*}{ Loop } & Wire colors & Resistance $(\Omega)$ & Loop & Wire colors & Resistance $(\Omega)$ \\
\hline & red/white & 92.7 & & black/white & 42.63 \\
\hline Insulation & & Resistance $(\Omega)$ & Insulation & & Resistance $(\Omega)$ \\
\hline shield-wire & & $>100 \mathrm{e} 6$ & shield-wire & & $27 \mathrm{e} 6$ \\
\hline \multicolumn{6}{|l|}{ Displacement Data } \\
\hline Micrometer (in) ${ }^{\mathrm{b}}$ & $\begin{array}{c}\text { Output } \\
\text { (decreasing } \mathrm{Vdc} \text { ) }\end{array}$ & $\begin{array}{c}\text { Output } \\
\text { (increasing } \mathrm{Vdc} \text { ) }\end{array}$ & Micrometer (in) ${ }^{\mathrm{b}}$ & $\begin{array}{c}\text { Output } \\
\text { (increasing } \mathrm{Vdc} \text { ) }\end{array}$ & $\begin{array}{c}\text { Output } \\
\text { (decreasing } \mathrm{Vdc})\end{array}$ \\
\hline .100 & 9.126 & 9.122 & .100 & -9.877 & -9.874 \\
\hline .125 & 7.855 & 7.853 & .125 & -8.797 & -8.793 \\
\hline .150 & 6.609 & 6.608 & .150 & -7.651 & -7.652 \\
\hline .175 & 5.401 & 5.398 & .175 & -6.458 & -6.458 \\
\hline .200 & 4.238 & 4.235 & .200 & -5.217 & -5.217 \\
\hline .225 & 3.116 & 3.114 & .225 & -3.944 & -3.944 \\
\hline .250 & 2.039 & 2.037 & .250 & -2.644 & -2.643 \\
\hline .275 & 1.004 & 1.005 & .275 & -1.322 & -1.322 \\
\hline .300 & -.005 & -.006 & .300 & .007 & .008 \\
\hline .325 & -1.012 & -1.015 & .325 & 1.340 & 1.339 \\
\hline .350 & -2.040 & -2.040 & .350 & 2.654 & 2.662 \\
\hline .375 & -3.108 & -3.106 & .375 & 3.962 & 3.951 \\
\hline .400 & -4.220 & -4.217 & .400 & 5.236 & 5.228 \\
\hline .425 & -5.382 & -5.379 & .425 & 6.479 & 6.474 \\
\hline .450 & -6.590 & -6.586 & .450 & 7.689 & 7.689 \\
\hline .475 & -7.833 & -7.831 & .475 & 8.846 & 8.835 \\
\hline .500 & -9.101 & -9.101 & .500 & 9.943 & 9.943 \\
\hline
\end{tabular}

a. LVDT resistance measurements using Fluke 8808A, serial number 9556082.

b. Uncorrected relative to the "null" position at " 0 ". 
Table A-6. Set 2 interference calibration inside long duration fixture.

\begin{tabular}{|c|c|c|c|c|c|}
\hline Date & \multicolumn{2}{|c|}{$9-30-2008$ \& 9-25-2008 } & \multicolumn{3}{|c|}{ D Kundjor } \\
\hline Calibration at & \multicolumn{2}{|c|}{ room temperature } & Furnace setpoint & na & \\
\hline \multicolumn{6}{|l|}{ LVDT } \\
\hline \multicolumn{3}{|c|}{ Vendor A 1096 (core 1059) } & \multicolumn{3}{|c|}{ Vendor B 1444} \\
\hline \multicolumn{6}{|c|}{ Secondary Coil Resistances ${ }^{\mathrm{a}}$} \\
\hline Loops & Wire colors & Resistance $(\Omega)$ & Loops & Wire colors & Resistance $(\Omega)$ \\
\hline $\mathrm{A}+\mathrm{B}$ & red/white & 385.8 & \multirow[t]{3}{*}{$\mathrm{A}+\mathrm{B}$} & \multirow[t]{3}{*}{ green/red } & \multirow[t]{3}{*}{129.6} \\
\hline A & black/red & 635.8 & & & \\
\hline $\mathrm{B}$ & black/white & 636.2 & & & \\
\hline Insulation & & Resistance $(\Omega)$ & Insulation & & Resistance $(\Omega)$ \\
\hline shield-wire & & $>100 \mathrm{e} 6$ & shield-wire & & $27 \mathrm{e} 6$ \\
\hline primary-secondary & & $>100 \mathrm{e} 6$ & primary-secondary & & $19 \mathrm{e} 6$ \\
\hline \multicolumn{6}{|c|}{ Primary Coil Resistances ${ }^{\mathrm{a}}$} \\
\hline \multirow[t]{2}{*}{ Loop } & Wire colors & Resistance $(\Omega)$ & Loop & Wire colors & Resistance $(\Omega)$ \\
\hline & red/white & 92.7 & & black/white & 42.63 \\
\hline Insulation & & Resistance $(\Omega)$ & Insulation & & Resistance $(\Omega)$ \\
\hline shield-wire & & $>100 \mathrm{e} 6$ & shield-wire & & $27 \mathrm{e} 6$ \\
\hline \multicolumn{6}{|l|}{ Displacement Data } \\
\hline Micrometer (in) ${ }^{\mathrm{b}}$ & $\begin{array}{c}\text { Output } \\
\text { (decreasing } \mathrm{Vdc} \text { ) }\end{array}$ & $\begin{array}{c}\text { Output } \\
\text { (increasing } \mathrm{Vdc} \text { ) }\end{array}$ & Micrometer (in) ${ }^{\mathrm{b}}$ & $\begin{array}{c}\text { Output } \\
\text { (increasing } \mathrm{Vdc} \text { ) }\end{array}$ & $\begin{array}{c}\text { Output } \\
\text { (decreasing } \mathrm{Vdc})\end{array}$ \\
\hline .100 & 9.089 & 9.084 & .106 & -9.825 & -9.825 \\
\hline .125 & 7.815 & 7.814 & .131 & -8.753 & -8.752 \\
\hline .150 & 6.575 & 6.570 & .156 & -7.616 & -7.616 \\
\hline .175 & 5.370 & 5.365 & .181 & -6.428 & -6.424 \\
\hline .200 & 4.212 & 4.216 & .206 & -5.192 & -5.189 \\
\hline .225 & 3.102 & 3.107 & .231 & -3.921 & -3.920 \\
\hline .250 & 2.034 & 2.039 & .256 & -2.626 & -2.622 \\
\hline .275 & 1.001 & 1.008 & .281 & -1.311 & -1.307 \\
\hline .300 & -.010 & -.004 & .306 & .014 & .016 \\
\hline .325 & -1.013 & -1.013 & .331 & 1.331 & 1.343 \\
\hline .350 & -2.042 & -2.040 & .356 & 2.657 & 2.658 \\
\hline .375 & -3.105 & -3.105 & .381 & 3.951 & 3.960 \\
\hline .400 & -4.217 & -4.215 & .406 & 5.232 & 5.225 \\
\hline .425 & -5.373 & -5.372 & .431 & 6.466 & 6.464 \\
\hline .450 & -6.576 & -6.576 & .456 & 7.665 & 7.663 \\
\hline .475 & -7.815 & -7.815 & .481 & 8.817 & 8.817 \\
\hline .500 & -9.079 & -9.079 & .506 & 9.929 & 9.929 \\
\hline
\end{tabular}

a. LVDT resistance measurements using Fluke 8808A, serial number 9556082.

b. Uncorrected relative to the "null" position at " 0 ". 


\section{APPENDIX B - CALIBRATION DATA}

Table B-1. Set 1 data at $200^{\circ} \mathrm{C}$.

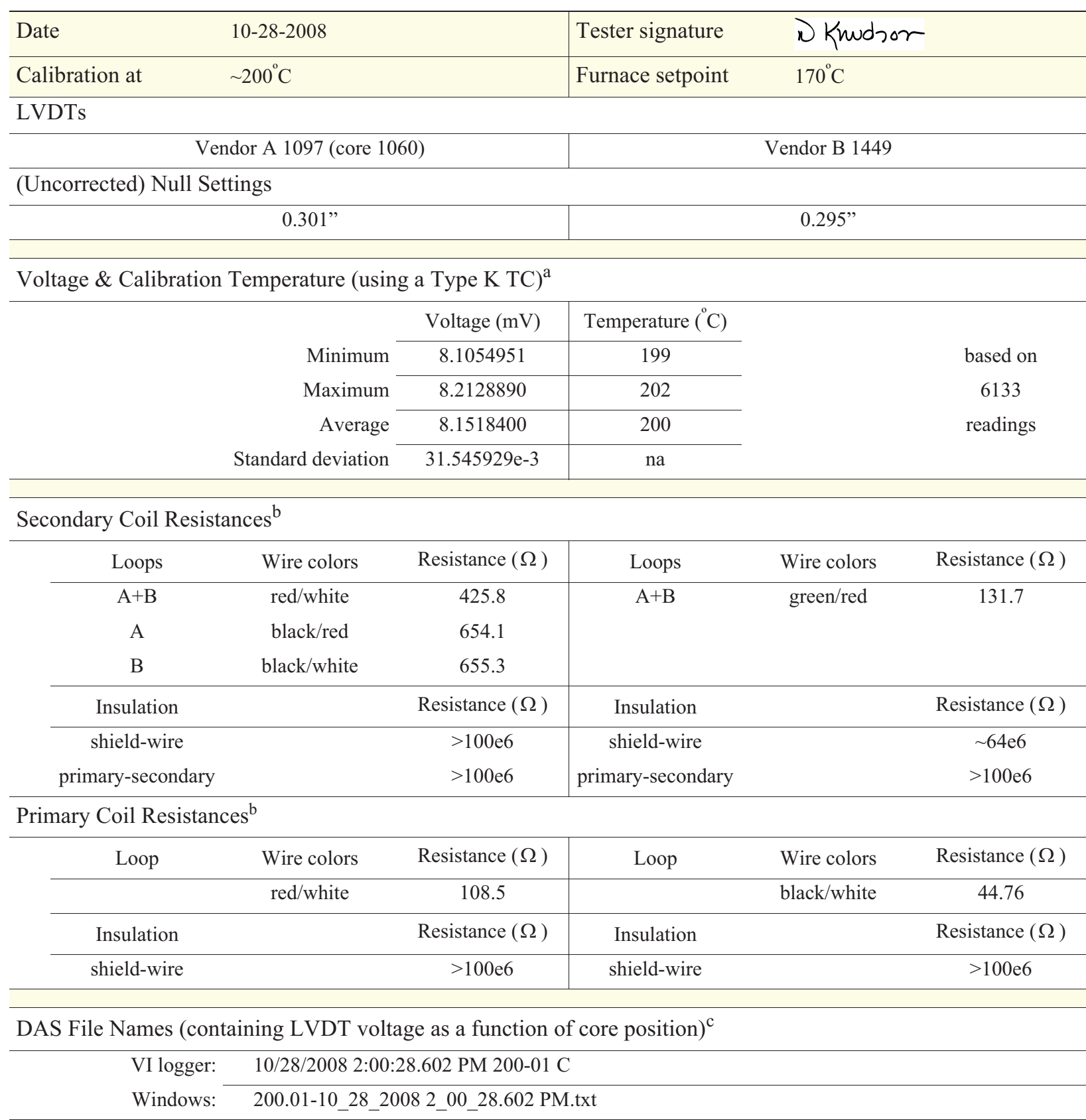

a. TC voltage measurements using Agilent 34420A, serial number SG42000457.

b. LVDT resistance measurements using Fluke 8808A, serial number 9556082.

c. LVDT voltage measurements using VI Logger 2.0.1 with NI-DAQmx 8.0.0f0. 
Table B-2. Set 1 data at $300^{\circ} \mathrm{C}$.

\begin{tabular}{|c|c|c|c|c|c|}
\hline Date & \multicolumn{2}{|l|}{$11-4-2008$} & Tester signature & \multicolumn{2}{|c|}{ D Knudsor } \\
\hline Calibration at & \multicolumn{2}{|l|}{$\sim 300^{\circ} \mathrm{C}$} & Furnace setpoint & \multicolumn{2}{|l|}{$304^{\circ} \mathrm{C}$} \\
\hline \multicolumn{6}{|l|}{ LVDTs } \\
\hline \multicolumn{3}{|c|}{ Vendor A 1097 (core 1060) } & \multicolumn{3}{|c|}{ Vendor B 1449} \\
\hline \multicolumn{6}{|c|}{ (Uncorrected) Null Settings } \\
\hline \multicolumn{3}{|c|}{$0.301 ”$} & \multicolumn{3}{|c|}{$0.292 ”$} \\
\hline \multicolumn{6}{|c|}{ Voltage \& Calibration Temperature (using a Type K TC) ${ }^{\mathrm{a}}$} \\
\hline & & Voltage $(\mathrm{mV})$ & Temperature $\left({ }^{\circ} \mathrm{C}\right)$ & & \multirow{5}{*}{$\begin{array}{l}\text { based on } \\
3107 \\
\text { readings }\end{array}$} \\
\hline & Minimum & 11.963034 & 294 & & \\
\hline & Maximum & 12.167573 & 299 & & \\
\hline & Average & 12.021332 & 295 & & \\
\hline & Standard deviation & $60.520309 e-3$ & na & & \\
\hline \multicolumn{6}{|c|}{ Secondary Coil Resistances ${ }^{b}$} \\
\hline Loops & Wire colors & Resistance $(\Omega)$ & Loops & Wire colors & Resistance $(\Omega)$ \\
\hline $\mathrm{A}+\mathrm{B}$ & $\mathrm{red} / \mathrm{white}$ & 447.4 & $\mathrm{~A}+\mathrm{B}$ & green/red & 138.1 \\
\hline A & black/red & 674.1 & & & \\
\hline $\mathrm{B}$ & black/white & 674.7 & & & \\
\hline Insulation & & Resistance $(\Omega)$ & Insulation & & Resistance $(\Omega)$ \\
\hline shield-wire & & $>100 \mathrm{e} 6$ & shield-wire & & $>100 \mathrm{e} 6$ \\
\hline primary-secondary & & $>100 \mathrm{e} 6$ & primary-secondary & & $>100 \mathrm{e} 6$ \\
\hline \multicolumn{6}{|c|}{ Primary Coil Resistances ${ }^{b}$} \\
\hline \multirow[t]{2}{*}{ Loop } & Wire colors & Resistance $(\Omega)$ & Loop & Wire colors & Resistance $(\Omega)$ \\
\hline & red/white & 119.6 & & black/white & 46.95 \\
\hline Insulation & & Resistance $(\Omega)$ & Insulation & & Resistance $(\Omega)$ \\
\hline shield-wire & & $>100 \mathrm{e} 6$ & shield-wire & & $>100 \mathrm{e} 6$ \\
\hline \multicolumn{6}{|c|}{ DAS File Names (containing LVDT voltage as a function of core position) ${ }^{c}$} \\
\hline VI logger: & \multicolumn{5}{|c|}{ 11/4/2008 1:37:58.610 PM 300-01 C } \\
\hline Windows: & \multicolumn{5}{|c|}{ 300.01-11_4_2008 1_37_58.610 PM.txt } \\
\hline
\end{tabular}

a. TC voltage measurements using Agilent 34420A, serial number SG42000457.

b. LVDT resistance measurements using Agilent 34420A, serial number SG42000457.

c. LVDT voltage measurements using VI Logger 2.0.1 with NI-DAQmx 8.0.0f0. 
Table B-3. Set 1 data at $400^{\circ} \mathrm{C}$.

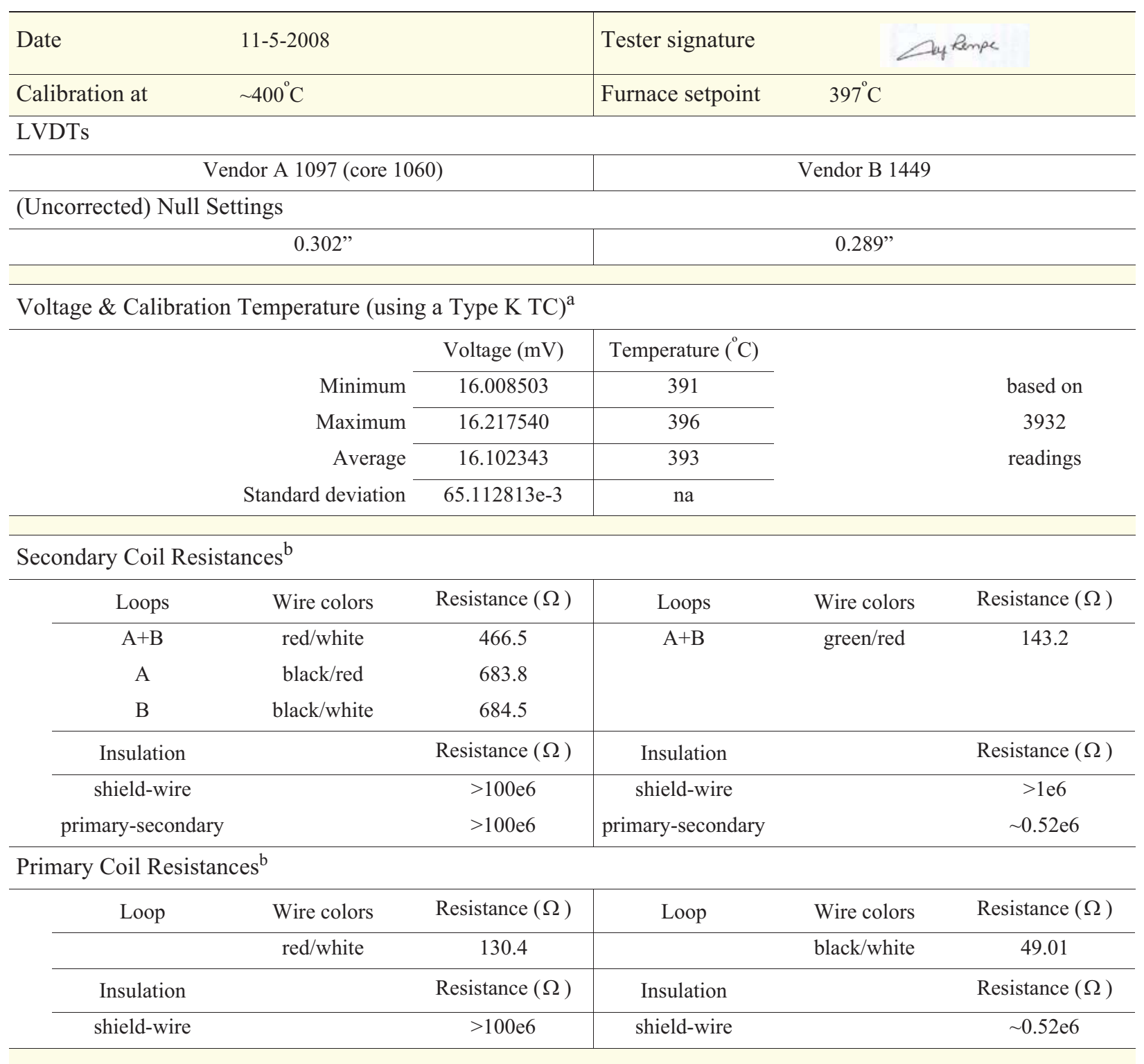

DAS File Names (containing LVDT voltage as a function of core position) ${ }^{\mathrm{c}}$
VI logger: $\quad$ 11/5/2008 12:41:24.637 PM 400-01 C
Windows: 400.01-11_5_2008 12_41_24.637 PM.txt
a. TC voltage measurements using Agilent 34420A, serial number SG42000457.
b. LVDT resistance measurements using Agilent 34420A, serial number SG42000457.
c. LVDT voltage measurements using VI Logger 2.0.1 with NI-DAQmx 8.0.0f0. 
Table B-4. Set 1 data at $500^{\circ} \mathrm{C}$.

\begin{tabular}{|c|c|c|c|c|c|}
\hline Date & \multicolumn{2}{|l|}{$11-10-2008$} & Tester signature & \multicolumn{2}{|c|}{$D$ Krudsor } \\
\hline Calibration at & \multicolumn{2}{|l|}{$\sim 500^{\circ} \mathrm{C}$} & Furnace setpoint & \multicolumn{2}{|c|}{$495^{\circ} \mathrm{C}$} \\
\hline \multicolumn{6}{|l|}{ LVDTs } \\
\hline \multicolumn{3}{|c|}{ Vendor A 1097 (core 1060) } & \multicolumn{3}{|c|}{ Vendor B 1449} \\
\hline \multicolumn{6}{|c|}{ (Uncorrected) Null Settings } \\
\hline \multicolumn{3}{|c|}{$0.301 ”$} & \multicolumn{3}{|c|}{$0.267 ”$} \\
\hline \multicolumn{6}{|c|}{ Voltage \& Calibration Temperature (using a Type K TC) } \\
\hline & & Voltage $(\mathrm{mV})$ & Temperature $\left({ }^{\circ} \mathrm{C}\right)$ & & \multirow{5}{*}{$\begin{array}{l}\text { based on } \\
3937 \\
\text { readings }\end{array}$} \\
\hline & Minimum & na & na & & \\
\hline & Maximum & 20.739981 & 502 & & \\
\hline & Average & na & na & & \\
\hline & Standard deviation & na & na & & \\
\hline \multicolumn{6}{|c|}{ Secondary Coil Resistances ${ }^{b, c}$} \\
\hline Loops & Wire colors & Resistance $(\Omega)$ & Loops & Wire colors & Resistance $(\Omega)$ \\
\hline $\mathrm{A}+\mathrm{B}$ & $\mathrm{red} / \mathrm{white}$ & $488.4(488.2)$ & $\mathrm{A}+\mathrm{B}$ & green/red & $147.6(144.9)$ \\
\hline A & black/red & $671.9(695.0)$ & & & \\
\hline $\mathrm{B}$ & black/white & $672.9(696.0)$ & & & \\
\hline Insulation & & Resistance $(\Omega)$ & Insulation & & Resistance $(\Omega)$ \\
\hline shield-wire & & $\sim 2 \mathrm{e} 6(\sim 1 \mathrm{e} 6)$ & shield-wire & & $\sim 4.5 \mathrm{e} 6(\sim 0.87 \mathrm{e} 6)$ \\
\hline primary-secondary & & $\sim 3 \mathrm{e} 6(\sim 1 \mathrm{e} 6)$ & primary-secondary & & $43.68(48.98)$ \\
\hline \multicolumn{6}{|c|}{ Primary Coil Resistances ${ }^{\mathrm{b}}$, } \\
\hline \multirow[t]{2}{*}{ Loop } & Wire colors & Resistance $(\Omega)$ & Loop & Wire colors & Resistance $(\Omega)$ \\
\hline & red/white & $142.2(142.5)$ & & black/white & $51.21(50.88)$ \\
\hline Insulation & & Resistance $(\Omega)$ & Insulation & & Resistance $(\Omega)$ \\
\hline shield-wire & & $\sim 3 \mathrm{e} 6(\sim 1 \mathrm{e} 6)$ & shield-wire & & $\sim 4.5 \mathrm{e} 6(\sim 0.9 \mathrm{e} 6)$ \\
\hline
\end{tabular}

DAS File Names (containing LVDT voltage as a function of core position) ${ }^{\mathrm{d}}$

$\begin{array}{ll}\text { VI logger: } & \text { 11/10/2008 10:55:58.152 AM 500-01 C } \\ \text { Windows: } & \text { 500.01-11_10_2008 10_55_58.152 AM.txt }\end{array}$

a. TC voltage measurements using Agilent 34420A, serial number SG42000457.

b. LVDT resistance measurements using Fluke 8808A, serial number 9556082.

c. LVDT resistance measurements using Agilent 34420A, serial number SG42000457, also (data in parenthesis).

d. LVDT voltage measurements using VI Logger 2.0.1 with NI-DAQmx 8.0.0f0. 
Table B-5. Room temperature data for Set 1 after high temperature calibration.

\begin{tabular}{|c|c|c|c|c|c|}
\hline Date & \multicolumn{2}{|l|}{$11-11-2008$} & \multicolumn{3}{|c|}{$D$ Knudjor } \\
\hline Calibration at & \multicolumn{2}{|c|}{ room temperature (after calibration) } & \multicolumn{3}{|l|}{ Furnace setpoint } \\
\hline \multicolumn{6}{|l|}{ LVDTs } \\
\hline \multicolumn{3}{|c|}{ Vendor A 1097 (core 1060) } & \multicolumn{3}{|c|}{ Vendor B 1449} \\
\hline \multicolumn{6}{|c|}{ (Uncorrected) Null Settings } \\
\hline \multicolumn{3}{|c|}{$0.299 ”$} & \multicolumn{3}{|c|}{$0.291 "$} \\
\hline \multicolumn{6}{|c|}{ Voltage \& Calibration Temperature (using a Type K TC) ${ }^{\mathrm{a}}$} \\
\hline & & Voltage (mV) & Temperature $\left({ }^{\circ} \mathrm{C}\right)$ & & \multirow{5}{*}{$\begin{array}{l}\text { based on } \\
2711 \\
\text { readings }\end{array}$} \\
\hline & Minimum & 1.1869131 & 30 & & \\
\hline & Maximum & 1.2140678 & 30 & & \\
\hline & Average & 1.2036601 & 30 & & \\
\hline & Standard deviation & $8.074181 \mathrm{e}-3$ & na & & \\
\hline \multicolumn{6}{|c|}{ Secondary Coil Resistances ${ }^{b, c}$} \\
\hline Loops & Wire colors & Resistance $(\Omega)$ & Loops & Wire colors & Resistance $(\Omega)$ \\
\hline $\mathrm{A}+\mathrm{B}$ & $\mathrm{red} / \mathrm{white}$ & $392.8(392.4)$ & $\mathrm{A}+\mathrm{B}$ & green/red & $122.8(122.8)$ \\
\hline A & black/red & $645.8(645.8)$ & & & \\
\hline $\mathrm{B}$ & black/white & $646.2(646.2)$ & & & \\
\hline Insulation & & Resistance $(\Omega)$ & Insulation & & Resistance $(\Omega)$ \\
\hline shield-wire & & $>100 \mathrm{e} 6(>1 \mathrm{e} 6)$ & shield-wire & & $>100 \mathrm{e} 6(>1 \mathrm{e} 6)$ \\
\hline primary-secondary & & $>100 \mathrm{e} 6(>1 \mathrm{e} 6)$ & primary-secondary & & $>100 \mathrm{e} 6(>1 \mathrm{e} 6)$ \\
\hline \multicolumn{6}{|c|}{ Primary Coil Resistances ${ }^{\mathrm{b}, \mathrm{c}}$} \\
\hline \multirow[t]{2}{*}{ Loop } & Wire colors & Resistance $(\Omega)$ & Loop & Wire colors & Resistance $(\Omega)$ \\
\hline & red/white & $91.82(91.57)$ & & black/white & $41.84(41.78)$ \\
\hline Insulation & & Resistance $(\Omega)$ & Insulation & & Resistance $(\Omega)$ \\
\hline shield-wire & & $>100 \mathrm{e} 6(>1 \mathrm{e} 6)$ & shield-wire & & $>100 \mathrm{e} 6(>1 \mathrm{e} 6)$ \\
\hline \multicolumn{6}{|c|}{ DAS File Names (containing LVDT voltage as a function of core position) ${ }^{\mathrm{d}}$} \\
\hline VI logger: & \multicolumn{5}{|c|}{ 11/11/2008 11:20:50.425 AM RT-AC01 } \\
\hline Windows: & \multicolumn{5}{|c|}{$\begin{array}{l}\text { RT.AC-11_11_2008 11_20_50.425 AM.txt (on backup CD) } \\
\text { RT.AC01-11_11_2008 11_20_50.425 AM.txt (on tc1) }\end{array}$} \\
\hline
\end{tabular}

a. TC voltage measurements using Agilent 34420A, serial number SG42000457.

b. LVDT resistance measurements using Fluke 8808A, serial number 9556082.

c. LVDT resistance measurements using Agilent 34420A, serial number SG42000457, also (data in parenthesis).

d. LVDT voltage measurements using VI Logger 2.0.1 with NI-DAQmx 8.0.0f0. 
Table B-6. Room temperature data for Set 2 before high temperature calibration.

\begin{tabular}{|c|c|c|c|c|c|}
\hline Date & \multicolumn{2}{|l|}{$11-12-2008$} & \multicolumn{3}{|c|}{ D Krudsor } \\
\hline Calibration at & \multicolumn{2}{|c|}{ room temperature (before calibration) } & Furnace setpoint & \multicolumn{2}{|c|}{$0^{\circ} \mathrm{C}$} \\
\hline \multicolumn{6}{|l|}{ LVDTs } \\
\hline \multicolumn{3}{|c|}{ Vendor A 1096 (core 1059) } & \multicolumn{3}{|c|}{ Vendor B 1444} \\
\hline \multicolumn{6}{|c|}{ (Uncorrected) Null Settings } \\
\hline \multicolumn{3}{|c|}{ 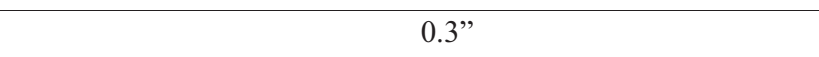 } & \multicolumn{3}{|c|}{$0.3 ”$} \\
\hline \multicolumn{6}{|c|}{ Voltage \& Calibration Temperature (using a Type K TC) } \\
\hline & & Voltage (mV) & Temperature $\left({ }^{\circ} \mathrm{C}\right)$ & & \multirow{5}{*}{$\begin{array}{l}\text { based on } \\
2161 \\
\text { readings }\end{array}$} \\
\hline & Minimum & 0.77247841 & 19 & & \\
\hline & Maximum & 0.78928736 & 20 & & \\
\hline & Average & 0.78249929 & 20 & & \\
\hline & Standard deviation & $4.808777 \mathrm{e}-3$ & na & & \\
\hline \multicolumn{6}{|c|}{ Secondary Coil Resistances ${ }^{b, c}$} \\
\hline Loops & Wire colors & Resistance $(\Omega)$ & Loops & Wire colors & Resistance $(\Omega)$ \\
\hline $\mathrm{A}+\mathrm{B}$ & $\mathrm{red} /$ white & $386.1(385.4)$ & $\mathrm{A}+\mathrm{B}$ & green/red & $129.5(129.4)$ \\
\hline A & black/red & $636.1(635.5)$ & & & \\
\hline $\mathrm{B}$ & black/white & $636.5(635.8)$ & & & \\
\hline Insulation & & Resistance $(\Omega)$ & Insulation & & Resistance $(\Omega)$ \\
\hline shield-wire & & $>100 \mathrm{e} 6(>1 \mathrm{e} 6)$ & shield-wire & & $\sim 15 \mathrm{e} 6(>1 \mathrm{e} 6)$ \\
\hline primary-secondary & & $>100 \mathrm{e} 6(>1 \mathrm{e} 6)$ & primary-secondary & & $\sim 15 \mathrm{e} 6(>1 \mathrm{e} 6)$ \\
\hline \multicolumn{6}{|c|}{ Primary Coil Resistances ${ }^{\mathrm{b}, \mathrm{c}}$} \\
\hline \multirow[t]{2}{*}{ Loop } & Wire colors & Resistance $(\Omega)$ & Loop & Wire colors & Resistance $(\Omega)$ \\
\hline & $\mathrm{red} /$ white & $92.69(92.33)$ & & black/white & $42.71(42.62)$ \\
\hline Insulation & & Resistance $(\Omega)$ & Insulation & & Resistance $(\Omega)$ \\
\hline shield-wire & & $>100 \mathrm{e} 6(>1 \mathrm{e} 6)$ & shield-wire & & $\sim 22 \mathrm{e} 6(>1 \mathrm{e} 6)$ \\
\hline \multicolumn{6}{|c|}{ DAS File Names (containing LVDT voltage as a function of core position) ${ }^{d}$} \\
\hline \multirow{2}{*}{$\begin{array}{l}\text { VI logger: } \\
\text { Windows: }\end{array}$} & \multicolumn{3}{|c|}{ 11/12/2008 9:21:03.358 AM RT-BC02 } & & \\
\hline & \multicolumn{3}{|c|}{ RT.BC02-11_12_2008 9_21_03.358 AM.txt } & & \\
\hline
\end{tabular}

a. TC voltage measurements using Agilent 34420A, serial number SG42000457.

b. LVDT resistance measurements using Fluke 8808A, serial number 9556082.

c. LVDT resistance measurements using Agilent 34420A, serial number SG42000457, also (data in parenthesis).

d. LVDT voltage measurements using VI Logger 2.0.1 with NI-DAQmx 8.0.0f0. 
Table B-7. Set 2 data at $200^{\circ} \mathrm{C}$.

\begin{tabular}{|c|c|c|c|c|c|}
\hline Date & \multicolumn{2}{|l|}{$11-12-2008$} & Tester signature & \multicolumn{2}{|c|}{ D Knudsor } \\
\hline Calibration at & \multicolumn{2}{|l|}{$\sim 200^{\circ} \mathrm{C}$} & Furnace setpoint & \multicolumn{2}{|l|}{$171^{\circ} \mathrm{C}$} \\
\hline \multicolumn{6}{|l|}{ LVDTs } \\
\hline \multicolumn{3}{|c|}{ Vendor A 1096 (core 1059) } & \multicolumn{3}{|c|}{ Vendor B 1444} \\
\hline \multicolumn{6}{|c|}{ (Uncorrected) Null Settings } \\
\hline \multicolumn{3}{|c|}{$0.302 "$} & \multicolumn{3}{|c|}{$0.296 ”$} \\
\hline \multicolumn{6}{|c|}{ Voltage \& Calibration Temperature (using a Type K TC) ${ }^{\mathrm{a}}$} \\
\hline & & Voltage $(\mathrm{mV})$ & Temperature $\left({ }^{\circ} \mathrm{C}\right)$ & & \multirow{5}{*}{$\begin{array}{l}\text { based on } \\
3073 \\
\text { readings }\end{array}$} \\
\hline & Minimum & 7.9415689 & 195 & & \\
\hline & Maximum & 8.0727560 & 198 & & \\
\hline & Average & 7.9852914 & 196 & & \\
\hline & Standard deviation & $40.794915 \mathrm{e}-3$ & na & & \\
\hline \multicolumn{6}{|c|}{ Secondary Coil Resistances ${ }^{b, c}$} \\
\hline Loops & Wire colors & Resistance $(\Omega)$ & Loops & Wire colors & Resistance $(\Omega)$ \\
\hline $\mathrm{A}+\mathrm{B}$ & red/white & $422.5(422.3)$ & $\mathrm{A}+\mathrm{B}$ & green/red & $139.8(139.7)$ \\
\hline A & black/red & $646.3(654.4)$ & & & \\
\hline $\mathrm{B}$ & black/white & $646.8(655.0)$ & & & \\
\hline Insulation & & Resistance $(\Omega)$ & Insulation & & Resistance $(\Omega)$ \\
\hline shield-wire & & $>100 \mathrm{e} 6(>1 \mathrm{e} 6)$ & shield-wire & & $\sim 15 \mathrm{e} 6(>1 \mathrm{e} 6)$ \\
\hline primary-secondary & & $>100 \mathrm{e} 6(>1 \mathrm{e} 6)$ & primary-secondary & & $\sim 13 \mathrm{e} 6(>1 \mathrm{e} 6)$ \\
\hline \multicolumn{6}{|c|}{ Primary Coil Resistances ${ }^{b, c}$} \\
\hline \multirow[t]{2}{*}{ Loop } & Wire colors & Resistance $(\Omega)$ & Loop & Wire colors & Resistance $(\Omega)$ \\
\hline & red/white & $111.2(111.0)$ & & black/white & $46.06(45.98)$ \\
\hline Insulation & & Resistance $(\Omega)$ & Insulation & & Resistance $(\Omega)$ \\
\hline shield-wire & & $>100 \mathrm{e} 6(>1 \mathrm{e} 6)$ & shield-wire & & $\sim 21 \mathrm{e} 6(>1 \mathrm{e} 6)$ \\
\hline
\end{tabular}

DAS File Names (containing LVDT voltage as a function of core position) ${ }^{\mathrm{d}}$
VI logger: $\quad$ 11/12/2008 1:24:02.311 PM 200-02 C
Windows: 200.02-11_12_20081_24_02.311 PM.txt
a. TC voltage measurements using Agilent 34420A, serial number SG42000457.
b. LVDT resistance measurements using Fluke 8808A, serial number 9556082.
c. LVDT resistance measurements using Agilent 34420A, serial number SG42000457, also (data in parenthesis).
d. LVDT voltage measurements using VI Logger 2.0.1 with NI-DAQmx 8.0.0f0. 
Table B-8. Set 2 data at $300^{\circ} \mathrm{C}$.

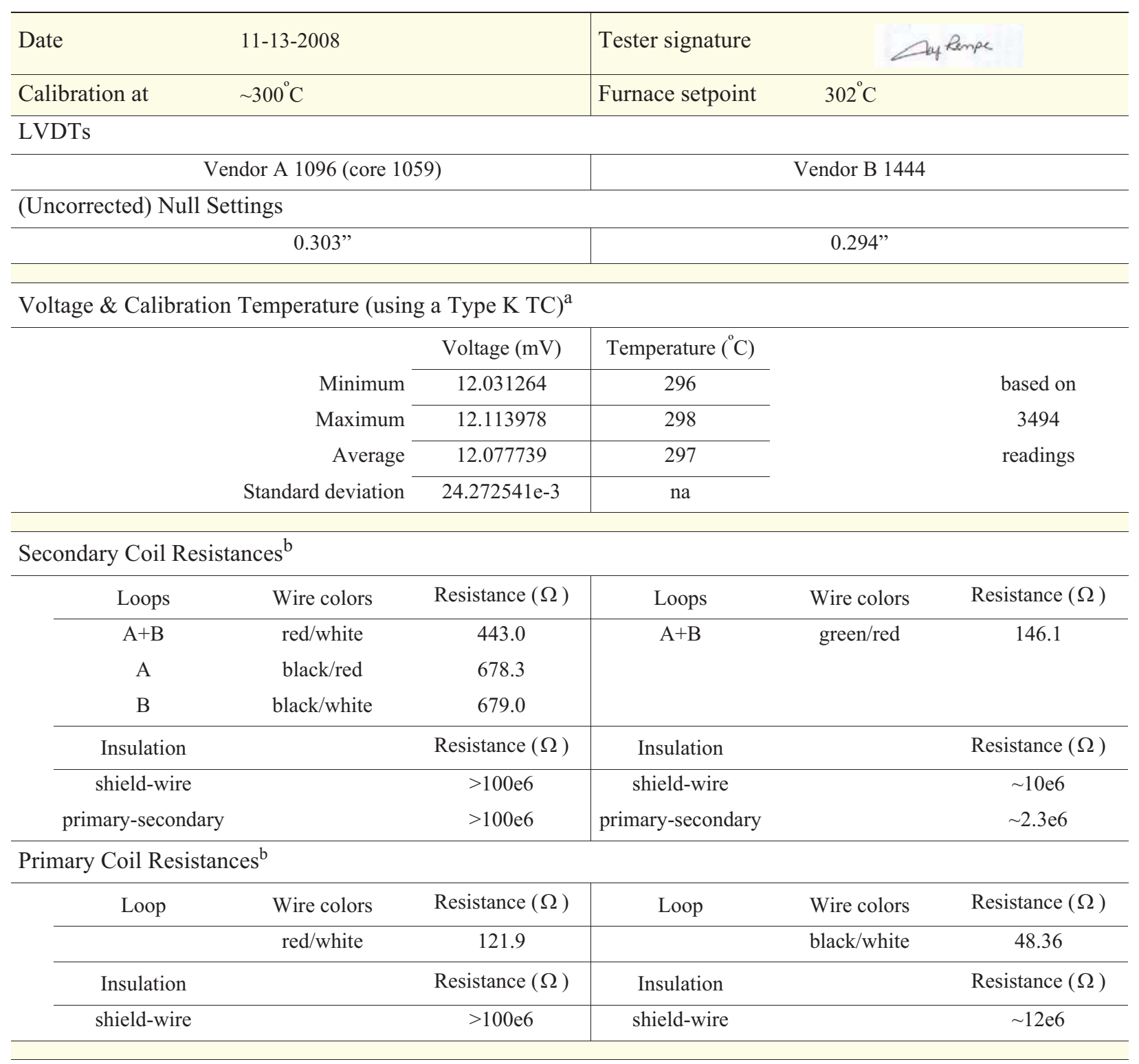

DAS File Names (containing LVDT voltage as a function of core position) ${ }^{\mathrm{c}}$

\begin{tabular}{|c|c|}
\hline VI logger: & 11/13/2008 10:58:15.471 AM 300-02 C \\
\hline Windows: & 300.02-11_13_2008 10_58_15.471 AM.txt \\
\hline
\end{tabular}


Table B-9. Set 2 data at $400^{\circ} \mathrm{C}$.

\begin{tabular}{|c|c|c|c|c|c|}
\hline Date & \multicolumn{2}{|l|}{$11-17-2008$} & Tester signature & \multicolumn{2}{|c|}{ D Krudjor } \\
\hline Calibration at & \multicolumn{2}{|l|}{$\sim 400^{\circ} \mathrm{C}$} & Furnace setpoint & \multicolumn{2}{|c|}{$399^{\circ} \mathrm{C}$} \\
\hline \multicolumn{6}{|l|}{ LVDTs } \\
\hline \multicolumn{3}{|c|}{ Vendor A 1096 (core 1059) } & \multicolumn{3}{|c|}{ Vendor B 1444} \\
\hline \multicolumn{6}{|c|}{ (Uncorrected) Null Settings } \\
\hline \multicolumn{3}{|c|}{$0.303 ”$} & \multicolumn{3}{|c|}{$0.292 ”$} \\
\hline \multicolumn{6}{|c|}{ Voltage \& Calibration Temperature (using a Type K TC) } \\
\hline & & Voltage $(\mathrm{mV})$ & Temperature $\left({ }^{\circ} \mathrm{C}\right)$ & & \multirow{5}{*}{$\begin{array}{l}\text { based on } \\
3060 \\
\text { readings }\end{array}$} \\
\hline & Minimum & 16.199025 & 395 & & \\
\hline & Maximum & 16.368181 & 399 & & \\
\hline & Average & 16.297141 & 398 & & \\
\hline & Standard deviation & $43.924133 \mathrm{e}-3$ & na & & \\
\hline \multicolumn{6}{|c|}{ Secondary Coil Resistances ${ }^{b}$} \\
\hline Loops & Wire colors & Resistance $(\Omega)$ & Loops & Wire colors & Resistance $(\Omega)$ \\
\hline $\mathrm{A}+\mathrm{B}$ & $\mathrm{red} / \mathrm{white}$ & 464.0 & $\mathrm{~A}+\mathrm{B}$ & green/red & 152.3 \\
\hline A & black/red & 657.6 & & & \\
\hline $\mathrm{B}$ & black/white & 658.3 & & & \\
\hline Insulation & & Resistance $(\Omega)$ & Insulation & & Resistance $(\Omega)$ \\
\hline shield-wire & & $\sim 24 \mathrm{e} 6$ & shield-wire & & $\sim 8.6 \mathrm{e} 6$ \\
\hline primary-secondary & & $\sim 57 \mathrm{e} 6$ & primary-secondary & & $\sim 0.23 \mathrm{e} 6$ \\
\hline \multicolumn{6}{|c|}{ Primary Coil Resistances $^{\mathrm{b}}$} \\
\hline \multirow[t]{2}{*}{ Loop } & Wire colors & Resistance $(\Omega)$ & Loop & Wire colors & Resistance $(\Omega)$ \\
\hline & $\mathrm{red} / \mathrm{white}$ & 133.9 & & black/white & 50.35 \\
\hline Insulation & & Resistance $(\Omega)$ & Insulation & & Resistance $(\Omega)$ \\
\hline shield-wire & & $\sim 44 \mathrm{e} 6$ & shield-wire & & $\sim 8.8 \mathrm{e} 6$ \\
\hline
\end{tabular}

DAS File Names (containing LVDT voltage as a function of core position) ${ }^{\mathrm{c}}$

VI logger: $\frac{11 / 17 / 2008 \text { 1:26:33.618 PM 400-02 C }}{\text { Windows: }}$ 400.02-11_17_2008 1_26_33.618 PM.txt
ge measurements using Agilent 34420A, serial number SG42000457.
esistance measurements using Fluke 8808A, serial number 9556082.
oltage measurements using VI Logger 2.0.1 with NI-DAQmx 8.0.0f0.


Table B-10. Set 2 data at $500^{\circ} \mathrm{C}$.

\begin{tabular}{|c|c|c|c|c|c|}
\hline Date & \multicolumn{2}{|l|}{$11-18-2008$} & Tester signature & \multicolumn{2}{|c|}{ D Krudjor } \\
\hline Calibration at & \multicolumn{2}{|l|}{$\sim 500^{\circ} \mathrm{C}$} & Furnace setpoint & \multicolumn{2}{|c|}{$490^{\circ} \mathrm{C}$} \\
\hline \multicolumn{6}{|l|}{ LVDTs } \\
\hline \multicolumn{3}{|c|}{ Vendor A 1096 (core 1059) } & \multicolumn{3}{|c|}{ Vendor B 1444} \\
\hline \multicolumn{6}{|c|}{ (Uncorrected) Null Settings } \\
\hline \multicolumn{3}{|c|}{$0.302 ”$} & \multicolumn{3}{|c|}{$0.285^{\prime \prime}$} \\
\hline \multicolumn{6}{|c|}{ Voltage \& Calibration Temperature (using a Type K TC) } \\
\hline & & Voltage $(\mathrm{mV})$ & Temperature $\left({ }^{\circ} \mathrm{C}\right)$ & & \multirow{5}{*}{$\begin{array}{c}\text { based on } \\
3044 \\
\text { readings }\end{array}$} \\
\hline & Minimum & 20.317019 & 492 & & \\
\hline & Maximum & 20.566795 & 498 & & \\
\hline & Average & 20.383596 & 494 & & \\
\hline & Standard deviation & $73.772418 \mathrm{e}-3$ & na & & \\
\hline \multicolumn{6}{|c|}{ Secondary Coil Resistances ${ }^{b}$} \\
\hline Loops & Wire colors & Resistance $(\Omega)$ & Loops & Wire colors & Resistance $(\Omega)$ \\
\hline $\mathrm{A}+\mathrm{B}$ & $\mathrm{red} / \mathrm{white}$ & 485.3 & $\mathrm{~A}+\mathrm{B}$ & green/red & 157.7 \\
\hline A & black/red & 663.7 & & & \\
\hline $\mathrm{B}$ & black/white & 664.7 & & & \\
\hline Insulation & & Resistance $(\Omega)$ & Insulation & & Resistance $(\Omega)$ \\
\hline shield-wire & & $\sim 2.5 \mathrm{e} 6$ & shield-wire & & $\sim 4.9 \mathrm{e} 6$ \\
\hline primary-secondary & & $\sim 5.5 \mathrm{e} 6$ & primary-secondary & & $\sim 34 \mathrm{e} 3$ \\
\hline \multicolumn{6}{|c|}{ Primary Coil Resistances $^{\mathrm{b}}$} \\
\hline \multirow[t]{2}{*}{ Loop } & Wire colors & Resistance $(\Omega)$ & Loop & Wire colors & Resistance $(\Omega)$ \\
\hline & $\mathrm{red} / \mathrm{white}$ & 145.1 & & black/white & 52.29 \\
\hline Insulation & & Resistance $(\Omega)$ & Insulation & & Resistance $(\Omega)$ \\
\hline shield-wire & & $\sim 8.5 \mathrm{e} 6$ & shield-wire & & $\sim 4.8 \mathrm{e} 6$ \\
\hline
\end{tabular}

DAS File Names (containing LVDT voltage as a function of core position) ${ }^{\mathrm{c}}$

VI logger: $\frac{11 / 18 / 2008 \text { 1:07:22.179 PM 500-02 C }}{\text { Windows: }}$ 500.02-11_18_2008 1_07_22.179 PM.txt
ge measurements using Agilent 34420A, serial number SG42000457.
esistance measurements using Fluke 8808A, serial number 9556082.
oltage measurements using VI Logger 2.0.1 with NI-DAQmx 8.0.0f0.


Table B-11. Room temperature data for Set 2 after high temperature calibration.

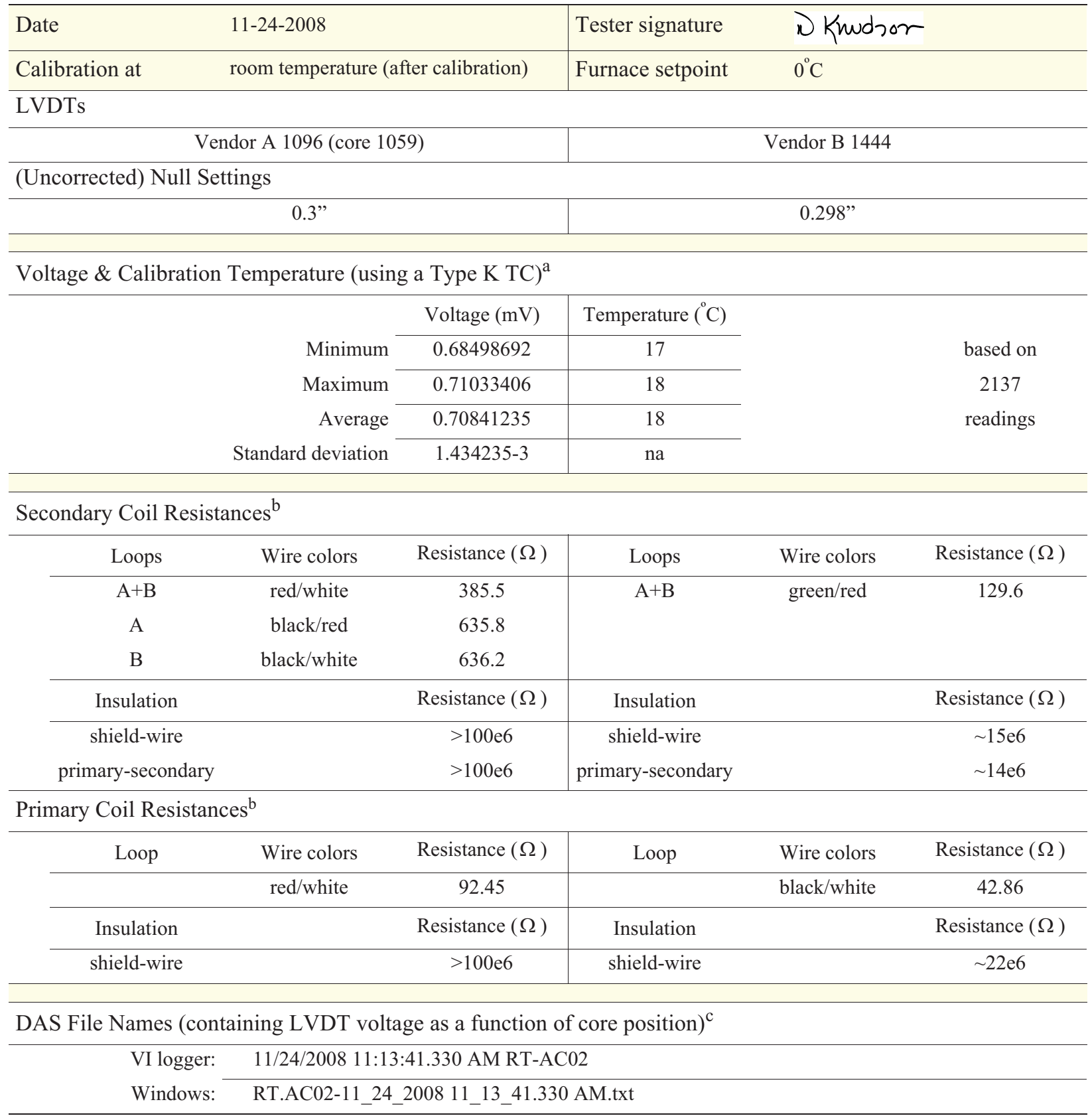

a. TC voltage measurements using Agilent 34420A, serial number SG42000457.

b. LVDT resistance measurements using Fluke 8808A, serial number 9556082.

c. LVDT voltage measurements using VI Logger 2.0.1 with NI-DAQmx 8.0.0f0. 